\title{
A winter's tale: microRNA biogenesis and regulation in the freeze-tolerant grey tree frog, Hyla versicolor
}

\author{
By \\ W. Aline Ingelson-Filpula \\ B.Sc. Honors, University of California Davis, 2016
}

A Thesis Submitted to the Faculty of Graduate Studies and Research in Partial Fulfillment of the Requirements for the Degree of

Master of Science

Department of Biology (Biochemistry Specialization)

Carleton University

Ottawa, Ontario, Canada

(C) Copyright 2021

W. Aline Ingelson-Filpula 


\section{ABSTRACT}

Grey tree frogs (Hyla versicolor) can endure full-body freezing over the winter, with survival aided by metabolic rate depression. Post-transcriptional controls on gene expression include microRNA regulation of gene transcripts that can aid implementation of protein changes required for freezing survival. Western immunoblotting was used to examine protein expression levels of the miRNA biogenesis pathway in three tissues.

During freezing, four proteins were upregulated in liver, whereas four proteins in muscle and five proteins in kidney were downregulated. Small RNA-sequencing and bioinformatic analysis of liver showed that seven miRNAs were freeze-upregulated and four were freeze-downregulated. Functions for these miRNAs may involve inhibition of signaling pathways, apoptosis, and nuclear processes. Interestingly, miRNAs may enhance ribosomal biogenesis. Overall, the data show miRNA biosynthesis is altered during freezing and differentially regulated across tissues, with computational predictions highlighting specific functions and processes that may be disproportionally altered during freezing. 


\section{ACKNOWLEDGEMENTS}

I know I need to first thank Ken Storey for making this whole endeavor a possibility to begin with. Thank you for providing the daily morning pep talks, encouraging my caffeine habit which I'll call a 'research tool' instead of just 'unhealthy', and fostering all my so-called demented aspirations with countless new opportunities.

The lab just wouldn't run without Jan Storey. My constant writing mistakes may cause your computer to run out of red ink at somepoint, but your guidance and advice has always been invaluable. Thank you for having many a Friday morning talk with me, and teaching me how to build my life and not just my career.

I might be more sane, but definitely less motivated, without the squad in the AAAS office. Anchal and Aakriti have been on a tireless quest to improve my spice tolerance, and I expect to be fluent in Hindi after another few years. Thanks to Sarah for being the best person to commiserate with re: constant food cravings such as DQ runs and mozzarella sticks. The rest of the Storey lab is pretty okay too. Special shoutout to Hanane for mentoring me and teaching me the ropes for all the techniques I've learned, and how to be a slightly more competent nerd and loser. I only hope to aspire to your awesomeness one day. Thanks to Stuart for mantis shrimp, and for being the ONLY person who understands Lord of the Rings references. Get cultured, the rest of you.

Special thanks to Levi for being my best friend-at-a-distance and having the tolerance to hear me prattle on about science of all flavors for...going on five years now. You constantly challenge my thinking, push me to learn more, and remind me of why I'm in this field and what I'm hoping to achieve with the research I do. You've shaped me into not only a better scientist, but a better person. Thank you.

Lastly, none of this would have been possible without the support from my family. While the constant pushing to be better may have been slightly irritating at times (sorry!), I now couldn't be more grateful. You taught me that persistence, tenacity, and hard work matter, and will pay off in the end. Your insight from when I was young shaped me into the person I am today, and I'll never stop being grateful for everything you've done for me. I hope to keep making you all proud. 


\section{TABLE OF CONTENTS}

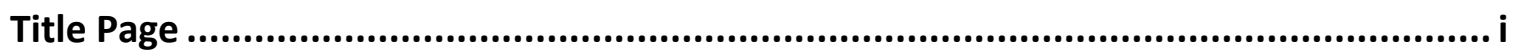

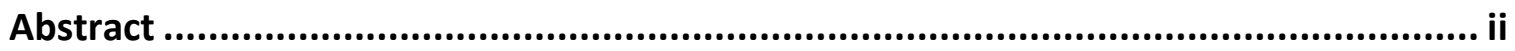

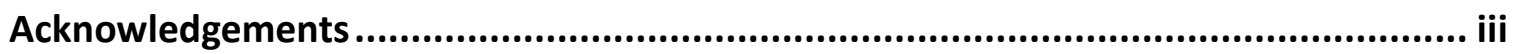

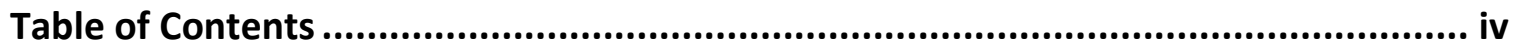

List of Abbreviations.................................................................................... vii

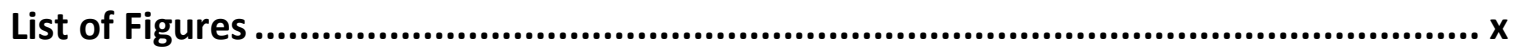

List of Appendices .................................................................................

Chapter 1 - General Introduction .................................................................. 1

1.1. Adaptations to extreme environmental stress: ........................................... 2

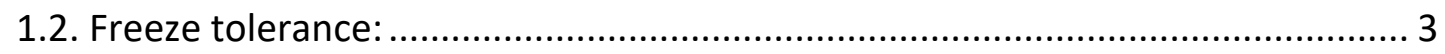

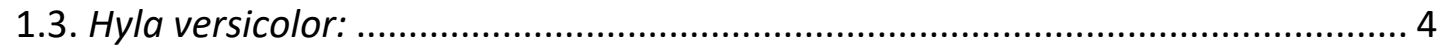

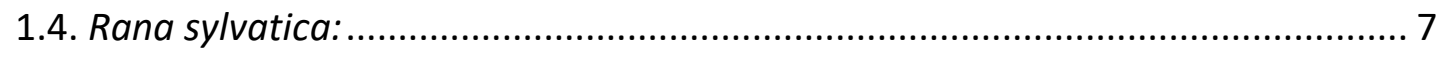

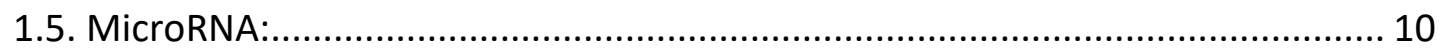

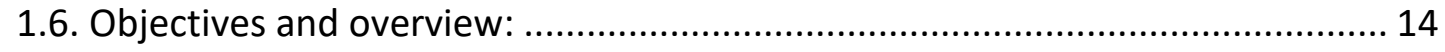

Chapter 2-General Materials and Methods................................................... 19

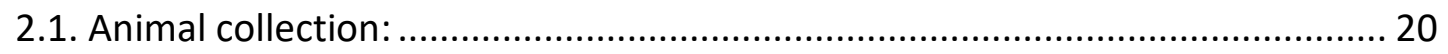

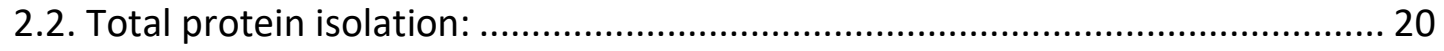

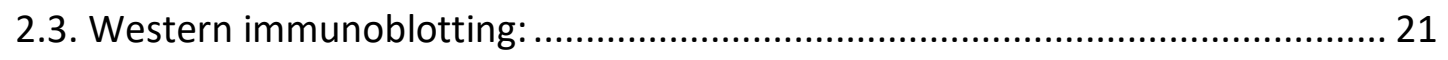

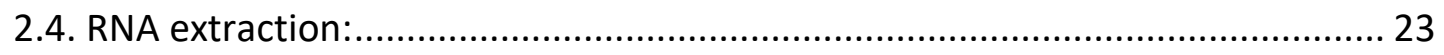

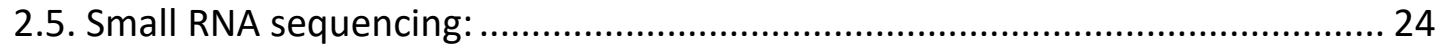

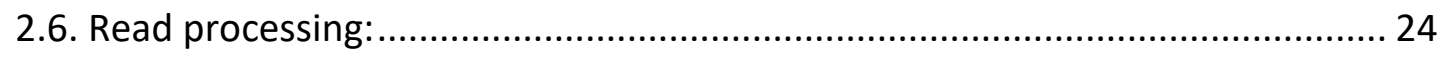

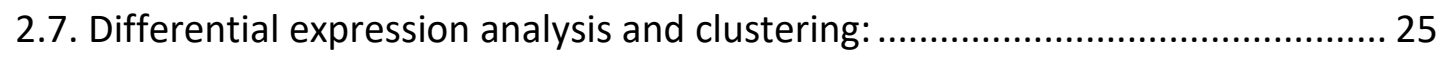

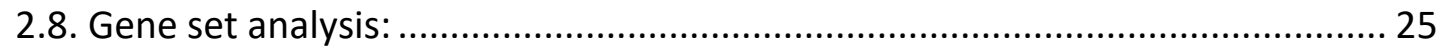

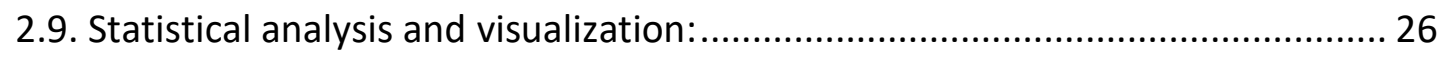

Chapter 3 - Differentially-Regulated MiRNA Biogenesis Across Tissues of $\boldsymbol{H}$. versicolor

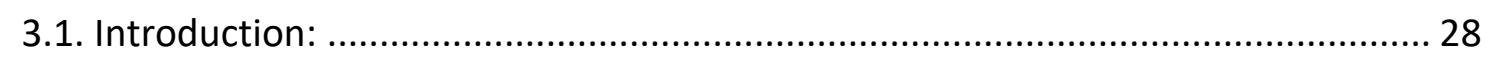

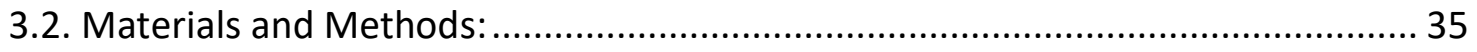

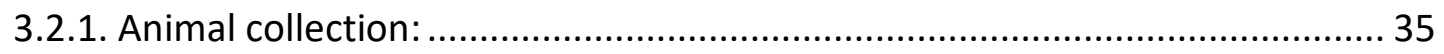




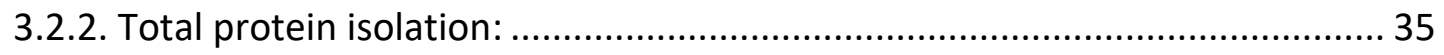

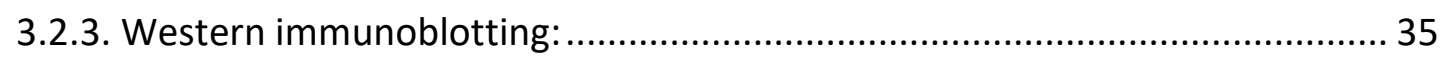

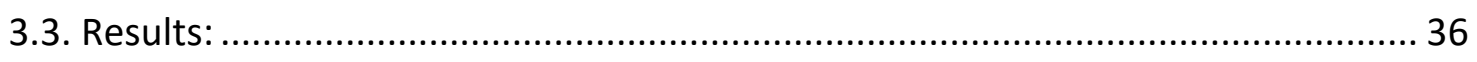

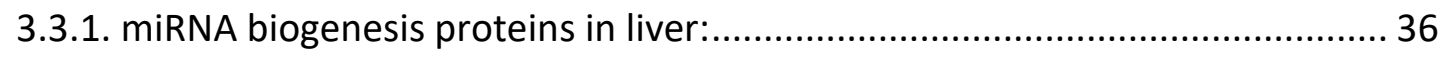

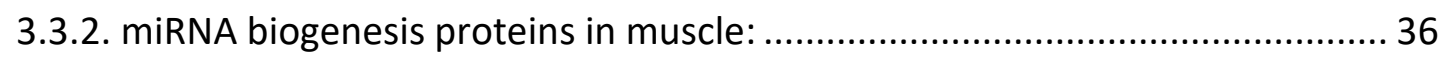

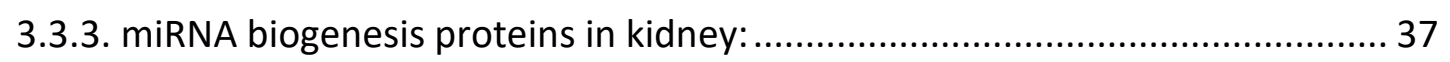

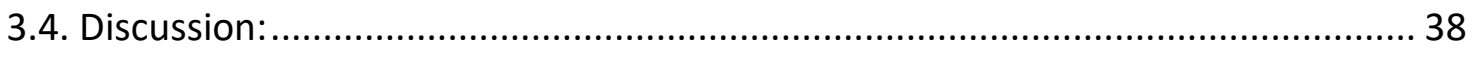

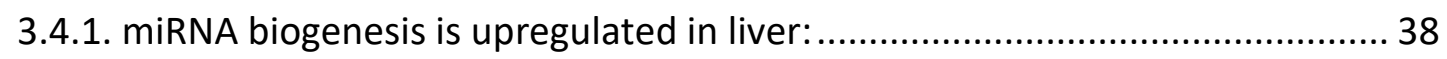

3.4.2. miRNA biogenesis is downregulated in muscle: ......................................... 41

3.4.3. miRNA biogenesis is downregulated in kidney, but distinct from muscle: ..... 43

3.4.4. miRNA biogenesis in freeze tolerance:....................................................... 44

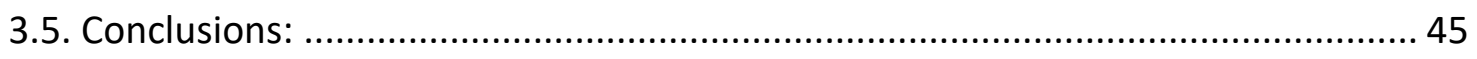

Chapter 4 - Bioinformatic Analysis and MiRNA Transcriptomics in Liver of $\boldsymbol{H}$. versicolor

50

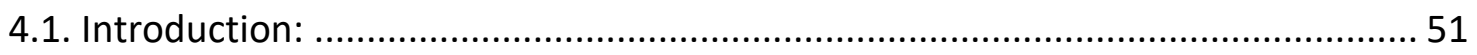

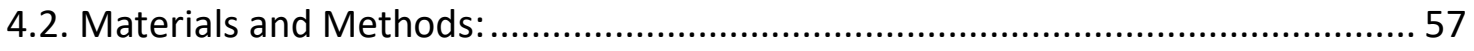

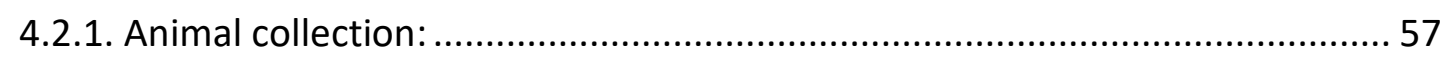

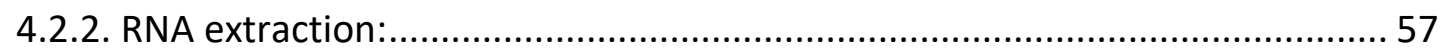

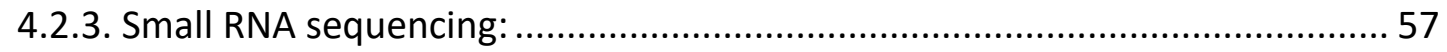

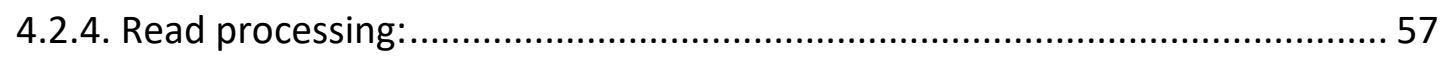

4.2.5. Differential expression analysis and clustering: ........................................ 57

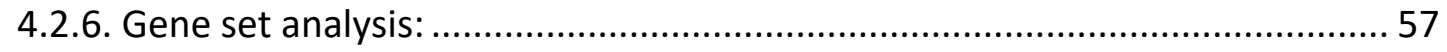

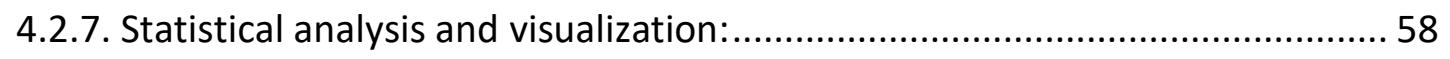

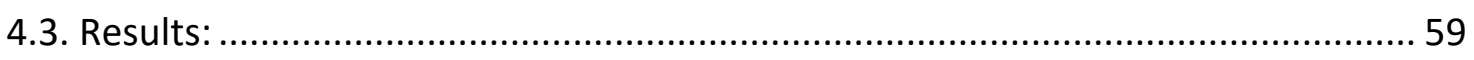

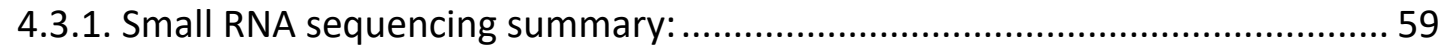

4.3.2. Differential expression of miRNA in response to freezing: .......................... 59

4.3.3. Gene ontology terms enriched for differentially expressed miRNA: ..............60

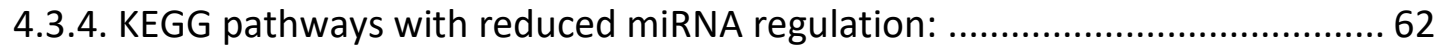

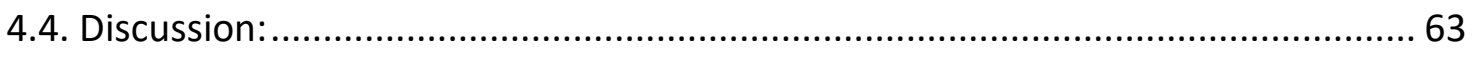

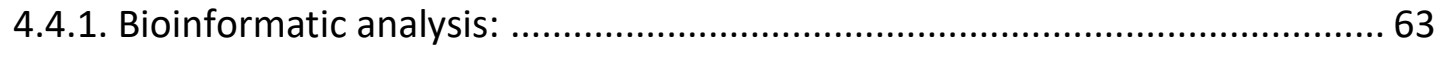

4.4.2. Signaling pathways and cell adhesion appear inhibited during freezing:....... 63 
4.4.3. Apoptosis and ubiquitination demonstrated robust downregulation:

4.4.4. Nuclear processes and cell cycle may be downregulated during freezing: .... 70

4.4.5. Enhanced ribosome biogenesis in response to freezing:.............................. 73

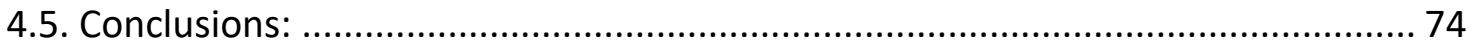

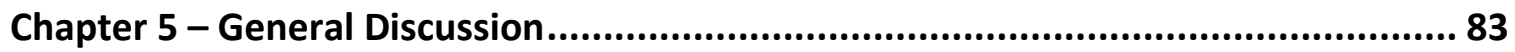

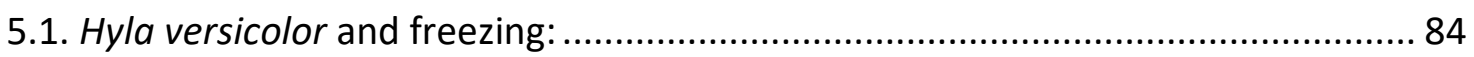

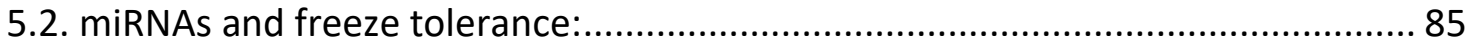

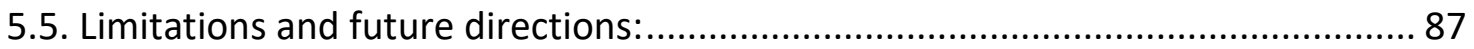

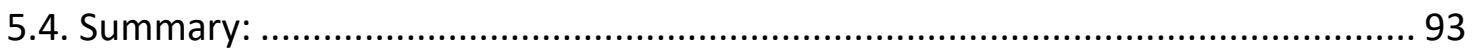

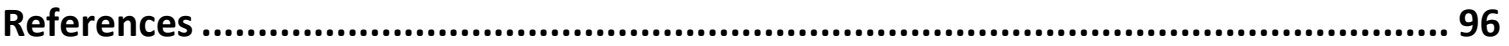

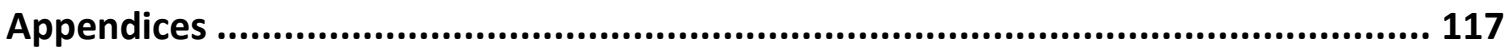

Appendix A - Antibody information and suppliers for Western immunoblotting ..... 118

Appendix B - Optimized immunoblotting conditions........................................... 119

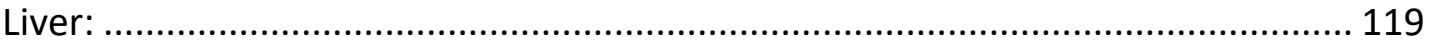

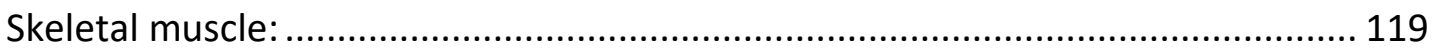

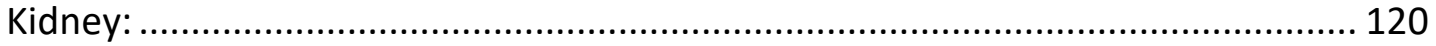

Appendix C - Verifying antibody specificity for Western immunoblotting ............... 121

Appendix D - Bioinformatics workflow for small RNA-seq dataset analysis ............. 124 


\section{LIST OF ABBREVIATIONS}

\begin{tabular}{|c|c|}
\hline AGO & Argonaute \\
\hline ATP & Adenosine triphosphate \\
\hline bp & Base pair \\
\hline BMP4 & Bone morphogenic protein 4 \\
\hline BRCA1 & Breast cancer type 1 susceptibility protein \\
\hline CAMP & Cyclic adenosine monophosphate \\
\hline CDK & Cyclin-dependent kinase \\
\hline cDNA & Complementary DNA \\
\hline ChREBP & Carbohydrate response element binding protein \\
\hline circRNA & Circular RNA \\
\hline DGCR8 & DiGeorge syndrome critical region gene 8 \\
\hline DNA & Deoxyribonucleic acid \\
\hline dNTP & Deoxynucleotide \\
\hline DROSHA & Drosha Ribonuclease III \\
\hline EDTA & Ethylenediaminetetraacetic acid \\
\hline EGFR & Epidermal growth factor receptor \\
\hline FDR & False discovery rate \\
\hline GO & Gene ontology \\
\hline GS & Gene set \\
\hline HEPES & 4-(2-hydroxyethyl)-1-piperazineethanesulfonic acid \\
\hline kDa & Kilodalton \\
\hline KEGG & Kyoto Encyclopedia of Genes and Genomes \\
\hline KRSP & $\mathrm{KH}$-type splicing regulatory protein \\
\hline IncRNA & Long noncoding RNA \\
\hline miRNA & MicroRNA \\
\hline mRNA & Messenger RNA \\
\hline mTOR & Mechanistic target of rapamycin \\
\hline
\end{tabular}




\begin{tabular}{|c|c|}
\hline MRD & Metabolic rate depression \\
\hline NGS & Next-generation sequencing \\
\hline nt & Nucleotide \\
\hline p53 & Transformation-related protein 53 \\
\hline p-body & Processing body \\
\hline PACT & Protein kinase RNA activator \\
\hline $\mathbf{P}_{\mathbf{i}}$ & Inorganic phosphate \\
\hline PI3K & Phosphoinositide 3-kinase \\
\hline piwiRNA & Piwi-interacting RNA \\
\hline PMSF & Phenylmethylsulfonyl fluoride \\
\hline pre-miRNA & Precursor microRNA \\
\hline pri-miRNA & Primary microRNA \\
\hline PTEN & Phosphatase and tensin homolog deleted on chromosome 10 \\
\hline PTM & Post-translational modifications \\
\hline PTP1B & Protein tyrosine phosphatase $1 \mathrm{~B}$ \\
\hline PVDF & Polyvinylidene fluoride \\
\hline RAN-GTP & RAs-related nuclear protein or GTP-binding nuclear protein Ran \\
\hline RISC & RNA-induced silencing complex \\
\hline RNA & Ribonucleic acid \\
\hline rRNA & Ribosomal RNA \\
\hline RT-qPCR & Quantitative real time PCR \\
\hline SAM & S-adenosyl methionine \\
\hline SDS-PAGE & Sodium dodecyl sulfate polyacrylamide gel electrophoresis \\
\hline siRNA & Small interfering RNA \\
\hline SnRNA & Small nuclear RNA \\
\hline SnORNA & Small nucleolar RNA \\
\hline SMAD & $\begin{array}{l}\text { Sma and Mad proteins from Caenorhabditis elegans and Drosophila, } \\
\text { respectively }\end{array}$ \\
\hline TBST & Tris-buffered saline and Tween-20 \\
\hline
\end{tabular}




$\begin{array}{ll}\text { TEMED } & \text { Tetramethylethyldiamine } \\ \text { TET } & \text { Ten-eleven translocation methylcytosine dioxygenase } \\ \text { TGF- } \boldsymbol{\beta} & \text { Transforming growth factor beta } \\ \text { TRBP } & \text { Transactivation response RNA binding protein } \\ \text { tRNA } & \text { Transfer RNA } \\ \text { UTR } & \text { Untranslated region } \\ \text { XPO5 } & \text { Exportin-5 }\end{array}$




\section{LIST OF FIGURES}

Figure 1.1. The geographical range of the grey tree frog, Hyla versicolor. 17

Figure 1.2. A diagram of the canonical miRNA biogenesis pathway. 18

Figure 3.1. Relative expression levels of AGO1-4, DGCR8, DICER, DROSHA, 47 PACT, RAN-GTP, TRBP, XPO5 in liver of control vs. $24 \mathrm{~h}$ frozen $H$. versicolor.

Figure 3.2 Relative expression levels of AGO1-4, DGCR8, DICER, DROSHA, 48 PACT, RAN-GTP, TRBP, XPO5 in control vs. $24 \mathrm{~h}$ frozen skeletal muscle of $H$. versicolor.

Figure 3.3. Relative expression levels of AGO1-4, DGCR8, DICER, DROSHA, 49 PACT, RAN-GTP, TRBP, XPO5 in control vs. 24 h frozen kidney of $H$. versicolor.

Figure 4.1. General workflow of miRNA preparation and downstream bioinformatic analysis.

Figure 4.2. Hierarchical clustering of significant differentially expressed miRNA in liver of control vs $24 \mathrm{~h}$ frozen $\mathrm{H}$. versicolor.

Figure 4.3. miRNA differentially expressed in control vs. $24 \mathrm{~h}$ frozen H. versicolor liver.

Figure 4.4. Volcano plot of GO Gene Ontology Biological Processes predicted from miRNA differential expression in control vs. 24 h frozen $H$. versicolor liver. 
Figure 4.5. Volcano plot of GO Gene Ontology Cellular Compartment predicted from miRNA differential expression in control vs.

$24 \mathrm{~h}$ frozen $H$. versicolor liver.

Figure 4.6. Volcano plot of GO Gene Ontology Molecular Function predicted from miRNA differential expression in control vs.

$24 \mathrm{~h}$ frozen $H$. versicolor liver.

Figure 4.7. Volcano plot of KEGG Pathway Analysis predicted from miRNA differential expression in control vs. $24 \mathrm{~h}$ frozen H. versicolor liver.

Figure 5.1. The "central" dogma of biology and molecular mechanisms 95 which can alter its traditional progression.

Figure C.1. Representative whole image of Western immunoblot of control vs $24 \mathrm{~h}$ frozen liver tissue from H. versicolor.

Figure C.2. Representative images of proteins of interest from control vs $24 \mathrm{~h}$ frozen liver Western immunoblots in $\mathrm{H}$. versicolor. 


\section{LIST OF APPENDICES}

APPENDIX A: Antibody information and suppliers for Western 118

immunoblotting

APPENDIX B: Optimized immunoblotting conditions

APPENDIX C: Verifying antibody specificity for Western immunoblotting

121

APPENDIX D: Bioinformatics workflow for analyzing small RNA-seq datasets

124 


\section{CHAPTER 1}

General Introduction 


\subsection{Adaptations to extreme environmental stress:}

The winter months are a stressful time for many organisms that must contend with subzero temperatures, food scarcity, and shorter photoperiods as a result of temperature decreases and inclement weather. Whereas some species employ migration as a tactic to avoid these challenges, other organisms have evolved strategies including freeze tolerance, freeze avoidance, and hibernation to 'wait out' the winter and emerge fully functional in the spring when more favourable conditions return. These types of approaches have been documented in a range of animals including soil microfauna, intertidal marine invertebrates, insects, mammals, and various ectothermic vertebrates including some turtles, snakes, salamanders and frogs (Costanzo et al., 2008; Holmstrup, 2014; Murphy, 1983; Ring, 1982; Storey and Storey, 2017;

Thomashow, 1999). All of these strategies take advantage of metabolic rate depression (MRD), or the ability to induce a hypometabolic state. MRD is characterized by the widespread downregulation of nonessential genes and processes, which allows cells to prolong the consumption of their endogenous fuel reserves and limit the buildup of toxic byproducts and waste. Energy-expensive processes such as the cell cycle are shut down and, depending on the species, metabolism can switch from aerobic to anaerobic routes of ATP production, and fuel supply can switch to either carbohydrate or lipid stores (Storey and Storey, 2013). To coordinate such an extensive global reorganization requires an interplay of regulatory mechanisms including transcriptional and posttranscriptional changes as well as alterations to enzyme activity levels. For winter survival strategies including freeze tolerance, which is characterized by organisms being 
in a nonresponsive, immobile state, MRD is important to mitigate the lack of feeding activity (and by extension, energy depletion) as well as buildup of waste products.

\subsection{Freeze tolerance:}

Freeze tolerance is a winter survival strategy used by selected frogs, salamanders, and hatchling turtles, as well as many insects and other invertebrates. Examples of well-studied model species include the North American frogs Rana sylvatica, Hyla versicolor, Hyla chrysoscelis, Pseudacris crucifer and Pseudacris triseriata; the goldenrod gall fly, Eurosta solidaginis; and the intertidal snail Littorina littorea (Murphy, 1983; Storey and Storey, 1986a). However, the ability of tissues to freeze/thaw comes with a myriad of physiological dangers that animals must contend with. Formation of intracellular ice crystals is a mechanical threat to cell microarchitecture and can lead to rupture of cell membranes and damage to subcellular architecture and organelles. Given this, freeze tolerance in animals is characterized by the formation of ice in extracellular spaces only, although this generates other potentially detrimental effects (Franks, 1985). Ice is a crystal of pure water, and as extracellular ice crystals grow, they exclude solutes from the ice lattice creating a hyperosmotic environment which draws intracellular water out to join the growing lattice and elevates the osmolality of the cell. This both dehydrates and threatens the cell with lethal shrinkage, and so freeze-tolerant animals flood their tissues with high levels of sugars or alcohols, these low molecular weight cryoprotectants acting to sustain survivable cell volumes (Storey and Storey, 2017). However, extreme concentrations of cryoprotectants, primarily glucose, can also create the counter-effect 
of widespread hyperglycemia (well known as the cause of diabetes) which must be controlled. This calls for alterations to insulin regulation to allow such high concentrations of glucose in the blood and tissues. In this vein, freeze-tolerant $R$. sylvatica possesses insulin with anomalous structural properties, which may contribute to regulation of glycogen phosphorylase that is responsible for synthesizing glucose from glycogen (Conlon et al., 1998).

As body water freezes in extracellular and extra-organ spaces (e.g. abdominal cavity), the heart ceases to beat and blood flow stops, creating ischemic conditions where oxygen cannot reach tissues (hypoxia/anoxia) and waste products cannot be exported (Storey and Storey, 2017). Gas exchange no longer occurs in the lungs, kidneys do not flush waste, and skeletal muscle may be subject to atrophy from disuse. Since nutrients are no longer supplied to any bodily systems, cells must survive with their own endogenous fuel reserves and preservation strategies for the duration of freezing. Metabolism and ATP generation are converted from aerobic respiration to anaerobic fermentation with the accumulation of end-products such as lactate and alanine (Storey and Storey, 2017). On a holistic level, prevention of widespread cell death as a result of all aforementioned stresses must be managed by changes in antioxidant defenses, chaperone proteins, and anti-apoptotic measures (Storey and Storey, 2017).

\subsection{Hyla versicolor:}

Hyla versicolor, the grey tree frog, is an arboreal species with a range encompassing the eastern United States and up into southern Ontario and Manitoba (Figure 1.1). It is a master of camouflage and can change colors to match its background 
- grey, white, green in many combinations/shades. When frozen, they turn a distinctive blue-grey color. H. versicolor is a tetraploid, possessing four homologous sets of chromosomes whereas Hyla chrysoscelis (largely restricted to the eastern USA) is the corresponding diploid organism, although it is relevant to note that the ploidy has no measurable effect on metabolic rate or functioning (Kamel et al., 1985; Wasserman, 1970). Freeze tolerant Hyla species use glycerol as their cryoprotectant during overwintering as opposed to the accumulation of glucose as the cryoprotectant in $R$. sylvatica (Schmid, 1982; Storey and Storey, 1986a). Glycerol itself as a cryoprotectant is not notable; most species of cold-hardy insects and other invertebrates, as well as selected marine fish, use glycerol as the cryoprotectant/antifreeze; and among insects this includes both freeze-tolerant and freeze-avoiding species (the latter using extra high glycerol levels to supercool deeply and avoid freezing) (Raymond, 1995, 1992; Ring, 1982). Sexually mature $H$. versicolor accumulate high levels of glycerol, whereas immature frogs accumulate both glycerol and glucose (Storey and Storey, 1985a). There is considerable variability in measured levels of cryoprotectants which was previously hypothesized to be due to geographic location (i.e. southern populations have less cryoprotectant than northern populations); however, this has since been refuted and may be due to different laboratory conditions or different time of year of collections (Irwin and Lee, 2003). Measured glycerol levels in $H$. versicolor are highest in blood, followed by lower levels in liver and brain, and finally lowest in muscle and gonads. Glycerol levels in mature frogs have been measured at as high as $422 \mu \mathrm{mol} / \mathrm{mL}$ in blood, $134 \mu \mathrm{mol} / \mathrm{g}$ in lung, and $465 \mu \mathrm{mol} / \mathrm{g}$ in brain; while immature frogs had lower levels in 
blood at $42 \mu \mathrm{mol} / \mathrm{mL}$ of glycerol and $60 \mu \mathrm{mol} / \mathrm{mL}$ of glucose (Storey and Storey, 1985a).

The reasons that $H$. versicolor employs both glycerol and glucose have not yet been elucidated, although several theories exist. It has been widely reported for the freezetolerant wood frog $R$. sylvatica that cryoprotectant synthesis is triggered by the initiation of freezing at body extremities, leading to rapid activation of glycogenolysis and glucose synthesis beginning within five minutes and taking only a few hours to complete (Storey and Storey, 1985b). However, some studies have demonstrated that $H$. versicolor synthesizes and circulates glycerol prior to the onset of freezing conditions (Irwin and Lee, 2003; Layne and Jones, 2001), which allows a more thorough and even distribution of the cryoprotectant than can be achieved for glucose, that is only released after the onset of freezing and can only be circulated a limited amount. This anticipatory mobilization of cryoprotectant, again, is not exclusive to $H$. versicolor but is the common mode of cryoprotectant production during autumn cold-hardening for many freezetolerant and freeze-avoiding insects and other invertebrates (Ring, 1982).

While there is some variability in how much total body water freezes in $\mathrm{H}$. versicolor during the overwintering process, multiple reports corroborate that at least about $42 \%$ of total body water freezes (Layne, 1999; Storey and Storey, 1985a). Energy usage in the frozen state switches entirely over to anaerobic metabolism as signified by a rise in lactate levels in liver and muscle (Storey and Storey, 1985a), since cessation of blood flow and freezing of extracellular water leads to widespread ischemia and a drastic reduction in oxygen availability. Reliance on anaerobic glycolysis for ATP synthesis creates conditions of intracellular acidosis, reduced ATP and creatine 
phosphate levels, and an increase in $\mathrm{P}_{\mathrm{i}}$ (Layne and Stapleton, 2009). Total soluble protein in liver has been demonstrated to increase by $50 \%$, which correlates to an increase in overall enzymatic activity by $49-88 \%$ (Storey and Storey, 1985a). This suggests that tissues respond to freezing in one of two ways: dehydration of cells to minimize the content of freezable 'bulk' water remaining in cells resulting in increased enzyme activities or protein content expressed per gram wet weight; or a nonspecific increase in cellular protein content which raises cellular osmotic pressure and aids in the prevention of cellular dehydration during extracellular freezing (Storey and Storey, 1985a).

\subsection{Rana sylvatica:}

The primary model organism for studying freeze tolerance among cold-hardy vertebrate species has been the wood frog $R$. sylvatica. In 1982, it was discovered that $R$. sylvatica, $H$. versicolor, and P. crucifer could survive freezing conditions whereas toads and species of aquatic frogs could not (Schmid, 1982; Storey and Storey, 1986a). These results were reinforced by subsequent studies, and the list of freeze-tolerant frogs was expanded to include H. chrysoscelis and Pseudacris triseriata (Layne and Jones, 2001; Layne and Stapleton, 2009; Storey and Storey, 1986a). All these species have been documented to bury into leaf litter at the bases of trees or other protected sites to overwinter, and survive extended freezing at subzero temperatures ranging from $-2{ }^{\circ} \mathrm{C}$ to $-8{ }^{\circ} \mathrm{C}$ (Storey and Storey, 1986 a). Supercooling was sustainable to $-2{ }^{\circ} \mathrm{C}$ or $-3^{\circ} \mathrm{C}$, but supercooling to $-30{ }^{\circ} \mathrm{C}$ as some insects are able to maintain proved lethal. 
The freezing process for $R$. sylvatica is as follows, based on documentation by Rubinsky et al. (2012). It is important to note that specific timepoints mentioned in this section may vary dependent on laboratory conditions and experimental setup. Freezing begins at a nonspecific area on the skin surface, and propagates inwards towards core organs. After $2 \mathrm{~h}$, ice formation is widespread throughout the entire body and body cavity except the liver, which is shrunken due to freezing-induced dehydration. After about $4 \mathrm{~h}$, the entire frog is frozen and can remain this way throughout the winter. Final glucose cryoprotectant concentrations range from $\sim 200 \mu \mathrm{mol} / \mathrm{g}$ wet weight in liver and heart, $100-125 \mu \mathrm{mol} / \mathrm{g}$ in other organs, and $<60 \mu \mathrm{mol} / \mathrm{g}$ in skeletal musculature and skin. This uneven distribution is due to the directionality of ice crystal propagation at freezing onset and vasoconstriction as a result of freezing stress: muscle and skin freeze first and therefore less cryoprotectant can permeate these tissues before fluids are frozen; conversely, internal organs have more time to accumulate cryoprotectant before ice penetrates the organs, thus explaining the higher levels of glucose deeper in the body. Indeed, liver which produces the glucose is always the last organ to freeze. Thawing, notably, does not follow the same process as freezing does (i.e. beginning on the outer surface of the skin and spreading centrally). Thawing is uniform throughout the entirety of the body, afforded by uneven glucose concentrations in the various organs and therefore allowing deeper organs with higher levels of cryoprotectant a similar rate of thawing to that of superficial tissues with less cryoprotectant. The higher concentration of glucose in internal organs lowers the freezing/melting points of water more than that in lower glucose-concentrated tissues such as muscle and skin. As a result, all bodily 
areas can reach their appropriate melting points at relatively similar timepoints to allow for uniform thawing. This also prevents skin and muscle from suffering damage caused by unavailable nutrients and blood flow while the rest of the body remains partially frozen. Complete reestablishment of muscle tone and movement is often well after the resumption of regular heartbeat, blood flow, and respiration although muscle fibers are responsive (Storey and Storey, 2017).

Synthesis of glucose cryoprotectant is catalyzed by glycogen phosphorylase in the liver from a large glycogen reserve accumulated during summer feeding (Storey and Storey, 1984). Activation of glycogen phosphorylase is controlled by cAMP-stimulated phosphorylation of glycogen phosphorylase, mediated by beta-adrenergic signaling (ie. adrenaline) that converts glycogen phosphorylase from its inactive $b$ form to active $a$ form. This is substantiated by an $\sim 80 \%$ increase in the active form, phosphorylated $a$, within minutes of the initiation of freezing whereas glycogen phosphorylase activity remained constant in all other tissues (Storey and Storey, 1984). It is important to note that neither the decrease in temperature to near-zero and subzero values above the supercooling point nor changes in photoperiod triggered cryoprotectant synthesis (Rubinsky et al., 1994b). Rather, the trigger is ice nucleation, detected on the skin, that stimulates adrenaline release to initiate glucose synthesis and triggers a huge increase in glycogen phosphorylase activity in liver within 5 min of freezing initiation (Storey and Storey, 1985b). Breakdown of glycogen occurs very rapidly and is driven catecholamines acting within the first 5 min post ice nucleation (Feder and Burggren, 1992; Storey and Storey, 1996). 


\subsection{MicroRNA:}

MicroRNA (miRNA) are short, single-stranded, noncoding RNA molecules 21-24 nt long which bind to mature mRNA transcripts and suppress their translation. The first miRNAs were discovered in 1993 in C. elegans, dubbed let-7 and lin-4, and were crucial regulators of the lin14 and lin41 genes which oversee developmental timing (Lee et al., 1993; Paciello et al., 2011; Reinhart et al., 2000). Since then, hundreds of miRNAs have been discovered across animal and plant species. These miRNAs exhibit very high conservation between species, and several important features of miRNA:mRNA binding have been established. miRNAs bind through complementarity to the seed sequence, a stretch of nucleotides at the $5^{\prime}$ end of the miRNA sequence which correspond with the 3' UTR of the mRNA sequence. Perfect complementarity leads to cleavage of the mRNA transcript, while imperfect binding leads to translational suppression through isolation of the mRNA transcript in p-bodies or stress granules (Bartel, 2004). In mammals, over $70 \%$ of miRNA genes are located within protein-coding gene introns with approximately $30 \%$ of these transcribed independently from the protein-coding gene within which they are located (Finnegan and Pasquinelli, 2013).

miRNA regulation has been observed in multiple models of metabolic rate depression including the freeze-tolerant frog ( $R$. sylvatica) and insect (Eurosta solidaginis), hibernating lemurs Microcebus murinus and ground squirrels Ictidomys tridecemlineatus, hypoxic crayfish Orconectes virilis, and estivating frogs Xenopus laevis (Biggar et al., 2018; English et al., 2018; Hadj-Moussa and Storey, 2018; Luu and Storey, 2015; Lyons et al., 2016; Wu and Storey, 2018). Most relevant to this study are the 
models of freeze tolerance. In E. solidaginis, 24 differentially expressed miRNAs were discovered with links to translational repression, reactive oxygen species, and hypoxic conditions (Lyons et al., 2016). This led to the establishment of a family of miRNAs specifically responsive to the cold, and dubbed cryomiRs (Lyons et al., 2015b, 2013a, 2013b). In wood frogs, R. sylvatica, Hadj-Moussa and Storey (2018) measured a series of 113 miRNAs in brain tissue, and observed widespread downregulation of both the miRNAs themselves as well as proteins of the miRNA biogenesis pathway in response to freezing stress. These miRNAs had roles in intracellular signal transduction and RNA processing and were therefore hypothesized to be involved in neuronal survival and neuroprotective functions during freezing (Hadj-Moussa and Storey, 2018).

miRNAs are synthesized canonically via the miRNA biogenesis pathway, which is illustrated in Figure $\mathbf{1 . 2}$ and is as follows. miRNAs are transcribed in the nucleus by RNA polymerase II to form the double-stranded primary miRNA (pri-miRNA), where the mature sequence is enclosed within a hairpin turn. This entire structure is $\sim 70 \mathrm{nt}$ long (Kim, 2005). The hairpin is cleaved off to form the double-stranded precursor-miRNA (pre-miRNA) by the microprocessor complex which is a $~ 650 \mathrm{kDa}$ (in humans) structure consisting of the enzymes DROSHA, an RNase III enzyme, and two molecules of DGCR8 (Finnegan and Pasquinelli, 2013; Kim, 2005). DROSHA is a large, conserved protein in animals (Filippov et al., 2000; Fortin et al., 2002; Wu et al., 2000) with two RNase III domains and a double-stranded RNA-binding domain which are central to its function (Kim, 2005). DGCR8, also known as Pasha in D. melanogaster and C. elegans, has two double-stranded RNA binding domains and while its exact biochemical role is not fully 
elucidated, it is hypothesized to assist DROSHA with substrate recognition through binding the apical stem of the pri-miRNA (Guo and Wang, 2019). The microprocessor itself is autoregulated through the ability of DROSHA and DGCR8 to posttranscriptionally regulate each other via protein-protein interactions (Finnegan and Pasquinelli, 2013).

At this stage, the pre-miRNA is exported out of the nucleus via nuclear export protein Exportin 5 (XPO5) and in the cytoplasm the RNase III enzyme DICER along with cofactors TAR RNA-binding protein (TRBP) and protein activator of PKR (PACT) process the pre-miRNA into the 21-24 nt long duplex miRNA. The 3' end of the duplex miRNA has a two-nucleotide overhang which is used to load the duplex miRNA onto the Argonaute (AGO) proteins. The strand holding the mature miRNA sequence is kept whereas the other strand is discarded (named passenger strand ejection), and this structure constitutes the miRNA induced silencing complex (RISC) which is fully prepared to target mRNAs.

The abovementioned process for miRNA biogenesis is widely accepted as the canonical pathway. However, it is important to note that there are other noncanonical methods of miRNA biogenesis should a loss-of-function mutation happen in one of the proteins. A group of miRNAs dubbed 'mirtrons' do not require DROSHA for their production (Berezikov et al., 2007; Ruby et al., 2007), since they are located within introns of host genes and when the introns are spliced out, the result is a pre-miRNA which can then be processed by DICER (Kim et al., 2016). 'Agotrons' are another specialized subset of miRNA that bypass canonical biogenesis entirely and associate with 
AGO proteins as full-length introns (Hansen et al., 2016). Other miRNAs that can be generated in a DROSHA-independent manner include some small nucleolar miRNAs, certain endogenous siRNAs, and 5' capped pre-miRNAs (Ender et al., 2008). As for DICER-independent miRNAs, only one miR-451 has been identified that directly associates with AGO2 following nuclear export (Kim et al., 2016). XPO5 is another protein which has not been studied extensively, although a group of miRNAs are known which utilize XPO1 instead of XPO5 for transport (Kim et al., 2016). Further studies are needed to elucidate the criticality of XPO5 in miRNA biogenesis.

There are many cellular pathways and stresses including genotoxic agents (UV and ionizing radiation, chemical mutagens, etc.) that regulate proteins of the miRNA biogenesis pathway, thereby altering miRNA expression and altering mRNA transcript expression (Olejniczak et al., 2018). Many of these are concentrated at the microprocessor step of miRNA biogenesis and are exerted by proteins such as SMADs, p53, and breast cancer 1 (BRCA1) proteins (Olejniczak et al., 2018). SMADs carry signals from transforming growth factor beta (TGF $\beta$ ) or bone morphogenic protein 4 (BMP4) and associate with DROSHA/DGCR8 to facilitate cleavage of the pri-miRNA to pre-miRNA (Davis et al., 2010). The KH-type splicing regulatory protein (KSRP) also aids in this process. Tumor suppressor BRCA1 has the ability to bind both the microprocessor complex and SMADs/p53, giving rise to regulation of yet more pri-miRNAs (Kawai and Amano, 2012). The environmental stress, hypoxia, has the direct ability to downregulate DROSHA, DICER, and AGO2, whereas oxidative stress affects DGCR8 in muscle (Kozakowska et al., 2012; Shen et al., 2013; Van Den Beucken et al., 2014). Hypoxia- 
induced phosphorylation reduces AGO2 to DICER, whereas hydroxylation shuttles AGO2 to stress granules (C. Wu et al., 2011).

\subsection{Objectives and overview:}

1.6.1. Objective 1: Examine miRNA biogenesis across three metabolically-variable tissues between control and frozen grey tree frogs.

This thesis provides an overview of one post-transcriptional form of regulation, miRNA, which may contribute to the implementation and maintenance of freezetolerance and MRD in $H$. versicolor. MiRNAs are synthesized via the miRNA biogenesis pathway and Chapter 3 focuses on measuring the expression levels of proteins in the miRNA biogenesis pathway in liver, skeletal muscle, and kidney to assess indirectly whether miRNA synthesis is altered in response to freezing stress. Liver is metabolically active during freezing given its responsibility for producing cryoprotectant, but oppositely skeletal muscle remains dormant during freezing given it has no crucial role and is one of the earliest tissues to freeze. One of the keystones of MRD is to only transcribe genes that are critical for cellular survival, and if miRNAs play an appreciative role in facilitating the downregulation of nonessential genes and processes, variable expression of miRNA biogenesis proteins should be observed which correspond to the relative roles that miRNAs play during MRD in that tissue. Hence, increased expression 
of biogenesis proteins in a tissue would give presumptive evidence of an increased role of miRNAs during freeze tolerance in that tissue, and vice versa.

\section{Hypothesis 1:}

Proteins of the miRNA biogenesis pathway will be differentially regulated across all three tissues, reflecting the general metabolic activity of these tissues during freezetolerance.

1.6.2. Objective 2: Analyze a small RNA-seq dataset to identify specific miRNAs being differentially expressed in liver from frozen grey tree frogs, and predict the cellular processes being altered by miRNA regulation.

miRNAs are an extremely versatile mode of post-transcriptional regulation, allowing for vast layers of complexity in the different combinations of the gene products they repress. In Chapter 4, bioinformatic analysis was performed on a small RNA-seq dataset comparing liver from control and $24 \mathrm{~h}$ frozen $\mathrm{H}$. versicolor to determine a) the miRNAs that are differentially-expressed during freezing, b) KEGG pathway analysis to isolate metabolic pathways of interest that are potentially regulated by miRNAs during freezing, and c) GO Gene Ontology for Biological Processes, Cellular Compartment, and 
Molecular Function to fully elucidate the cellular processes regulated by miRNAs during a frozen state.

\section{Hypothesis 2:}

A subset of miRNAs will be differentially expressed in liver during freezing, and will predict what pathways and cellular processes are affected to contribute to MRD and freeze tolerance in this tissue. 


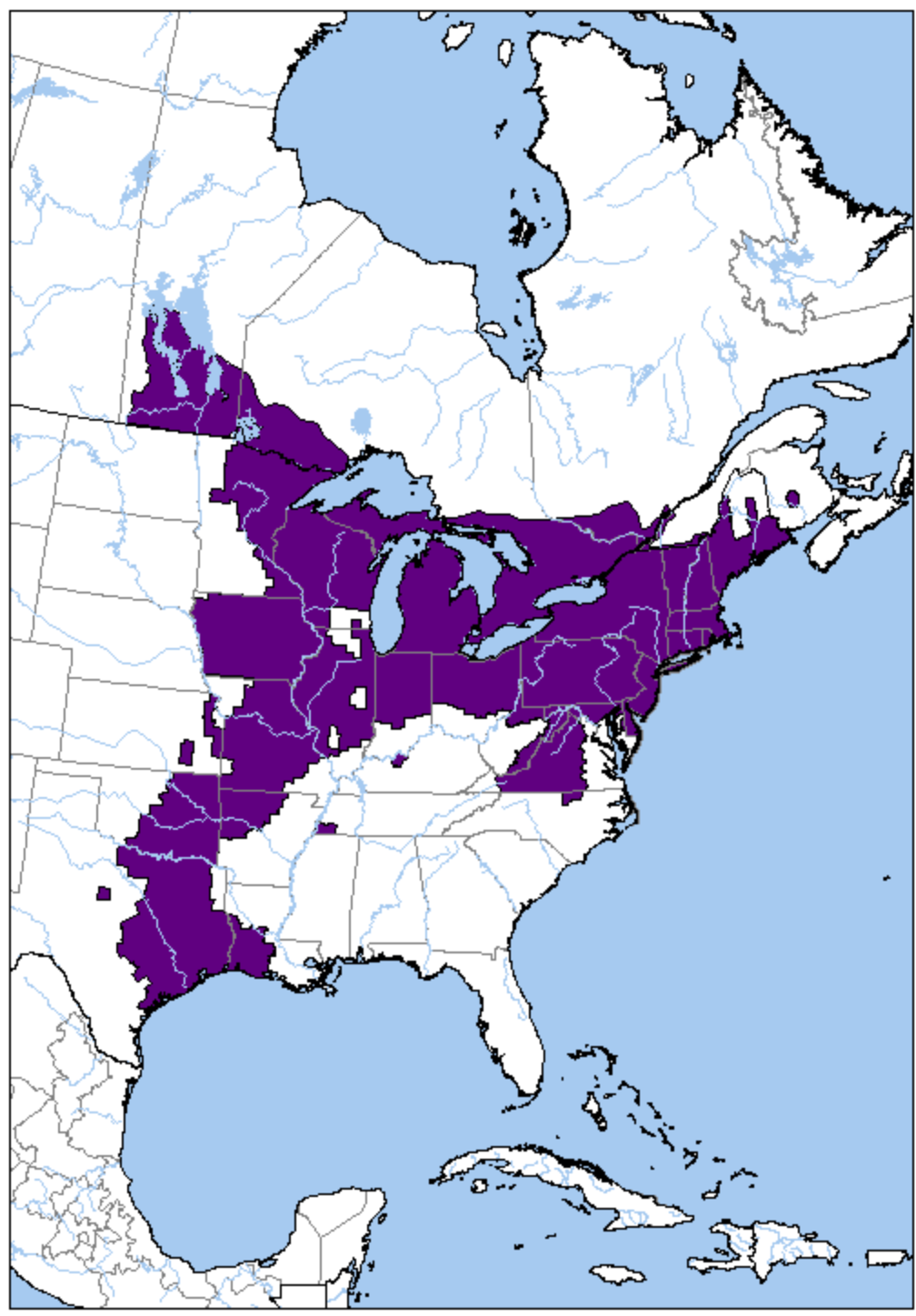

0750 Kilometers

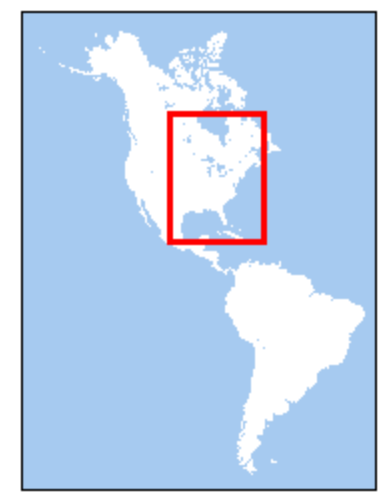

Permanent Resident Introduced

Extirpated/Extinct

National boundary

Subnational boundary

River

Water body

\section{IUCN}

$$
\text { Tra }
$$

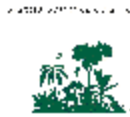

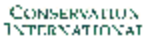

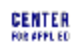

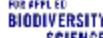

SCIENCE

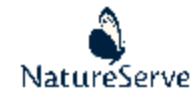

Map created June 2005

Figure 1.1: Geographical range of the grey tree frog, Hyla versicolor. Image from the Tennessee Wildlife Resources Agency. Retrieved from https://www.tn.gov/content/dam/tn/twra/images/amphibians/gray-treefrograngemap.gif on June 8, 2021. 


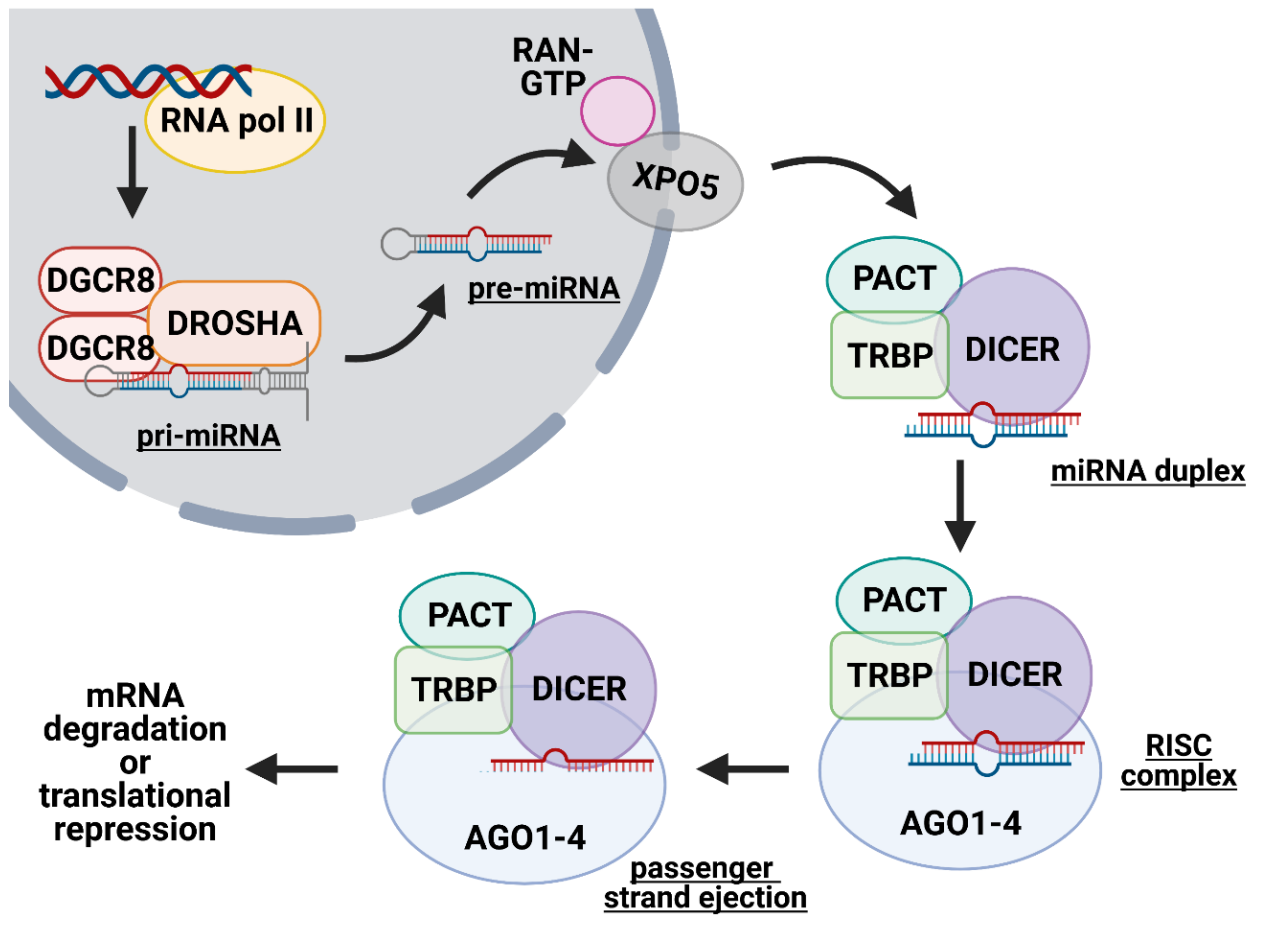

Figure 1.2: A diagram of the canonical miRNA biogenesis pathway. Image created using BioRender.com 


\section{CHAPTER 2}

General Materials and Methods 


\subsection{Animal collection:}

Male $H$. versicolor between 6 and $11 \mathrm{~g}$ were collected in the Ottawa area during the spring breeding season. Frogs were washed in a tetracycline bath, placed in boxes lined with sphagnum moss, and acclimated in a $5{ }^{\circ} \mathrm{C}$ fridge. Frogs were not fed. Animals were randomly assigned to control or frozen groups, consisting of 19 and 13 frogs, respectively. For freezing, two trays containing the frogs were lined with damp paper towel and lowered to $-3.9 \pm 0.1{ }^{\circ} \mathrm{C}$ for $2 \mathrm{~h}$ to trigger ice nucleation. Subsequently, temperature was adjusted to the final level of $-2.8^{\circ} \mathrm{C}$, and after a total of $5 \mathrm{~h}$, all frogs were crouched in the water-holding position on the bottom of the trays and were slightly rigid to the touch. After $24 \mathrm{~h}$, all animals were blue in color and solidly frozen, with ice throughout the body cavity. Frozen frogs were sampled from this condition and control animals were sampled from the initial acclimation conditions, described above. All frogs were euthanized by double-pithing. Tissues were rapidly dissected, flash frozen in liquid nitrogen, and stored at $-80^{\circ} \mathrm{C}$ until use. All animal care protocols, experimentation, and euthanasia had the approval of the Carleton University Animal Care Committee, in accordance with the guidelines set by the Canadian Council on Animal Care.

\subsection{Total protein isolation:}

To prepare soluble protein extracts, $\sim 0.5 \mathrm{~g}$ samples of frozen $H$. versicolor liver, skeletal muscle, and kidney tissue were crushed under liquid nitrogen and transferred to test tubes. Several crystals of PMSF and $10 \mu \mathrm{L} / \mathrm{mL}$ of Sigma Protease Inhibitor (CAT\# PIC001; BioShop) were added immediately before homogenization 1:2.5 w/v in 
homogenization buffer (20 mM HEPES, pH 7.5, 200 mM NaCl, 0.1 mM EDTA, 10 mM

$\mathrm{NaF}, 1 \mathrm{mM} \mathrm{Na} \mathrm{VO}_{4}, 15 \mathrm{mM} \beta$-glycerophosphate). Homogenates were centrifuged at $4{ }^{\circ} \mathrm{C}$ for $15 \mathrm{~min}$ at $10,000 \times \mathrm{g}$ before supernatants were collected. Protein concentrations were determined using the BioRad Protein Assay with bovine serum albumin as the standard. Absorbance readings were measured at $595 \mathrm{~nm}$ on a Bio-Tek Power Wave HT Spectrophotometer using Gen5 software. Protein concentrations were standardized and mixed 1:1 v:v ratio with $2 \times$ SDS loading buffer (100 mM Tris-base, $4 \%$ w:v SDS, $20 \%$ v:v glycerol, $0.2 \%$ w:v bromophenol blue, $10 \%$ v:v 2-mercaptoethanol). Samples were then boiled for $10 \mathrm{~min}$ to denature the proteins, and stored at $-80^{\circ} \mathrm{C}$ until use.

\subsection{Western immunoblotting:}

Samples containing standardized masses of protein (20-37.5 $\mu$ g depending on the abundance of the protein of interest) were loaded onto $6,8,10$, or $15 \%$ SDS polyacrylamide gels. Gels were composed of 6-15 \% v/v acrylamide, $130 \mathrm{mM}$ Tris buffer (pH 6.8 for stacking gel and $\mathrm{pH} 8.8$ for resolving gel), $0.1 \%$ SDS, $0.1 \%$ ammonium persulfate, and $0.1 \%$ TEMED. Proteins were separated via electrophoresis for $45-130$ min at $180 \mathrm{~V}$ in Tris-glycine running buffer (stock buffer contained $75.5 \mathrm{~g}$ Tris-base, 460 g glycine, $25 \mathrm{~g}$ SDS, with $\mathrm{ddH}_{2} \mathrm{O}$ to a total of $2.5 \mathrm{~L}$ ) using a BioRad Mini-Protean 3 System. Aliquots of $5.5 \mu \mathrm{L}$ of pre-stained protein molecular weight ladders (either Froggabio Pink Plus Prestained Protein Ladder; Cat. \# PM005-0500 or BLUeye Prestained Protein Ladder; Cat. \# PM007-0500) were run on each gel concurrently with the samples to serve as a molecular weight reference. The amount of protein loaded, gel percentage and run time varied depending on the protein target. 
Following electrophoresis, proteins were electroblotted by wet transfer onto $0.45 \mu \mathrm{m}$ PVDF membranes (Millipore, Cat. \#: IPVH00010) in transfer solution (25 mM Tris $\mathrm{pH} 8.8,192 \mathrm{mM}$ glycine, and $10 \% \mathrm{v} / \mathrm{v}$ methanol) at $4{ }^{\circ} \mathrm{C}$ for $1.5-15 \mathrm{~h}$ (depending on the molecular weight of the protein) at $160 \mathrm{~mA}$ using BioRad Mini-Protean Transfer cells. After transfer, PVDF membranes were blocked with 2-10\% milk (the \% depending on nonspecific binding to the protein of interest) for $30 \mathrm{~min}$, before washing $3 \times 5 \mathrm{mins}$ in TBST (10 mM Tris, 150 mM NaCl, $0.05 \%$ v/v Tween-20, pH 7.5). Membranes were incubated with 1:1000 v:v primary antibody overnight at $4{ }^{\circ} \mathrm{C}$. For a complete list of antibodies used for Western immunoblotting, please see Appendix A: Antibody information and suppliers for Western immunoblotting.

Following overnight incubation with the primary antibody, all PVDF membranes were washed $4 \times 5$ min in TBST. Membranes were incubated in 1:5000 v:v diluted HRPconjugated secondary antibody (anti-rabbit; Bioshop; Cat. \# APA007P) in TBST for 30 min. Membranes were washed $4 \times 5$ min with TBST and visualized using chemiluminescence (1.4 mL of luminol and $\mathrm{H}_{2} \mathrm{O}_{2}$ in a 1:1 ratio) in a Chemi-Genius BioImaging System (Syngene, Frederick, MD) with quantification of band densities using the GeneSnap software. Membranes were then stained with Coomassie blue $(0.25 \%$ w:v Coomassie brilliant blue, $7.5 \%$ v:v acetic acid, $50 \%$ v:v methanol) and protein band densities were quantified with the Chemi-Genius Bio-Imaging System using normal light settings to image the blue bands.

For Western immunoblotting, variability in protein loading across each time course was ensured by standardizing target band intensities on PVDF membranes 
against the total intensity of a group of Coomassie-stained protein bands in the same lane (not including the target protein) that showed constant expression across the experimental time course (Eaton et al., 2013). Control values were then standardized to 1 and experimental conditions are reported relative to controls. Data are reported as the mean \pm SEM $(n=4-5)$. RBioPlot software (Zhang and Storey, 2016) was used for histogram generation and to test for significant differences between control and experimental conditions using a Student's $t$-test, with $p<0.05$ accepted as a significant difference.

\subsection{RNA extraction:}

RNA was extracted from control and frozen $H$. versicolor liver tissue $(n=4$ for all samples). Frozen tissue weighing $\sim 0.5 \mathrm{~g}$ was crushed under liquid nitrogen and homogenized in $1 \mathrm{~mL}$ of TRIzol reagent (Invitrogen; Cat. \# 15596-018), before adding $200 \mu \mathrm{L}$ of chloroform and centrifuging at $10,000 \times \mathrm{g}$ for $15 \mathrm{~min}$ at $4{ }^{\circ} \mathrm{C}$. The upper aqueous phase (containing RNA) was transferred to a sterile microcentrifuge tube, 500 $\mu \mathrm{L}$ of 2-propanol was added, and tubes were incubated for $10 \mathrm{~min}$ at room temperature to form an RNA precipitate. Samples were pelleted by centrifugation at $10,000 \times \mathrm{g}$ for 15 $\min$ at $4{ }^{\circ} \mathrm{C}$, washed $2 \times$ with $70 \%$ ethanol, and air-dried for $10-15 \mathrm{~min}$. RNA pellets were resuspended with $50 \mu \mathrm{L}$ of RNAse-free water, and concentration/purity was determined using a BioTek Take3 microspot plate and a PowerWave HT microplate spectrophotometer with OD 260/280 ratio of 2.0. RNA integrity was confirmed via $1 \%$ agarose gel electrophoresis. 


\subsection{Small RNA sequencing:}

RNA samples from liver of control vs $24 \mathrm{~h}$ frozen $H$. versicolor were sequenced by Genome British Columbia (Vancouver, BC, Canada). An Agilent Bioanalyzer 2100 system (Agilent Technologies, Santa Clara, CA, USA) was used to corroborate RNA quality prior to miRNA library construction. Small RNA cDNA libraries were constructed, validated with the Bioanalyzer, and sequenced using an Illumina HiSeq 2500 platform.

\subsection{Read processing:}

Raw read data was processed as described in Zhang et al. (2016). Cutadapt (Martin, 2011) was used to discard low-quality reads and trim the 6-nucleotide adapters off, and FastQC was used to validate successful adapter removal and distribution of small RNA lengths (Andrews, 2015). To remove reads corresponding to non-miRNA small RNAs (tRNA, rRNA, piRNA, snRNA, and snoRNA) a negative reference file compiled from Rfam (Kalvari et al., 2018) and piRNABank databases (Sai lakshmi and Agrawal, 2008) was used along with bowtie (Langmead et al., 2009) to eliminate reads that aligned to this negative reference index. All reads that did not align were then aligned using bowtie to all mature miRNA sequences from miRBase, the miRNA database (Kozomara et al., 2019), allowing only perfect seed sequence matches and seed sequence length parameter set to 20 nucleotides. The reads that aligned to mature miRNA sequences were sorted, and read counts were determined for each microRNA using samtools (Li et al., 2009) and Unix command line tools. miRNAs with less than four reads were removed and read counts were normalized using the voom method (Law et al., 2014) as described (Zhang et al., 2016). 


\subsection{Differential expression analysis and clustering:}

Differential expression of miRNAs between control and frozen animals was determined using linear model fitting with empirical Bayesian testing via the limma $R$ package (Ritchie et al., 2015). Differentially expressed miRNAs were considered significant with a false discovery rate (FDR)-corrected $p$-value $<0.05$ and a fold-change that satisfied the following equation:

$$
\left|\log _{2} F C\right| \geq \log _{2} 1.5
$$

Significantly differentially expressed miRNAs were hierarchically clustered by miRNA and sample using the Ward method (Ward, 1963).

\subsection{Gene set analysis:}

Gene set analysis was conducted using the RBiomirGS R package (Zhang and Storey, 2018) which implements a logistic regression-based analysis to determine significantly enriched gene ontology (GO) terms (Carbon et al., 2019) and Kyoto Encyclopedia of Genes and Genomes (KEGG) pathways (Kanehisa et al., 2019). This package uses multiple databases to enumerate miRNA:mRNA interactions, and since the genome of $H$. versicolor has not yet been sequenced, fully conserved human miRNA orthologs were used in substitute. Once miRNA:mRNA interactions are assembled, RBiomirGS calculates a miRNA score ( $S_{\text {microRNA }}$ ) for each miRNA through its expression as previously described (Garcia-Garcia et al., 2016) with the following equation:

$$
S_{\text {microRNA }}=-\log _{10} p \times \operatorname{signum}\left(\log _{2} F C\right)
$$


In this equation, $p$ is the FDR-adjusted $p$-value and $F C$ is the fold-change of the miRNA between control and frozen animals from the differential expression analysis. A mRNA score $\left(S_{m R N A}\right)$ is also calculated for each mRNA target as the sign reversed summation of $S_{\text {microRNA }}$ of targeting miRNAs using the following equation:

$$
S_{m R N A}=-\sum_{i=1}^{n} S_{\text {microRNA }}^{i}
$$

The number of miRNAs targeting the given mRNA is denoted as $n$, and $S_{\text {microRNA }}{ }^{i}$ is the $S_{\text {microRNA }}$ of the $i^{\text {th }}$ targeting miRNA.

RBiomirGS uses the calculated $S_{m R N A}$ of mRNAs to isolate significantly enriched gene sets (FDR-adjusted $p$-value $\geq 0.05$ ) and corresponding model coefficients for each GO term and KEGG pathway. A positive model coefficient indicates negative regulation by miRNA is decreased, and a negative coefficient indicates negative regulation is increased by miRNA in the frozen group relative to the control group. Estimated model coefficients and standard error are calculated by a logistic regressed based method, which are then applied to determine statistical significance (Zhang and Storey, 2018).

\subsection{Statistical analysis and visualization:}

Volcano plots, heatmaps, and biplots for differential expression and gene set analysis were produced using either matplotlib and seaborn python packages, or Microsoft Excel (Hunter, 2007; Waskom et al., 2014). Hierarchical clustering of significantly differentially regulated miRNAs was produced by the gplots R package (Warnes et al., 2019). 


\title{
CHAPTER 3
}

\section{Differentially-Regulated MiRNA Biogenesis Across}

\author{
Tissues of $\boldsymbol{H}$. versicolor
}




\subsection{Introduction:}

The winter months are characterized by a variety of extreme environmental stresses including lack of food resources, decreased photoperiod, and cold, often subzero, temperatures. To combat this, animals use strategies including migration to warmer climates, seeking well-buffered shelter underground or under water, or implementing biochemical adaptations to mitigate and survive the aforementioned conditions. The grey tree frog (Hyla versicolor) is a holarctic tree frog that, in North America, resides in the eastern United States and southeastern Canada and utilizes freeze-tolerance to endure the winter. Freeze-tolerance is characterized by the freezing of $42-65 \%$ of total body water into extracellular spaces, the cessation of heartbeat and breathing, and a completely immobile and nonresponsive state until spring temperatures permit thawing (Layne and Lee, 1989; Storey and Storey, 2017). Ice formation is induced near the equilibrium freezing point of the animal's bodily fluids, allowing for a slow nucleation across the integument (avoiding a potentially lethal ice surge) before penetrating deeper into the inner body cavity and remaining stable at -3 ${ }^{\circ} \mathrm{C}$ (Rubinsky et al., 1994b). However, the process of freeze-tolerance induces several physiological detriments including anoxia induced by the lack of oxygen intake, ischemia via the absence of blood flow, and hyperosmotic stress from water exiting cells to join growing ice masses (Storey and Storey, 2017). To combat this, $H$. versicolor synthesizes large amounts of glycerol and glucose cryoprotectants to act as osmolytes and prevent further mechanical stress due to lethal cell shrinkage; however, this also contributes to extreme hyperglycemia (Layne and Jones, 2001). The concentration of glucose and 
glycerol in blood plasma can vary widely; however, measurements have suggested $\sim 29$ mM glucose and 177 - 423 mM glycerol (Layne and Stapleton, 2009; Storey and Storey, 1985a).

To mitigate the challenges brought on by freeze-tolerance, $H$. versicolor undergoes metabolic rate depression (MRD). MRD is the global downregulation of nonessential genes and processes into a hypometabolic state until conditions are once again favorable to resume normal physiological activity (Storey and Storey, 2004). The principle surrounding MRD is largely energy-centric given that ATP consumption must not exceed ATP production, which is severely limited during MRD and/or a frozen state and, hence, animals must often rely on the less efficient pathways of anaerobic metabolism to generate ATP (Storey and Storey, 2004). Energy-expensive processes including the cell cycle, active transport, and many forms of biosynthesis, to name a few, must be strongly suppressed or shut down, which requires extensive coordination and regulation to do successfully. Cells must be able to quickly call upon a range of regulatory mechanisms to exert and coordinate the necessary modifications. Examples of such regulatory mechanisms include epigenetic controls (including histone modification and DNA methylation), post-translational modifications on enzymes, changes in enzyme activity, enhancement of protective mechanisms including chaperone proteins and antioxidant enzymes, and microRNA inhibition of gene translation (Storey and Storey, 2017).

MicroRNAs (miRNAs) are short, noncoding, single-stranded RNA, typically 18-25 nt long, which target mRNA transcripts for post-transcriptional repression. They are 
synthesized via the miRNA biogenesis pathway, and target mRNA transcripts as part of a structure called the RISC complex, which enacts complementary 8 nt seed-sequence pairing to the mRNA and thereby triggers mRNA repression or degradation (Bartel, 2004). Perfect complementarity of the seed sequence of an miRNA to a mRNA transcript is linked to degradation of the mRNA transcript via endonuclease action, whereas imperfect complementarity can lead to repression and storage of the mRNA in stress granules or p-bodies (Bartel, 2004). One miRNA can target several different mRNAs, and alternately, one mRNA can be targeted by multiple miRNAs. The rapid, reversible nature of miRNA regulation as well as their target versatility makes miRNAs ideal for implementing transient phenotypes, and therefore an appealing mode for regulation of transitions between different metabolic states such as during freeze/thaw cycles in $H$. versicolor.

miRNA biogenesis is enabled by several key proteins and modulated through cofactors and thermodynamic stability (Figure 1.1). In the canonical miRNA biogenesis pathway, miRNAs are transcribed in the nucleus by RNA polymerase II to form the double-stranded primary miRNA (pri-miRNA), in which the mature sequence is enclosed within a hairpin turn and the entire structure is $~ 70 \mathrm{nt}$ long (Kim, 2005). The hairpin is cleaved off to form the double-strand precursor-miRNA (pre-miRNA) by the microprocessor complex which is a $\sim 650 \mathrm{kDa}$ structure consisting of the enzymes DROSHA, an RNase III enzyme, and DGCR8 (Finnegan and Pasquinelli, 2013; Kim, 2005). DROSHA is a large, conserved protein in animals and contains two RNase III domains and a double-stranded RNA-binding domain that are central to its function (Kim, 2005). 
DGCR8, also known as Pasha in D. melanogaster and C. elegans, has two doublestranded RNA binding domains and aids in binding and stabilizing DROSHA, as well as in recognizing the apical UGU motif located in the hairpin loop of the pri-miRNA (Nguyen et al., 2015). At this stage, the pre-miRNA is exported out of the nucleus via nuclear export protein Exportin 5 (XPO5), where the RNase III enzyme DICER, along with cofactors TAR RNA-binding protein (TRBP) and protein activator of PKR (PACT), process it into the 21-24 nt long duplex miRNA. The 3' end of the duplex miRNA has a twonucleotide overhang which is used to load it onto the Argonaute (AGO) proteins. The strand holding the mature miRNA sequence is kept while the other strand is discarded, known as passenger strand ejection, and this structure constitutes the miRNA induced silencing complex (RISC) which is fully prepared to target mRNAs (Bartel, 2004).

miRNA regulation has already been analyzed in other models of MRD including freeze-tolerant frogs Rana sylvatica and insects Eurosta solidaginis, hibernating lemurs Microcebus murinus and ground squirrels Ictidomys tridecemlineatus, hypoxic crayfish Orconectes virilis, and estivating frogs Xenopus laevis (Biggar et al., 2018; English et al., 2018; Hadj-Moussa and Storey, 2018; Luu and Storey, 2015; Lyons et al., 2016; Wu and Storey, 2018). The aforementioned organisms which undergo freeze tolerance are most applicable to the current study. In E. solidaginis, 24 differentially expressed miRNAs were identified with links to translational repression, reactive oxygen species, and hypoxic conditions (Lyons et al., 2016). In wood frog R. sylvatica, Hadj-Moussa and Storey (2018) measured a series of 113 miRNAs in brain tissue, and observed widespread downregulation of both the miRNAs themselves as well as proteins of the 
miRNA biogenesis pathway. In fact, the growing relevance of miRNAs directly induced by cold temperatures has given rise to a family of miRNAs called cryomiRs, and further research is expanding the members and specific functional roles of this family (Lyons et al., 2013a, 2015a).

miRNA expression is not uniform throughout the entire organism. There is wide variability in tissue composition, roles during euthermic and freeze-tolerant stresses, freezing duration, and susceptibility to cellular stress. Not only is it expected, but it has been observed, that miRNA expression varies substantially across tissues in response to freezing. In skeletal muscle of wood frogs, 16 miRNAs increased during freezing whereas only 1 miRNA increased in heart tissue. In fact, there was widespread downregulation of miRNA expression in heart, with predicted roles of these miRNAs including actin cytoskeleton and cardiac myopathy (Bansal et al., 2016). In brain tissue, only 2 miRNAs were upregulated during freezing and 23 were downregulated, with the downregulated miRNAs predicted to have roles in intracellular signal transduction, synaptic signaling, and DNA replication (Hadj-Moussa and Storey, 2018). With this in mind, the three tissues currently chosen for study reflect the different functions that each tissue serves during freeze-tolerance. Liver is the last organ to freeze and the first to thaw, being the most metabolically active and is responsible for synthesis of cryoprotectants. The extensive stores of glycogen used to produce both glucose and glycerol as well as provide energy for anaerobic metabolism are located in the liver, and are much larger than in freeze-intolerant frogs (Churchill and Storey, 1993; Storey and Storey, 2017). Enzyme activities were also notable in liver: 5 enzymes showed freeze-specific increases 
in enzyme maximal activities in contrast to other tissues the showed an overarching reduction of enzyme activities or, in the case of skeletal muscle, no change during freezing but an increase in enzyme activity upon thawing (Cowan and Storey, 2001). By contrast, during freezing skeletal muscle is largely metabolically inactive and is one of the first tissues to freeze. Muscle also shows variable metabolic end products compared to liver. Frog tissues can produce both L-lactate and L-alanine as end products of anaerobic glycolysis, and in skeletal muscle of frozen wood frogs the ratio lactate:alanine was 1:2 whereas in liver it was is 1:1 (Storey and Storey, 1986b). Lactate was overwhelmingly the primary end product in kidney, the last tissue of interest in this study. Kidney showed relatively low levels of glycerol cryoprotectant in comparison with other organs, for example, showing $74 \mu \mathrm{mol} / \mathrm{mL}$ in comparison with $188 \mu \mathrm{mol} / \mathrm{mL}$ in liver (Storey and Storey, 1986b). However, kidney plays an important role during freezing where it is responsible for recovering cryoprotectants (glucose, glycerol, urea) from the kidney filtrate and bladder water when $H$. versicolor thaws. Indeed, studies of the closely-related $\mathrm{H}$. chrysocelis indicate that kidney increases its resorption rate of glycerol during thawing in order to minimize net carbon loss from the frog; this is carried out be a modified transmembrane water channel, an aquaglyceroporin (Zimmerman et al., 2007). A novel freeze-responsive protein discovered in $R$. sylvatica, FR10, showed upregulation in many tissues in response to freezing, but rose specifically in kidney in response to anoxia stress (Sullivan et al., 2015). It can be suggested that despite the cessation of urination or the removal of waste products while the frog is in a frozen 
state, kidney is nevertheless a relevant tissue with unique metabolic responses during freeze tolerance that warrants investigation.

The present study measured the expression levels of 11 proteins in the canonical miRNA biogenesis pathway in liver, skeletal muscle, and kidney comparing control $\left(5^{\circ} \mathrm{C}\right.$ acclimated) and $24 \mathrm{~h}$ frozen $\left(-2.8^{\circ} \mathrm{C}\right)$ mature $H$. versicolor. Up- or downregulation of these proteins could infer that more or fewer miRNAs, respectively, are being synthesized in these tissues in response to freezing stress. Differences in miRNA biogenesis protein expression could postulate the variable nature of miRNA expression, and its relative importance during freeze tolerance across different tissues. Taken together, these findings present an introduction to miRNA biogenesis and its potential role in mitigating MRD and freeze-tolerance in a freeze tolerant frog. 


\subsection{Materials and Methods:}

\subsubsection{Animal collection:}

Animals were collected as per the protocol laid out in Chapter 2.1.

\subsubsection{Total protein isolation:}

Soluble protein extracts were made as described in Chapter 2.2.

\subsubsection{Western immunoblotting:}

Western immunoblotting was performed for liver, skeletal muscle, and kidney comparing samples taken from control $5^{\circ} \mathrm{C}$ acclimated frogs and $24 \mathrm{~h}$ frozen $\left(-3^{\circ} \mathrm{C}\right)$ frogs as detailed in Chapter 2.3. Protein expression levels of $A G O 1, A G O 2, A G O 3, A G O 4$, DGCR8, DICER, DROSHA, PACT, RAN-GTP, TRBP, and XPO5 were measured. See Appendix A: Antibody information and suppliers for Western immunoblotting and Appendix B: Western immunoblotting conditions for a full list of parameters for each protein target. 


\subsection{Results:}

\subsection{1. miRNA biogenesis proteins in liver:}

Relative protein expression levels of 11 proteins of the miRNA biogenesis pathway (AGO1-4, DGCR8, DICER, DROSHA, PACT, RAN-GTP, TRBP, and XPO5) were measured in liver tissue of control and $24 \mathrm{~h}$ frozen $\mathrm{H}$. versicolor. Of these, four displayed statistically significant upregulation in response to freezing whereas the rest remained unchanged between control and stress conditions (Figure 3.1). DICER showed the strongest upregulation of 3.47-fold, followed closely by DROSHA at 2.65 -fold ( $p<0.05$, Figure 3.1). Levels of XPO5 were 2.08-fold higher in liver from frozen frogs vs. controls, and TRBP showed upregulation of 1.54-fold ( $p<0.05$, Figure 3.1). For representative images of both whole blots and various bands of interest, please see Appendix C:

\section{Verifying antibody specificity for Western immunoblotting.}

\subsection{2. miRNA biogenesis proteins in muscle:}

Relative protein expression levels of 11 proteins of the miRNA biogenesis pathway (AGO1-4, DGCR8, DICER, DROSHA, PACT, RAN-GTP, TRBP, PACT, and XPO5) were measured in hind leg skeletal muscle from control and $24 \mathrm{~h}$ frozen $\mathrm{H}$. versicolor. Four of these proteins exhibited statistically-significant downregulation. Relative abundance of AGO1 dropped to $13 \%$ of control values, while XPO5 protein levels fell to just $33 \%$ of control values ( $p<0.05$, Figure 3.2). Levels of DGCR8 fell to $46 \%$ of control values, and AGO2 decreased to $51 \%(p<0.05$, Figure 3.2). All other proteins in muscle showed no statistically significant changes between control and frozen tissue. 
Antibodies for DROSHA, AGO3, and AGO4 displayed no cross-reactivity with proteins in skeletal muscle and as such, could not be analyzed.

\subsection{3. miRNA biogenesis proteins in kidney:}

Relative protein expression levels of 11 proteins of the miRNA biogenesis pathway (AG01-4, DGCR8, DICER, DROSHA, PACT, RAN-GTP, TRBP, PACT, and XPO5) were measured in kidney of control and $24 \mathrm{~h}$ frozen $\mathrm{H}$. versicolor. All four AGO proteins demonstrated a statistically significant downregulation to $14 \%, 4 \%, 2 \%$, and $4 \%$ of control values, respectively ( $p<0.05$, Figure 3.3). DGCR8 was downregulated during 24 h freezing to $15 \%$ of control levels, and RAN-GTP was also downregulated to $36 \%$ of control levels. All other proteins remained unchanged between control and $24 \mathrm{~h}$ frozen $(p<0.05$, Figure 3.3). 


\subsection{Discussion:}

miRNA action is a form of post-transcriptional regulation that can enact rapid, reversible changes to the translation of mRNA transcripts while not affecting the DNA sequence itself. Control via miRNA can be extremely powerful given that (a) one miRNA type can regulate multiple mRNA transcripts, and (b) one mRNA transcript can be affected by multiple miRNA types. Additionally, miRNA action can lead to either degradation mRNA transcripts by targeting them for catabolism, or redirect transcripts towards stress granules for storage until they can be translated later. Given that freezetolerance is an inherently transient ability, it was hypothesized that miRNA control exerts a regulatory role on cellular pathways involved in the transition to and maintenance of a frozen state. This study measured expression levels of miRNA biogenesis proteins in liver, skeletal muscle, and kidney of grey tree frogs to determine whether these biogenesis proteins, and by extension miRNAs themselves, responded to freezing stress.

\subsection{1. miRNA biogenesis is upregulated in liver:}

Using Western immunoblotting, protein expression levels of eleven canonical miRNA biogenesis proteins were measured in liver tissue from control vs $24 \mathrm{~h}$ frozen frogs (Figure 3.1). Of these, four proteins (DICER, DROSHA, TRBP, and XPO5) were significantly upregulated (Figure 3.1). All other proteins showed no statistically significant changes between control and frozen states. The tandem upregulation of DROSHA and XPO5 suggests that more pre-miRNAs are being generated and exported from the nucleus during the freezing process. In the canonical miRNA biogenesis 
pathway, RNA polymerase II transcribes the primary-miRNA transcript, or pri-miRNA, which is a large piece of RNA containing a hairpin structure. This pri-miRNA is then cleaved into a $70 \mathrm{nt}$ long precursor-miRNA (pre-mRNA) by a microprocessor complex consisting of DROSHA and DGCR8 (Saliminejad et al., 2019). These pre-miRNAs are then exported from the nucleus via XPO5 and its cofactor RAN-GTP. It is important to note that while the upregulation of DROSHA and XPO5 were observed, there was no corresponding upregulation in either DGCR8 or RAN-GTP. With regards to DROSHA/DGCR8, the predominant form of the microprocessor complex is heterotrimeric and consists of two molecules of DGCR8 to one molecule of DROSHA (Herbert et al., 2016). However, DROSHA is capable of binding RNA in the absence of DGCR8, and serves both recognition purposes as well as being the primary catalytic subunit (Nguyen et al., 2015). Hence, DROSHA is likely the rate-limiting protein of the microprocessor complex. DGCR8 aids in binding and stabilizing DROSHA, as well as recognizing the apical UGU motif located in the hairpin loop of the pri-miRNA, but is not strictly necessary for DROSHA to carry out functionality (Nguyen et al., 2015). With regards to RAN-GTP, the mechanism of pre-miRNA transport involves XPO5 binding to the pre-miRNA at high RAN-GTP levels in the nucleus, before translocation of this trimeric complex to the cytoplasm. Hydrolyzed RAN and the pre-miRNA are released before XPO5 returns to the nuclear compartment (Bohnsack et al., 2004; Kutay et al., 1997). RAN-GTP is required for many nuclear importins/exportins, GTP hydrolysis providing the energy to drive the transport process between nucleus and cytoplasm (Fornerod et al., 1997; Kutay et al., 1997). However, XPO5 is highly specific to miRNA 
transport (Lund et al., 2004). Therefore, the XPO5 upregulation is undoubtedly the ratelimiting factor and the increased XPO5 levels measured in liver are indicative of increased miRNA transport during the freezing process.

Two other proteins, TRBP and DICER, were also upregulated in response to freezing, showing 1.54- and 3.47-fold increases, respectively (Figure 3.2). In the cytoplasm, TRBP is a cofactor that facilitates DICER-mediated cleavage of the hairpin structure off the pre-miRNA to form the $\sim 22 \mathrm{nt}$ miRNA duplex. Hence, these two proteins are crucial to setting up the further processing of miRNA transcripts in the cytoplasm. Therefore, it is not surprising, that both proteins are upregulated under conditions (freezing) where increased storage/protection of mRNA transcripts is likely needed to preserve these transcripts until frogs thaw and new protein synthesis is rapidly restarted.

The following step, which is DICER-independent in mammals (Kobayashi and Tomari, 2016), involves recruitment of an AGO protein to the miRNA-mRNA duplex to form the RISC complex (Kawamata and Tomari, 2010). Humans have 8 different AGO proteins, and AGO1-4 are all capable of loading miRNA duplexes (Yoda et al., 2010). However, none of the AGO proteins in this study showed a change in protein expression in response to freezing (Figure 3.1). Possible reasons for this can be postulated. One is that the baseline concentrations of AGO proteins in the cell are greatly in excess of what is required and are therefore already capable of handling increased miRNA duplex synthesis without a corresponding increase in protein expression. Another possibility centers around AGO protein functions themselves. Once an AGO protein is recruited to 
form the RISC complex, the 'unneeded' miRNA strand, called the passenger strand, is removed to allow formation of the final $-3 p$ or $-5 p$ miRNA that can then bind to its target mRNA. What happens to the mRNA differs based on the AGO protein present in the RISC complex. AGO2 is the only AGO protein that possesses endonuclease 'slicer' activity (Meister et al., 2004), allowing it to completely degrade target mRNA whereas the other AGO proteins repress mRNA targets through nonslicer mechanisms via GW182 proteins (Ipsaro and Joshua-Tor, 2015). It is possible that all the AGO proteins in liver are recruiting miRNA duplexes in a consistent manner such that no specific AGO protein is disproportionally pressured, allowing protein expression levels of all four AGOs to remain constant.

\subsection{2. miRNA biogenesis is downregulated in muscle:}

Interestingly, skeletal muscle of frogs showed the opposite response to liver with clear evidence of downregulation of miRNA biogenesis proteins, as well as a different suite of affected proteins, as compared with liver (Figures 3.1 and 3.2). AGO1 and AGO2 were significantly downregulated to $13 \%$ and $51 \%$, respectively, of control values whereas DGCR8 showed a similar decrease to $46 \%$ of controls. XPO5 also showed a downregulation to $33 \%$ of control values (Figure 3.2). Similar but opposite parallels can be made for muscle as compared with the miRNA biogenesis pathway in liver. DGCR8 is linked to DROSHA to form the microprocessor that generates pre-mRNA from primiRNA, and whereas DROSHA is the primary catalytic unit for the microprocessor, DGCR8 has a key role in stabilizing DROSHA as well as recognizing the hairpin loop of the pri-miRNA (Nguyen et al., 2015). DROSHA can process pri-miRNAs independently of 
DGCR8, but at reduced efficiency, indicating that miRNA biogenesis may be hindered in muscle at the pri-miRNA level (Nguyen et al., 2015). This could be beneficial for cells considering that they would not need to expend unnecessary GTP to transport the premiRNA to the cytoplasm, and likewise no further energy would be consumed by processing the pre-miRNA to completion. This claim is further accentuated by the downregulation of XPO5, which sits at a crucial junction to regulate export pre-miRNAs into the cytoplasm to be processed into miRNA duplexes. Finally, both AGO1 and AGO2 were downregulated in frog muscle as well. In humans, AGO2 is the only AGO protein that possesses endonuclease 'slicer' activity and is the most efficient at targeting mRNA for degradation (Meister et al., 2004), therefore it may be the critical miRNA endonuclease in frog muscle. Other AGO proteins have the ability to bind miRNAs and form a functional RISC complex, but they typically direct the mRNA transcripts to $p$ bodies or stress granules for translational repression rather than complete degradation (Fabian and Sonenberg, 2012; Huntzinger and Izaurralde, 2011). Since AGO1 is also downregulated, it may suggest that suppression of these two proteins is tied to global MRD, rather than specifically directing mRNAs to either degradation or translational suppression. Collectively, the downregulation of AGO1, AGO2, DGCR8, and XPO5 suggest that the miRNA biogenesis pathway is inhibited along all steps, from nuclear primiRNA processing to cytoplasmic RISC formation in the frozen frog, and may be due to global MRD and relative metabolic inactivity of this tissue. 


\subsection{3. miRNA biogenesis is downregulated in kidney, but distinct from muscle:}

Similar to skeletal muscle, all miRNA biogenesis proteins that demonstrated a statistically significant change in kidney were downregulated ( $p<0.05$, Figure 3.3). Noticeably, however, all four AGO proteins were strongly downregulated in response to $24 \mathrm{~h}$ freezing stress. As mentioned above, the final step in formation of the RISC complex is association with an AGO protein to allow passenger strand ejection, followed by targeting and binding to the mRNA target for translational repression (Bartel, 2004). Loss of the AGO protein would essentially hobble the functionality of the RISC complex. The AGO proteins themselves are essential: knockout of AGO2 in mice results in embryonic lethality (Liu et al., 2004) whereas double-knockout AGO1 and AGO3 mice proved to be more susceptible to influenza mortality, inferring that AGO1 and AGO3 have significant roles in RNAi (perhaps by mediating nonredundant aspects of RNAi machinery or binding specific subsets of miRNAs) despite not being crucial during development (Van Stry et al., 2012). AGO3, for example, is most effective as a translational repressor when paired with a reporter mRNA (Wu et al., 2008). It has been consistently reported that all four AGO proteins bind endogenous miRNA indistinguishably (Liu et al., 2004; Meister et al., 2004). Therefore, downregulation of all four AGO proteins as we observe in kidney from $24 \mathrm{~h}$ frozen frogs (Figure 3.3) would serve to holistically disable mature miRNA, RISC formation, and mRNA targeting. A broader perspective as to why an extensive form of post-transcriptional regulation may be downregulated during freeze tolerance, it may be that miRNAs are not crucial to facilitate MRD in this tissue, and therefore AGO downregulation may be part of the 
global downregulation of nonessential genes and processes to strictly conserve necessary cellular energy.

Results showed that RAN-GTP was also downregulated to $36 \%$ of control levels during freezing (Figure 3.3). In the miRNA biogenesis pathway, RAN-GTP facilitates the export of pre-miRNAs from the nucleus to the cytoplasm via XPO5, by providing energy from the hydrolysis of GTP to GDP (Bartel, 2004). It is curious that a decrease in levels of XPO5 was not observed, given XPO5 is an exportin rather specific to miRNA precursors and its downregulation would suggest that pre-miRNAs export from the nucleus is suppressed in frozen frogs. Conversely, RAN-GTP is a crucial protein in nucleocytoplasmic transport and in fact is the major source of asymmetry across the nuclear envelope (Görlich et al., 1996). For example, RAN-GTP cooperates with importin $\alpha$ and $\beta$ to transport nuclear localization signals, which are found in many proteins requiring translocation to the nucleus (Kutay et al., 1997). RAN-GTP also plays multiple roles in cell division, from kinetochore attachment to reassembly of the new nuclear envelopes (Arnaoutov and Dasso, 2005). If levels of RAN-GTP are decreased, then it could be suggested that rates of nuclear export as a whole are also decreased, again lending support to the theme of global MRD in this tissue.

\subsection{4. miRNA biogenesis in freeze tolerance:}

MiRNA biogenesis has been studied in other models of animal MRD, including freeze tolerance specifically. For example, in the wood frog $R$. sylvatica, levels of AGO2, DROSHA, DGCR8, XPO5, and PACT all decreased during $24 \mathrm{~h}$ freezing in brain tissue while the other proteins remained unchanged (Hadj-Moussa and Storey, 2018). 
Therefore, in R. sylvatica brain, the data suggest a global downregulation in miRNA biogenesis and processing, with a focus on nuclear maturation (Hadj-Moussa and Storey, 2018). This may allow for energy conservation in this tissue while other mechanisms (e.g. DNA methylation, histone modification) fulfill regulatory roles, or it is possible that necessary miRNA regulation in brain was completed earlier than the $24 \mathrm{~h}$ timepoint or in anticipation of freezing. While members of the miRNA biogenesis pathway were not assessed in any other research involving $R$. sylvatica, studies have been done on specific miRNAs themselves in the wood frog. For example, one miRNA in heart showed a 1.30-fold upregulation during freezing, whereas 7 miRNAs showed reduced expression (Bansal et al., 2016). Skeletal muscle showed 16 miRNAs that were increased in expression during freezing whereas 2 were downregulated (Bansal et al., 2016). A limited study in frozen R. sylvatica liver measured the transcript levels of 3 miRNAs which regulate the protein PTEN, and all 3 were upregulated during freezing (Zhang and Storey, 2013). This lends well to our observations of miRNA biogenesis being upregulated in liver (Figure 3.1), since liver is essential to both cryoprotectant synthesis and maintenance of essential functions during freezing. Therefore, tight regulatory control is needed to constrain the expenditure of cellular energy to acceptable levels.

\subsection{Conclusions:}

This study provided the first overview of miRNA biogenesis and regulation in a novel organism in response to freezing stress. MiRNA biogenesis protein expression was upregulated in liver, which may correspond to increased synthesis of miRNAs in liver and which is corroborated by other studies performed in a freeze-tolerant frog. 
Conversely, miRNA biogenesis proteins exhibited downregulation in skeletal muscle and kidney, which would suggest that miRNA synthesis is reduced during $24 \mathrm{~h}$ freezing in these two tissues. It is important to point out that different proteins in each tissue were downregulated, which may reflect the alternate functions of some proteins (e.g. RANGTP's role as a nucleocytoplasmic transport cofactor, and AGO2 as the only AGO protein possessing endonuclease activity). Overall, this study highlights miRNA regulation during freeze tolerance in $\mathrm{H}$. versicolor and offers intriguing paths for further study to determine how this frog maintains MRD and alters its metabolic processes to protect its cells for winter freezing survival. 


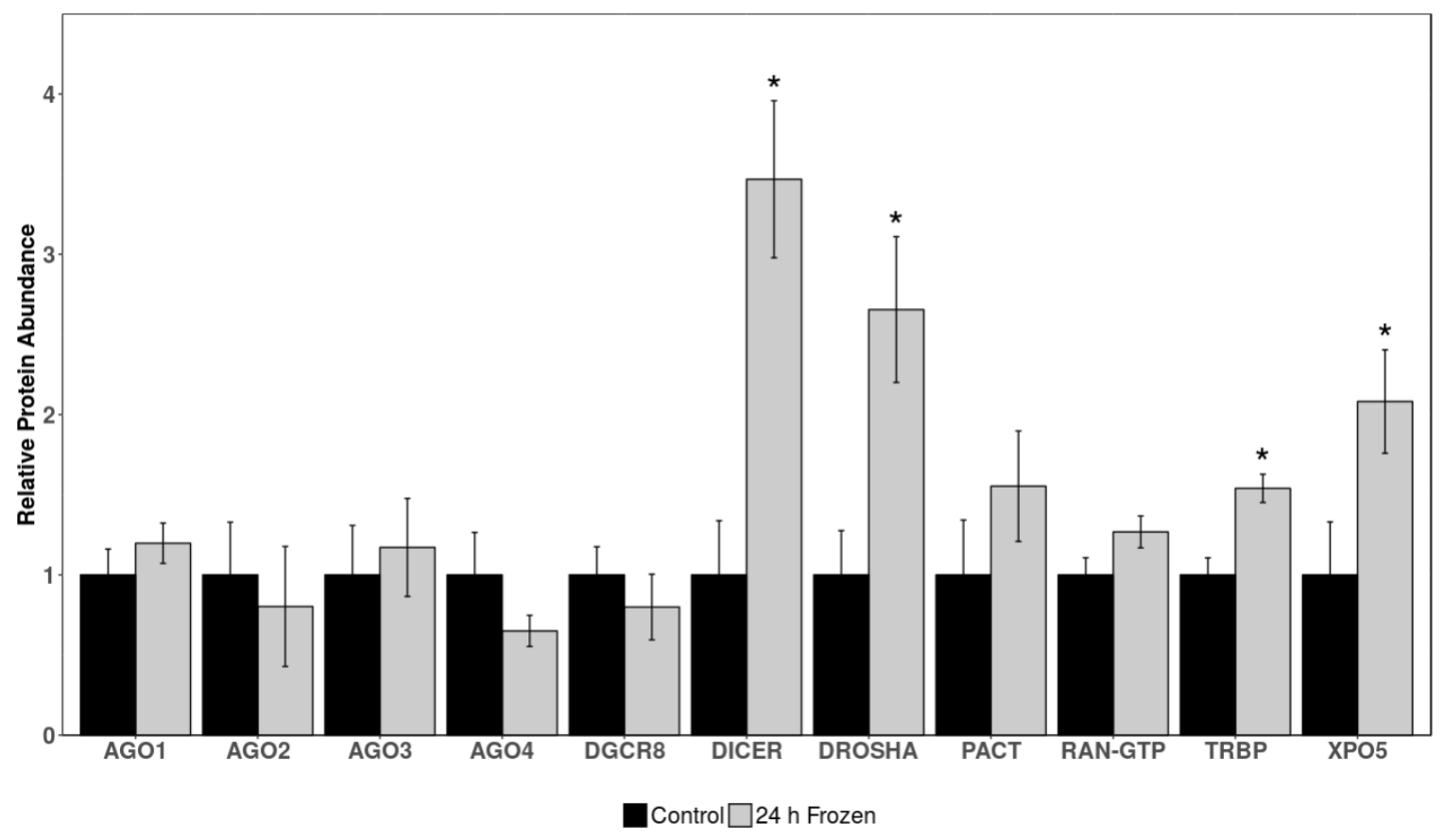

Figure 3.1. Expression of miRNA biogenesis proteins in $\boldsymbol{H}$. versicolor liver. Relative expression levels of mRNA transcripts of AGO1-4, DGCR8, DICER, DROSHA, PACT, RANGTP, TRBP, XPO5 were assessed in control vs. $24 \mathrm{~h}$ frozen $\mathrm{H}$. versicolor. Data were displayed as mean band densities ( \pm SEM, $n=4-5$ ). Data was analyzed with a Student's $t$-test $(p<0.05)$. Values for frozen frogs that are statistically different from the corresponding control are denoted by an asterisk. 


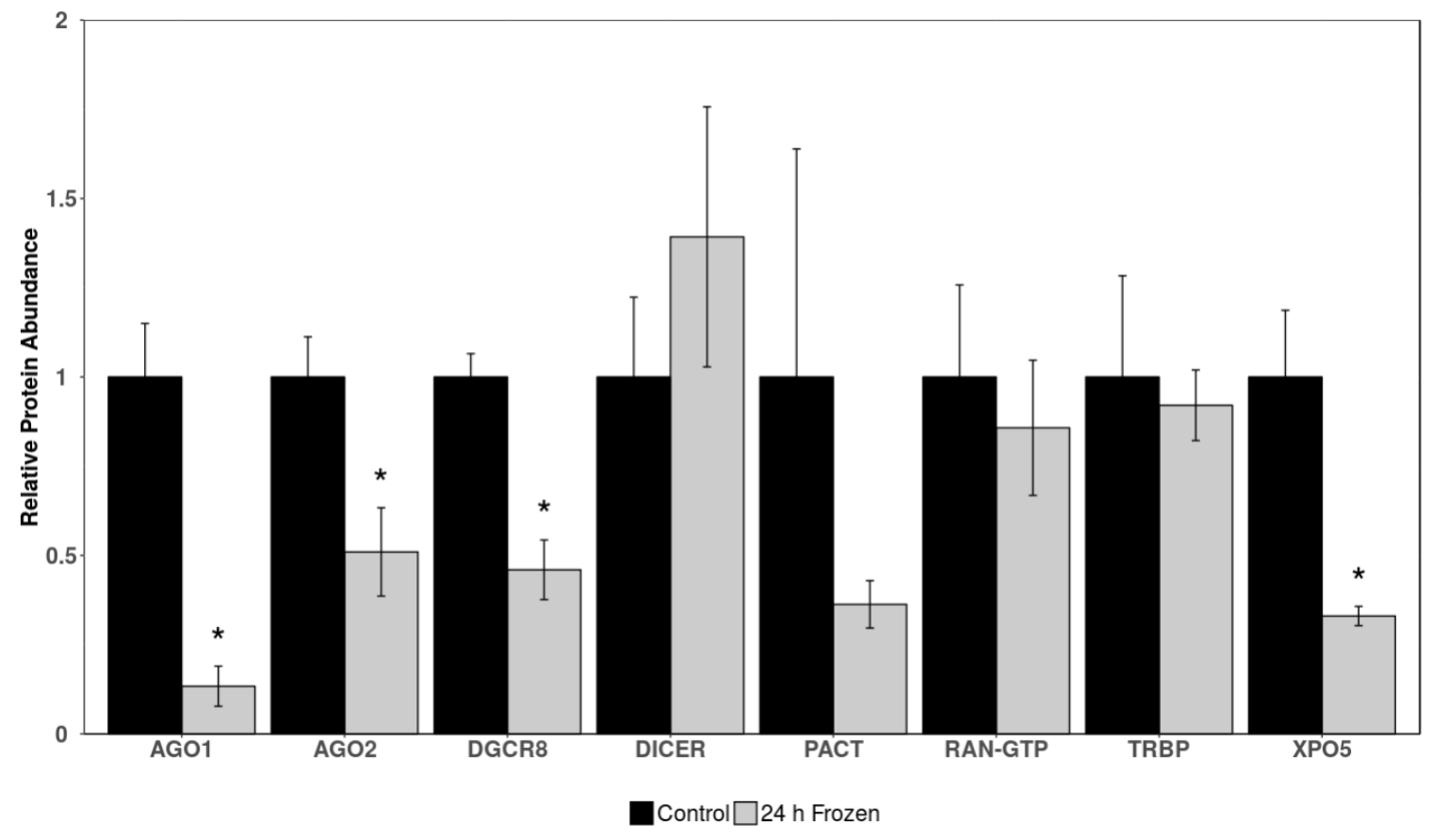

Figure 3.2. Expression of miRNA biogenesis proteins in $\boldsymbol{H}$. versicolor skeletal muscle. Relative expression levels of mRNA transcripts of AGO1-4, DGCR8, DICER, DROSHA, PACT, RAN-GTP, TRBP, XPO5 in control vs. $24 \mathrm{~h}$ frozen $\mathrm{H}$. versicolor. Data were displayed as mean band densities ( \pm SEM, $n=4-5$ ). Data was analyzed with a Student's $t$-test $(p<0.05)$. Values for frozen frogs that are statistically different from the corresponding control are denoted by an asterisk. 


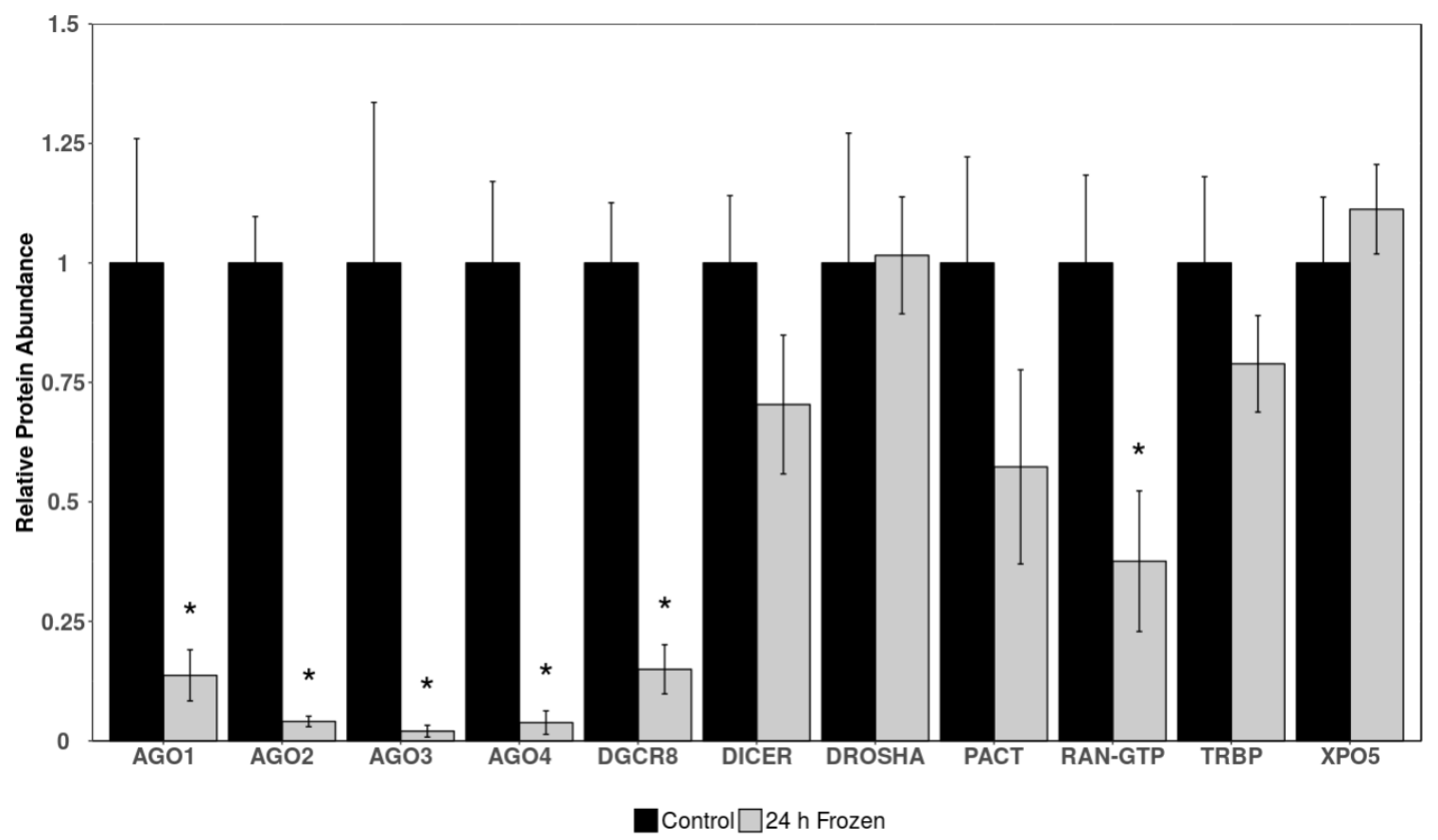

Figure 3.3. Expression of miRNA biogenesis proteins in $\boldsymbol{H}$. versicolor kidney. Relative expression levels of mRNA transcripts of AGO1-4, DGCR8, DICER, DROSHA, PACT, RANGTP, TRBP, XPO5 in control vs. $24 \mathrm{~h}$ frozen $H$. versicolor. Data are displayed as mean band densities ( \pm SEM, $n=4-5)$. Data were analyzed with a Student's $t$-test $(p<0.05)$. Values for frozen frogs that are statistically different from the corresponding control are denoted by an asterisk. 


\section{CHAPTER 4}

Bioinformatic Analysis and MiRNA Transcriptomics

in Liver of $\boldsymbol{H}$. versicolor 


\subsection{Introduction:}

The growing relevance of miRNA to all manner of global cell functions has necessitated the rise of powerful bioinformatic tools to assess the full spectrum of miRNA influence on various cellular processes. miRNAs are short, noncoding, single-stranded RNA molecules 18-25 nt long which bind mRNA transcripts to direct them either to degradation or translational suppression (Bartel, 2004). Given that one miRNA species can target the mRNA transcripts of multiple genes, and oppositely that one mRNA gene transcript can be affected by multiple species of miRNA, the level of regulatory control that miRNAs are capable of enacting rapidly becomes very complex. Coupled with the advent of next-generation sequencing (NGS) which has vastly reduced the cost of genome sequencing whole organisms, it is now possible to identify novel miRNAs, predict their targets, and assess their influences on critical regulatory pathways prior to experimental validation of these steps. Furthermore, as new small RNAs such as circular RNAs and long noncoding RNAs are discovered that can directly affect the miRNAs themselves, the ability to predict small RNA:small RNA and small RNA:mRNA interactions has allowed a new level of detail to be uncovered on everything from disease pathology to stress responses (Ratti et al., 2020; Verduci et al., 2019).

Currently, the bioinformatics tools most widely used in miRNA analysis are grouped into the following main topics: miRNA identification, miRNA target prediction, miRNA-regulated network, expression profile, features (disease or stress, biomarker) association, NGS tools, tools based on machine learning algorithms, and tools specific for plants (Chen et al., 2019). Since the discovery of the first miRNA, lin-4 in 1993, a central 
repository database called miRBase has now logged 38,589 different mature miRNAs across 271 species (Castellano and Stebbing, 2013; Kozomara et al., 2019). Several software programs for miRNA:mRNA target prediction have arisen and include miRanda, TargetScan, and miRDB (Agarwal et al., 2015; Chen and Wang, 2020; Enright et al., 2003). Other programs have more specialized functions: for example, RNAhybrid generates the minimum free energy hybridization of a long and short RNA (Rehmsmeier et al., 2004). MiRDeep associates directly with next-generation sequencing data, and draws on other databases including TargetScan to complete its functions (An et al., 2013). Certain software programs delineate between predicted and experimentally-validated miRNAs, such as TarBase (Karagkouni et al., 2018). Finally, software miRscan identify genes conserved in more than one genome (Lim et al., 2003). Such databases contain information including mature miRNA sequences of the $-3 p$ and $-5 p$ forms, pre-miRNA secondary structure, miRNA gene loci, and other annotation information. Secondary and tertiary structures of miRNAs are also relevant to binding with either binding proteins (such as DGCR8 in the biogenesis pathway) or other RNAs. Software such as miRPara and miRBoost also train Support Vector Machines (SVMs) to predict information including miRNA coding regions in the genome of an organism or miRNA precursors located within abnormal hairpin loops, respectively (Tran et al., 2015; Y. Wu et al., 2011). Collectively, the breadth of computational tools available allow for a great deal of precision and detail in assessing miRNA characteristics, and they are harnessed in this study to provide a more thorough look at miRNA regulation during freeze-tolerance. 
Freeze-tolerance is a winter survival strategy co-opted by several animal species including goldenrod gall fly E. solidaginis, wood frog $R$. sylvatica, and grey tree frog $H$. versicolor. Many studies have already been done which highlight the extraordinary level of metabolic reorganization needed for these species to successfully induce, maintain, and recover from freeze-tolerance (Storey and Storey, 2017, 2012), and the use of NGS coupled with bioinformatic tools are included among these. For example, a study by HadjMoussa and Storey (2018) used the programs and databases FindTar3, String, and GO Gene Ontology to predict temperature thermodynamics of miRNA:mRNA binding and functional target enrichment of these miRNAs. Another study focused on NGS, which was utilized to predict freezing-responsive miRNAs in E. solidaginis which were further dubbed cryomiRs (Lyons et al., 2016). While this is largely the extent of bioinformatics studies in freeze-tolerance, other studies have been done in dehydration-tolerant $X$. laevis, hibernating primate Microcebus murinus, and hypoxic naked mole rats Heterocephalus glaber, highlighting the importance and versatility of these tools in analyzing methods of extreme environmental stress tolerance (Hadj-Moussa et al., 2021, 2020; Hawkins and Storey, 2020).

The research into every cellular mechanism which governs freeze-tolerance is far from complete, and other studies have highlighted a myriad of pathways, transcription factor families, and even novel genes which are all differentially regulated during freezetolerance. For example, the NFkB pathway is responsible for responding to oxidative stress which generates reactive oxygen species (ROS), which can be induced by anoxia (a subcomponent of freeze tolerance) (Gupta et al., 2020). The NFKB pathway is also 
involved in apoptosis, since proteosomal degradation of inhibitor proteins IKBs cause NFKB to activate and promote pro-survival pathways (Oeckinghaus and Ghosh, 2009). Apoptosis regulation during anoxia was further studied in R. sylvatica, where it was shown that pro-survival proteins were upregulated in liver and skeletal muscle (Gerber et al., 2016).

To reflect the holistic nature of freeze-tolerance, signaling pathways which have the potential to regulated and direct gene expression are likewise differentially-regulated in response to freezing stress. In freeze-tolerant E. solidaginis, the cAMP-dependent protein kinase A (PKA) family was examined during freezing due to its connection with enzymes which synthesize polyol cryoprotectant (Hayakawa and Chino, 1983; Pfister and Storey, 2006). The various PKA members fluctuated according to seasonality, reflecting their roles in carbohydrate metabolism and polyol synthesis alike (Pfister and Storey, 2006). The SMAD transcription factor family which orchestrates the TGF $\beta$ signaling pathway, Akt signaling, and MAPK signaling are all differentially-regulated in tissues of $R$. sylvatica during freezing, possibly enacting pro-survival functions (Aguilar et al., 2016; Cowan and Storey, 2003; Zhang and Storey, 2013).

Two key pathways which are altered during freezing are the cell cycle and circadian rhythm. Both are very energetically-expensive pathways, and in line with global MRD, it would make sense for these to be suppressed to conserve endogenous ATP reserves. A study by Zhang and Storey (2012) measured the levels of cyclin and Cdk proteins during freezing in $R$. sylvatica liver and discovered that some proteins were downregulated, thus in line with MRD, but some were upregulated which may have 
alternative roles in cryoprotectant synthesis (Zhang and Storey, 2012). With regards to the circadian rhythm, the Mondo:MLX complex modulates genes in both circadian rhythm and glucose metabolism, making it an attractive target for freeze-tolerance regulation (Singh and Storey, 2020). In liver, the Mondo:MLX complex appeared to be active in liver for both glucose metabolism (via TXNIP, ARRDC4, HK-2, and PFKFB-3) and circadian rhythm (via CLOCK, BMAL1, KLF-10, and others) (Singh and Storey, 2020).

It is clear that many cellular pathways are affected by freeze-tolerance, and the regulatory tools used to alter these pathways are diverse in nature. It is especially interesting that liver appears to be the site of many pro-survival functions across multiple pathways, while in other tissues there is widespread downregulation in response to MRD (Aguilar et al., 2016; Cowan and Storey, 2003; Gerber et al., 2016; Zhang and Storey, 2013). To capture a broad-spectrum overview of one versatile mode of regulation, miRNAs, and how they may affect many different processes in the cell, the present chapter focused on a small RNA-seq dataset comparing liver from control vs. 24 h frozen $H$. versicolor. In Chapter 3, it was predicted that miRNA biogenesis is enhanced in liver and suppressed in skeletal muscle and kidney. Chapter $\mathbf{4}$ focuses specifically on liver by analyzing both particular miRNAs and specific pathways being differentiallyregulated in response to freezing. Using bioinformatics tools and the wide repositories of knowledge in existing miRNA databases (Figure 4.1), a subset of differentiallyexpressed miRNAs predicted to be crucial to the freezing process was identified. Further GO Gene Ontology and KEGG Pathway Analysis revealed potential cellular targets and functions affected by miRNA regulation. Taken together, this study provided insight into 
how miRNA regulation in the liver of $H$. versicolor changed during freezing, and the specific cellular processes that were altered as a direct result of miRNA influence and post-transcriptional regulation during freeze-tolerance. 


\subsection{Materials and Methods:}

\subsubsection{Animal collection:}

Animal collection was carried out as described in Chapter 2.1.

\subsubsection{RNA extraction:}

Total RNA was extracted according to the protocol in Chapter $\mathbf{2 . 4}$

\subsubsection{Small RNA sequencing:}

Total RNA samples were sequenced as per Chapter 2.5.

\subsubsection{Read processing:}

Reads were processed according to the layout in Chapter 2.6. For a more detailed workflow including the specific UNIX commands, please see Appendix D: Bioinformatics workflow for small RNA-seq dataset analysis.

\subsubsection{Differential expression analysis and clustering:}

Differential expression analysis of specific miRNAs was generated via RStudio according to Chapter 2.7 and Appendix D: Bioinformatics workflow for small RNA-seq dataset analysis.

\subsubsection{Gene set analysis:}

Gene Ontology and KEGG Pathway Analysis was performed in RStudio according to Chapter 2.8 and Appendix D: Bioinformatics workflow for small RNA-seq dataset analysis. 
4.2.7. Statistical analysis and visualization:

Statistical analyses were carried out according to Chapter 2.9. 


\subsection{Results:}

\subsubsection{Small RNA sequencing summary:}

The mean of raw reads from liver of 4 control and 4 frozen animals was $17,134,780 \pm 1,373,809$ and $19,618,443 \pm 2,041,422$, respectively. Trimming and quality filtering via cutadapt decreased these numbers to $16,908,851 \pm 1,356,345$ and $19,377,951 \pm 2,043,990$ reads, respectively, for control vs frozen. Subsequent to negative filtering, 4,406,330 \pm 493,832 and 5,361,006 $\pm 1,502,029$ reads aligned to 99 known miRNA sequences from control and frozen samples. Adapter ligation bias in small RNA sequencing is known to occur in a sequence-dependent manner (Raabe et al., 2014) and appears to result mostly in under- rather than over-representation of specific miRNA (Fuchs et al., 2015), which could cause some low expressed miRNA to not be detected in the analysis. To mitigate this effect, analysis was performed via relative expression between control and frozen samples, rather than between control and frozen miRNA.

\subsubsection{Differential expression of miRNA in response to freezing:}

Of the 99 identified miRNAs in all liver samples, 11 were significantly differentially regulated between control and frozen animals (Figures 4.2 and 4.3). Of these 11, 4 miRNAs were downregulated during freezing (miR-140-3p, miR-181a-5p, miR-206-3p, and miR-451a) whereas 7 were upregulated (miR-19a-3p, miR-101-3p, miR30e-5p, miR-142-3p and $-5 p$, miR-21-5p, and miR-34a-5p), as compared with controls. These results are visualized using a volcano plot where red markers indicate miRNAs that are significantly downregulated and blue markers indicate miRNAs that are 
significantly upregulated in frozen animals (Figure 4.3). Hierarchical clustering analysis of significant differentially expressed miRNAs showed three of the four frozen samples clustered together, with the fourth frozen sample more similar to a cluster of three control samples than the fourth control (Figure 4.2). MiRNA expression values for each miRNA were standardized to have the same mean and standard deviation giving a zscore. Z-scores are indicated by color where negative z-scores are more orange and positive z-scores are more purple (Figure 4.2).

\subsubsection{Gene ontology terms enriched for differentially expressed miRNA:}

Gene set enrichment analysis was performed on the GO Molecular Function, Biological Process, and Cellular Component databases. Results showed that $382 \mathrm{GO}$ Biological Process terms were statistically significantly enriched (FDR-adjusted $p$-value $<$ $0.05)$, the majority of these having negative model coefficients and the three of greatest magnitude being GO Negative Regulation of Gene Expression, GO Negative Regulation of Nitrogen Compound Metabolic Processes, and GO Cell Death. The large quantity of GO terms seemingly enacted by 11 miRNAs is reflective of miRNA's unique ability to bind multiple mRNA transcripts, which allows a wide breadth of regulation and in great enough quantities, may even affect further downstream genes. A positive model coefficient indicates negative regulation by miRNA is decreased and a negative coefficient indicates negative regulation is increased by microRNA in the frozen group relative to the control group. GO Biological Process enrichment results are visualized in

\section{Figure 4.4.}


GO Cellular Compartment enrichment showed 63 significantly enriched terms, 12 of which had positive model coefficients and 51 of which had negative model coefficients (Figure 4.5). The most significantly enriched GO Cellular Compartment terms included GO Nuclear Chromatin, GO Cytosolic Large Ribosomal Subunit, and GO Nuclear Chromosome. Many of the significantly enriched terms related to DNA functions of the cell, including GO Nuclear Chromatin and GO Nuclear Chromosome as mentioned above, as well as GO Chromatin, GO Chromosome, and GO DNA Packaging Complex. Other cellular compartments centered around RNA processing, including GO Cytosolic Large Ribosomal Subunit, GO Ribonucleoprotein Granule, GO Cytosolic Ribosome, and GO Large Ribosomal Subunit.

Enrichment analysis of GO Molecular Function terms also showed a high skew towards terms having negative model coefficients (Figure 4.6), where 56 were less than zero and 13 were greater than zero. The top three most enriched molecular functions included GO Enzyme Binding, GO Ubiquitin-Like Protein Transferase Activity, and GO GProtein Coupled Receptor Activity. However, it is important to note that many kinase and signaling functions were enriched, including GO Kinase Binding, GO Kinase Activity, GO Signaling Receptor Activity, and GO Kinase Regulator Activity in the top 20 most enriched functions (Figure 4.6). 


\subsubsection{KEGG pathways with reduced miRNA regulation:}

KEGG pathway enrichment was performed in the same manner as GO term enrichment using RBiomirGS. KEGG enrichment analysis showed that 29 KEGG pathways were significantly enriched, only 4 having positive model coefficients (Figure 4.7). The top three KEGG pathways with the lowest FDR-adjusted $p$-values were KEGG MAPK Signaling Pathway, KEGG Apoptosis, and KEGG Ribosome. KEGG Ribosome was one of the 4 pathways with positive model coefficients. 


\subsection{Discussion:}

\subsubsection{Bioinformatic analysis:}

Bioinformatic analysis of miRNA-seq data comparing control vs. frozen $\mathrm{H}$. versicolor liver yielded four main groupings of information: KEGG; GO Molecular Function; GO Cellular Compartment; and GO Biological Processes (Figure 4.4-4.7). If all miRNAs targeting a specific pathway increase during freezing, the miRNAs would contribute negative regulation to the members of that pathway, and the model coefficient would be negative to reflect this probable downregulation. The reverse is also true; if all miRNAs targeting a pathway decrease, a positive model coefficient is produced to reflect reduced potential negative regulation by those miRNAs. In all four groupings, the data was skewed towards negative model coefficients, signaling that increased miRNA levels are contributing more negative regulation and therefore downregulating pathways/processes. By cross-referencing related entries across groupings, a picture of potential cellular processes more affected by miRNA regulation could be assembled.

\subsubsection{Signaling pathways and cell adhesion appear inhibited during freezing:}

Signaling pathways appeared to be of great import. KEGG analysis indicated the MAPK signaling pathway as the one most strongly altered in freezing under miRNA regulation, with an FDR-adjusted $p$-value of $3.60 \times 10^{-5}$ and a model coefficient of -0.10573 , corresponding to downregulation to $78.4 \%$ of control values. GO Biological Processes corroborated this with GO Regulation of MAP Kinase Activity and GO Regulation of MAPK Cascade demonstrating statistically significant negative model 
coefficients (Figure 4.4). The mTOR signaling pathway was included in the statistically significant KEGG analysis and reinforced with GO Regulation of TOR Signaling in GO Biological Processes, both with negative model coefficients (Figures 4.4 and 4.7). Other signaling pathways included in the top 25 most potentially regulated pathways included, in order of smallest FDR-adjusted $p$-value: Toll-like receptor; p53; NOD-like receptor, RIG-I-like receptor; FcعRI; B cell receptor; insulin; and TGF $\beta$. P53 signaling had the additional related GO Biological Process of GO Signal Transduction by p53 Class Mediator (Figure 4.4). All of these pathways had negative model coefficients; that is, they are predicted to be downregulated as a result of increased miRNA expression during freezing. As a whole, alteration of signaling pathway function is reinforced by GO Molecular Function analysis, where GO Enzyme Binding, GO Kinase Binding, GO Kinase Activity, GO Signaling Receptor, and GO Kinase Regulator were in the top 20 potentially regulated molecular functions with negative model coefficients. GO Biological Processes corroborated this with GO Regulation of Kinase Activity; GO Positive Regulation of Kinase Activity; and GO Positive Regulation of Catalytic Activity as statistically significant with negative model coefficients. GO Cellular Compartment also reported GO Catalytic Complex as having a statistically significant FDR-adjusted $p$-value of $1.65 \times 10^{-5}$, and a negative model coefficient of -0.05037 , which corresponds with a downregulation to 89 \% of control values (Figure 4.5). While KEGG did not register the NFkB pathway as statistically significant, GO Biological Processes suggested a possible role with IkB kinase appearing twice and NIK kinase appearing once, both of which were statistically 
significant and with negative model coefficients. This would suggest that both canonical and noncanonical pathways of NFKB are downregulated.

It is perhaps unnecessary to focus on each signaling pathway in great detail considering that all predictions were that of robust downregulation. These signaling pathways span a wide range of functions, with NFKB related to immune response and survival, MAPK linked to apoptosis and cell cycle regulation, and p53 responding to cellular stress which can affect downstream DNA replication and cell division (Harris and Levine, 2005; Mitchell et al., 2016; Sun et al., 2015). All of these pathways rely on phosphorylation of numerous kinases to enact their respective functions and would be very energetically expensive for the cell to maintain in a state of MRD / frozen unless their activation were strictly necessary. In other animal models of MRD, a tissue- and stress-differentiated responses of many signaling pathways are seen. For example, in dehydration-tolerant $X$. laevis, MAPKs were decreased in heart during dehydration and mostly unchanged in brain, whereas in anoxia-tolerant turtles (T. s. elegans) MAPKs were activated in liver, heart, kidney, and brain (Greenway and Storey, 1999; Wu et al., 2020). In freeze-tolerant $R$. sylvatica, some MAPKs were activated in liver and kidney in response to freezing, and unchanged in brain (Greenway and Storey, 2000). Similar patterns in other signaling pathways have been investigated in freeze-tolerant $R$. sylvatica (Dieni and Storey, 2014; Gerber et al., 2016; Greenway and Storey, 2000; Rider et al., 2006). Further research will elucidate details regarding the responses of signaling pathways to freezing stress in $H$. versicolor. 
Methods of cellular adhesion may also be downregulated in response to freezing stress. GO Cellular Compartment reported negative model coefficients and statistically significant FDR-adjusted $p$-values for GO Cytoskeleton and GO Microtubule Cytoskeleton (Figure 4.5), whereas KEGG pathway analysis showed KEGG Regulation of Actin Cytoskeleton, KEGG Focal Adhesion, and KEGG Adherens Junction as statistically significant, and all with negative model coefficients (Figure 4.7). GO Biological Processes reinforced these findings with GO Regulation of Cytoskeleton Organization and GO Positive Regulation of Cell Communication. The cytoskeleton serves a multitude of functions within the cell and, as it stands, we do not have enough information to postulate an exact reason for the downregulation of cytoskeletal-related activities as suggested by our results. However, mechanical stress due to cell volume shrinkage as water exits into extracellular ice crystals may be a probable cause. Subcellular architecture must be responsive to the major changes in cell volume imposed by freezing and equally must be flexible to return to normal structure when frogs thaw, and indeed this has been experimentally observed in both freeze-tolerant turtles and $R$. sylvatica through cryomicroscopy (Rubinsky et al., 1994a, 1994b; Storey et al., 1992). Further studies are needed to understand the mechanisms supporting this extreme flexibility in cell volume and subcellular architecture that must occur over freeze/thaw.

\subsubsection{Apoptosis and ubiquitination demonstrated robust downregulation:}

Apoptosis appears to be very robustly downregulated in response to freezing, as evidenced by KEGG pathway analysis: GO Molecular Function, GO Cellular Compartment, and GO Biological Processes. On a broad, overarching level, GO Biological 
Processes reported GO Apoptotic Signaling Pathway, GO Regulation (as well as both Positive and Negative Regulation) of Apoptotic Signaling Pathway, and GO Regulation (as well as both Positive and Negative Regulation) of Cell Death as statistically significant. Both extrinsic and intrinsic pathways of apoptosis were downregulated, as evidenced by 8 and 6 (respectively) GO Biological Processes with statistically significant negative model coefficients. The intrinsic apoptotic pathways was further reinforced with significance in GO Apoptotic Mitochondrial Changes; GO Regulation of Protein Insertion Into Mitochondrial Membrane Involved in Apoptotic Signaling Pathway; GO Positive Regulation of Mitochondrial Membrane Permeability; GO Regulation of Mitochondrial Membrane Permeability Involved in Apoptotic Process; GO Regulation (and Positive Regulation) of Mitochondrial Outer Membrane Permeabilization Involved in Apoptotic Signaling Pathway; and GO Regulation (and Positive Regulation) of Release of Cytochrome C from Mitochondria. GO Molecular Function reported peptidase and cysteine-type endopeptidase activity related to apoptosis as significantly downregulated, and furthermore, GO Cellular Compartment reported Inner Mitochondrial Membrane Protein Complex, Mitochondrial Protein Complex, and Mitochondrial Protein Part as statistically significant. However, all three had positive model coefficients suggesting decreased negative regulation via miRNAs. Overall, the data points towards a holistic downregulation of apoptosis-related processes in response to freezing stress. This makes sense, given there are a myriad of stresses during freeze-tolerance including anoxia/ischemia, cell volume reduction, and overall metabolic stress from ROS and anaerobic ATP generation which threaten cells with 
lethal consequences. Widespread apoptosis in any tissue would jeopardize the survival of the frog itself. Aside from stress-specific pathways which target apoptosis to prevent its occurrence, frogs in general are very resilient to water loss due to their waterpermeable skin, which has evolved numerous epithelial adaptations to prevent desiccation and ion loss (Larsen, 2021). Some frog species including $X$. laevis and $X$. tropicalis take dehydration-tolerance to an extreme, capable of surviving months of drought with $30 \%$ loss of total body water. Urea is typically used as an osmolyte to combat changes in cell volume, and studies in $R$. sylvatica point to differential phosphorylation of urea cycle enzymes during freezing as well as utilization of urea as a cytoprotective mechanism (Costanzo and Lee, 2008; Hawkins et al., 2019; Hillman, 1978). Apoptosis and cell survival have been studied in $R$. sylvatica where, in response to anoxic stress, liver and skeletal muscle had upregulated levels of anti-apoptotic and pro-survival genes (Gerber et al., 2016). Moreover, freezing stress in the liver of $R$. sylvatica affects Akt signaling by upregulating the active phosphorylated forms of Akt which may serve pro-survival purposes (Zhang and Storey, 2013). Enzymes such as CuZnSOD and Mn-SOD show greater activity during freezing, which correlates to survival function since elevation of superoxide production upon thawing in the mitochondria is a known initiator of apoptosis (Storey and Storey, 2020). Therefore, it is conceivable that $H$. versicolor is prioritizing anti-apoptosis and pro-survival pathways including downregulation of apoptosis mechanisms themselves.

There was a small cluster of ubiquitin-related processes which were present in KEGG pathway analysis, GO Biological Processes, GO Cellular Compartment, and GO 
Molecular Function (Figure 4.4-4.7). The KEGG pathway ubiquitin-mediated proteolysis reported a negative model coefficient and a FDR-adjusted $p$-value $=0.019$ (Figure 4.7) . GO Biological Processes expanded on this with GO Protein Ubiquitination, GO Protein K63- (and K48-) Linked Deubiquitination, GO Protein Poly- and Autoubiquitination, GO Protein Ubiquitination Involved in Ubiquitin-Dependent Protein Catabolic Process, and GO Regulation of Protein Polyubiquitination; all of which possessed negative model coefficients. The specificity of K63-linked ubiquitination was reinforced by GO Molecular Function reporting K63-Linked Polyubiquitination Binding as statistically significant, as well as 8 other broad ubiquitin-linked functions. These appear to be localized around GO Ubiquitin Ligase Complex (as well as GO Cullin Ring and GO SCF Ubiquitin Ligase Complex) as reported by GO Cellular Compartment with statistical significance and negative model coefficients. These ubiquitin-related processes may tie into freezetolerance similar to that of apoptosis: widespread proteosomal degradation would run counter to the theme of energy conservation since it would be more beneficial to conserve existing proteins rather than synthesizing new ones. High levels of protein ubiquitination may deprive the cell of much-needed proteins and also draw on limited energy reserves; therefore, downregulation of this process would align with global MRD.

Intriguingly, the NFkB pathway (as well as its upstream NOD-like receptor signaling and Toll-like receptor signaling pathway) are all linked to ubiquitin-mediated proteolysis. In particular, NFKB is linked to the aforementioned process through the canonical pathway (although both canonical and noncanonical pathways were statistically significant and predicted to be downregulated). The coupled 
downregulation of these signaling pathways may be related to the suppression of ubiquitin-mediated proteolysis, indicating that protein degradation via ubiquitination is greatly decreased during freezing. The ubiquitin proteolytic system is far-reaching, with roles in the cell cycle, modulation of the immune and inflammatory responses, and control of signal transduction pathways and, therefore, its downregulation may be twofold (Ciechanover et al., 2000). Since there is a major focus on energy management during MRD, stopping protein degradation may be a conservative approach to prolong the lifespan of existing proteins while also preventing unnecessary energy expenditure.

\subsubsection{Nuclear processes and cell cycle may be downregulated during freezing:}

Nuclear processes are also of interest. GO Cellular Compartment reported GO Chromatin (and Nuclear Chromatin), GO Chromosome (and Nuclear Chromosome), GO Ribonucleoprotein Granule, and GO DNA Packaging Complex as having the smallest statistically significant FDR-adjusted $p$-values, and all with negative model coefficients (Figure 4.5). GO Biological Processes has GO Chromosome Organization; GO Regulation (and Positive Regulation) of Chromosome Organization; GO Chromatin Remodeling; GO Chromatin Assembly or Disassembly; GO Chromatin Organization; GO Regulation of Chromatin Organization; GO Chromatin Modification; GO Positive Regulation of Chromatin Modification; GO Covalent Chromatin Modification; GO Chromatin Silencing; and GO Regulation of Chromatin Silencing. Likewise, GO Molecular Function highlighted GO Chromatin Binding, GO Methyl CpG Binding, and GO Histone Binding as two categories with statistically significant FDR-adjusted $p$-values and negative model coefficients, suggesting that the nuclear processes in question may be related to histone 
epigenetics. Histone methylation has been studied in freeze-tolerant wood frogs, $R$. sylvatica, and revealed a tissue-differentiated response of both histone methyltransferases and histone methyl marks in response to freezing and subsequent thawing (Hawkins and Storey, 2018). It is reasonable to suggest that histones also play a role in freeze tolerance regulation for $\mathrm{H}$. versicolor; however, further investigation is warranted to validate this hypothesis.

It is unfortunate that KEGG Cell Cycle was not statistically significant (FDRadjusted $p$-value $=0.145)$, given that many terms in GO Cellular Compartment, GO Molecular Function, and GO Biological Processes align with cell cycle processes. GO Biological Processes reported a multitude of terms with negative model coefficients and statistically significant FDR-adjusted $p$-values encompassing cell cycle as a whole, as well as specific functions including phase transitions, DNA integrity checkpoints, and cytokinesis, indicating that miRNA regulation of the cell cycle exhibits overall downregulation. Related cell cycle processes include GO Regulation (as well as Negative Regulation) of Cyclin-Dependent Protein Kinase Activity. GO Cellular Compartment also demonstrated GO Midbody with a $p$-value of $3.95 \times 10^{-7}$ and negative model coefficient. The midbody is a transient intracellular bridge-like structure present at the end of cytokinesis which connects the two daughter cells, and is composed of an antiparallel microtubule bundle at the core which helps coordinate abscission (Hu et al., 2012). This would indicate that a round of cell division has neared completion and is further supported by the statistical significance of GO Microtubule Cytoskeleton from GO Cellular Compartment analysis, and GO Regulation of Microtubule-Based Process from 
GO Biological Processes. The other nuclear processes previously mentioned in GO Cellular Compartment and GO Molecular Function may be linked to DNA synthesis and chromosome formation, and the collective downregulation of all these would indicate suppression of the cell cycle, a very energetically-expensive process which we hypothesized to be downregulated as a part of MRD. It is possible, given that midbody and cytokinesis processes are relevant to end-stage cell cycle, that $H$. versicolor halts further cell division at this point when freezing occurs. A study by Zhang and Storey (2012a) corroborates this, as cell cycle is arrested during freezing in $R$. sy/vatica liver before returning to control levels upon recovery. Perhaps the return to $\mathrm{G}_{1}$ stage is temporally associated with KEGG Cell Cycle returning to unchanged levels, as reported by KEGG Pathway Analysis. Further investigation of specific proteins in the cell cycle during different freezing timepoints of $H$. versicolor would be warranted to elucidate this.

The cell cycle as it relates to MRD has been robustly studied in animals that undergo extreme stress responses, including $R$. sylvatica. Responses to $24 \mathrm{~h}$ freezing, 24 h anoxia, or $40 \%$ dehydration as well as recovery from these stresses were analyzed, and all demonstrated suppression of the cell cycle during stress before rising to baseline levels again during recovery. The results showed very similar responses by cell cycle components to anoxia or dehydration and were consistent with cell cycle suppression under stress and reversal during recovery (Zhang and Storey, 2012). What discrepancies there were in protein expression were hypothesized to have cryoprotective roles by acting as transcription factors and, given that $H$. versicolor also employs cryoprotectant 
glycerol during freeze-tolerance, it is possible that similar mechanisms are at play. A closer look at the cell cycle during freezing stress in $\mathrm{H}$. versicolor would be warranted.

4.4.5. Enhanced ribosome biogenesis in response to freezing:

Interestingly, ribosomal processes appear to be positively affected by miRNA regulation; i.e., there is less downregulation of these processes during freezing. KEGG analysis reported KEGG Ribosome as one of only four pathways with a positive model coefficient, suggesting less negative regulation via miRNAs in freezing stress (Figure 4.7). GO Cellular Compartment continued this trend, with GO Cytosolic Ribosome, GO Cytosolic Large Ribosomal Subunit, GO Large Ribosomal Subunit, GO Ribosomal Subunit, and GO Ribosome all displaying positive model coefficients. GO Ribosome Biogenesis and GO rRNA Metabolic Process are statistically significant with the corresponding positive model coefficients in GO Biological Processes, as well as GO Structural Constituent of Ribosome in GO Molecular Function (Figures 4.4 and 4.6). GO Biological Processes also reported GO Chromatin Silencing At Ribosomal DNA (rDNA) with a negative model coefficient, which would suggest that chromatin silencing at rDNA is negatively regulated and thus fits in with the narrative of ribosome biosynthesis.

While this may appear to run counter to the overarching principle of MRD, in that global downregulation of nonessential genes and processes would not be expected to support synthesis of more ribosomes (which may in turn imply increased protein synthesis), a few hypotheses may be proposed for this. Increased ribosome biogenesis may be necessary to sustain translational capacity throughout the freeze not only to continue synthesis of selected proteins, but to be prepared for thawing when there 
could be high pressure to rapidly replace damaged proteins. A rapid translation capacity for making miRNA biogenesis proteins themselves may occur, as supported by the upregulation of DICER, DROSHA, TRBP, and XPO5 during freezing in $\mathrm{H}$. versicolor liver

(Figure 3.1). It is difficult to postulate what other proteins/protein functions may be affected by an increased number of ribosomes, namely because ribosomal biosynthesisrelated functions were the only categories with positive model coefficients across GO analysis. Other categories with positive model coefficients pertained to enzyme or receptor activity. Increased ribosome biosynthesis could also be related to pro-survival pathways as observed in other models of MRD. For example, $R$. sylvatica increases levels of ChREBP to adjust carbohydrate metabolism during freezing, upregulates heat shock proteins which act as protective chaperones, and activates the MondoA:MLX complex to mitigate gene expression under high cryoprotectant concentrations (Al-Attar et al., 2020; Singh and Storey, 2020; Storey and Storey, 2019).

\subsection{Conclusions:}

This study provides the first overview of miRNA bioinformatic analysis in $H$. versicolor and sheds light on specific functions and miRNAs that are affected during freezing. A subset of 11 miRNAs (miR-140-3p, miR-181a-5p, miR-206-3p, miR-451a, miR19a-3p, miR-101-3p, miR-30e-5p, miR-142-3p and -5p, miR-21-5p, and miR-34a-5p) were predicted to be the most crucial to the miRNA response to freezing stress. Crossreferencing Gene Ontology results (including Biological Processes, Cellular Compartment, and Molecular Function) with KEGG pathway analysis yielded several processes of interest. Signaling pathways, apoptosis, and protein degradation via 
ubiquitination were hypothesized to be strongly downregulated as a result of miRNA regulation during freezing. There was strong evidence that nuclear processes and the cell cycle are similarly downregulated. Finally, ribosomal biogenesis may be enhanced by a lack of miRNA regulation during freezing, although further study would need to be done to elucidate what purpose this would fulfill. Overall, this thesis highlights miRNA regulation during freeze tolerance in $\mathrm{H}$. versicolor, and offers intriguing paths for further study to fully understand how this frog species survives the winter. 
Freezing frog experiments

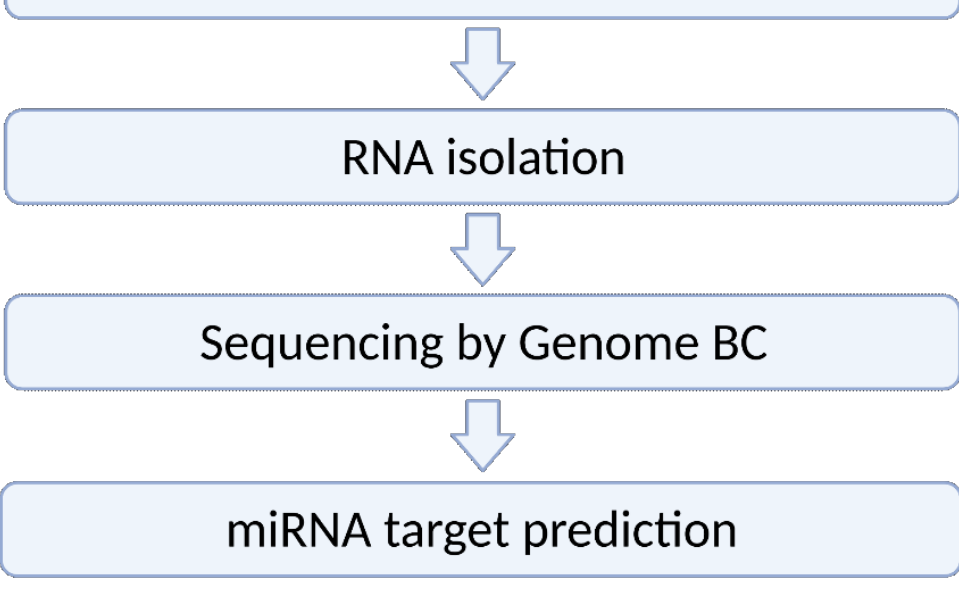

Gene Ontology enrichment

KEGG Pathway analysis

Figure 4.1. General workflow of miRNA preparation and downstream bioinformatic analysis. Figure created with BioRender.com 

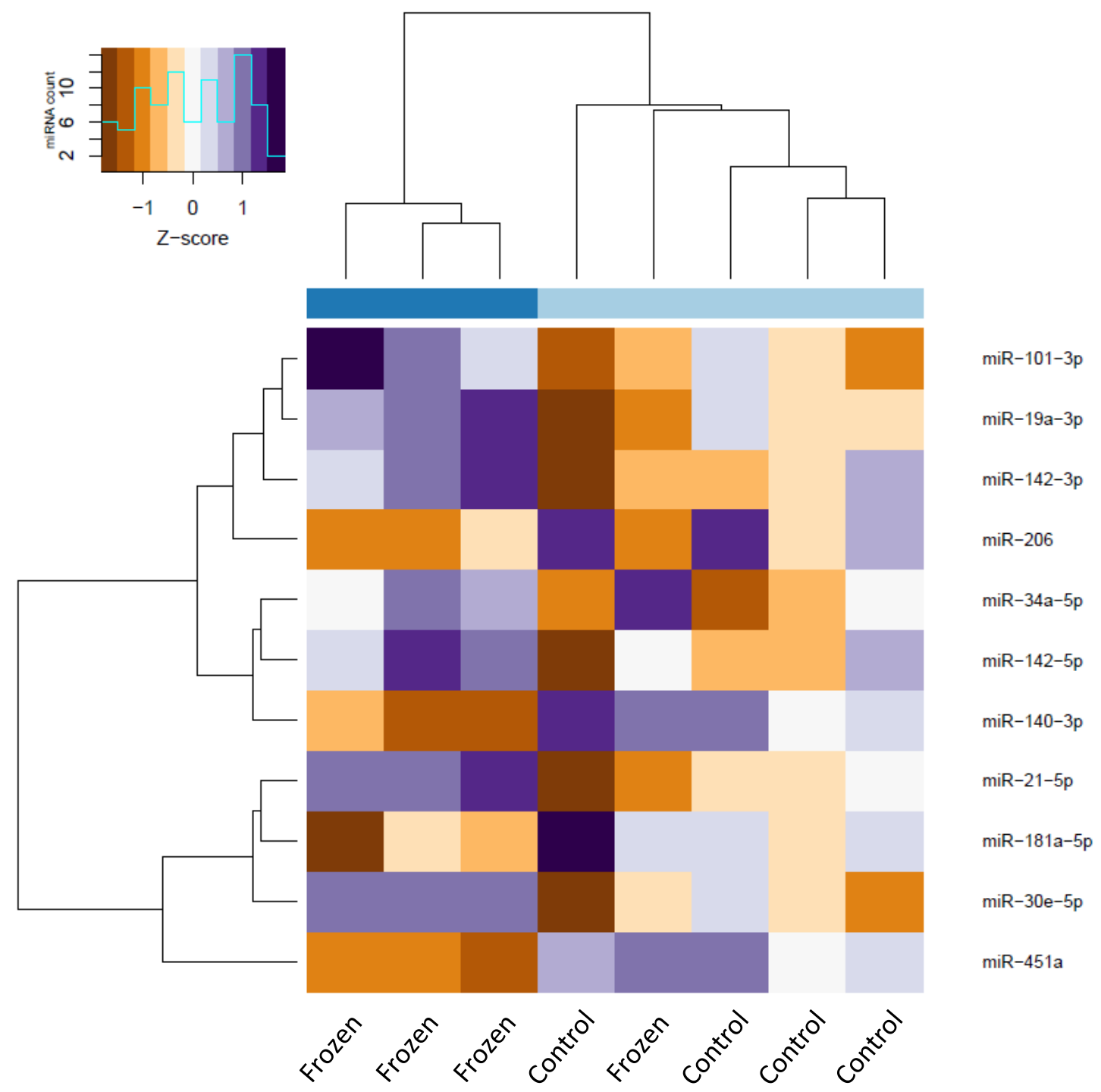

Figure 4.2. Hierarchical clustering of significant differentially expressed miRNA in liver of control vs $\mathbf{2 4} \mathbf{h}$ frozen $\boldsymbol{H}$. versicolor. Clustering of samples and miRNA was done using the Ward method. Purple and orange indicate, respectively, higher and lower zscores (standardized expression level) for each miRNA in each sample. Clustering of samples at the highest level of the dendrogram is indicated by dark and light blue bar above the heat map. 


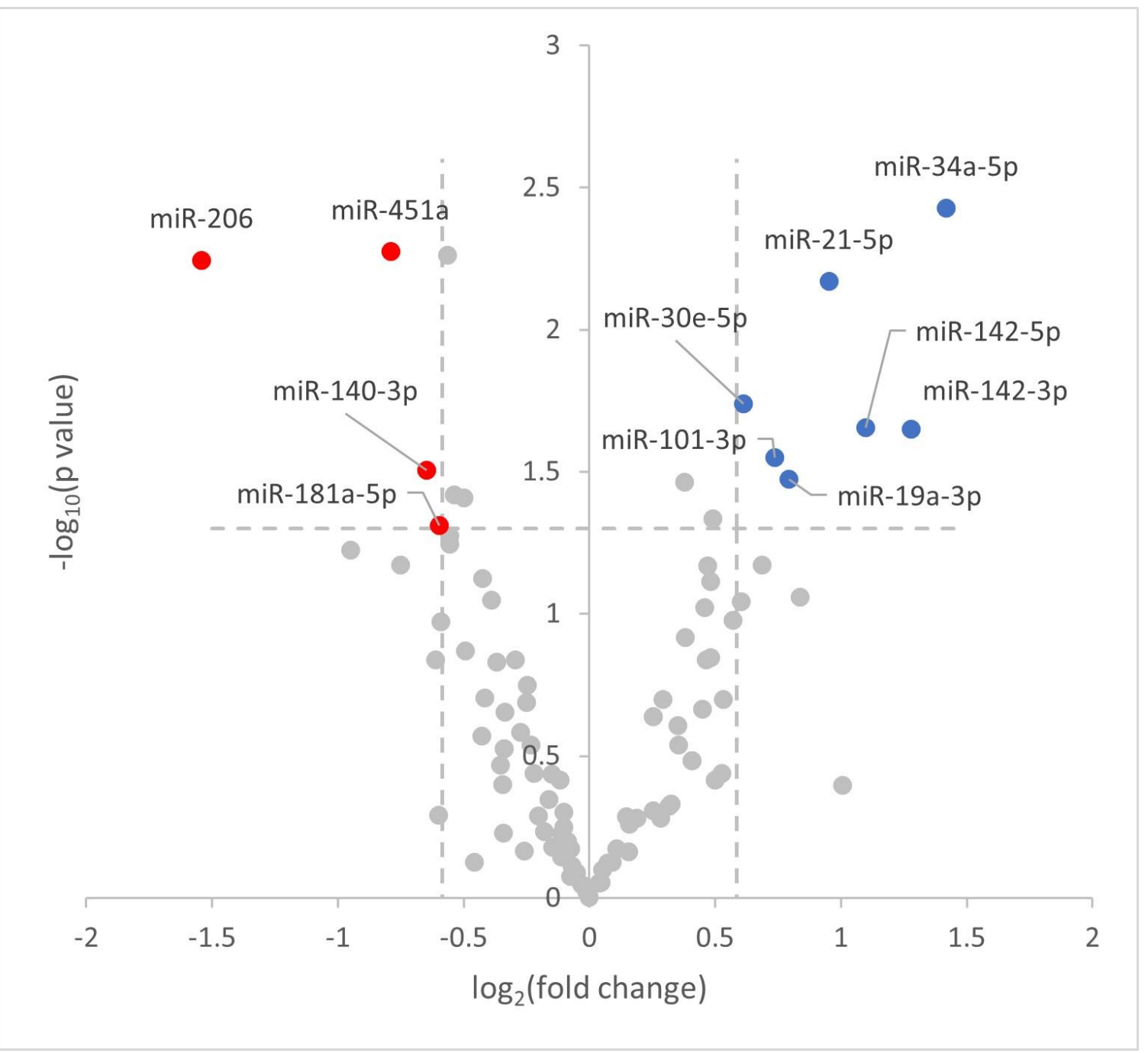

Figure 4.3. MiRNA differentially expressed in control vs. $24 \mathrm{~h}$ frozen $\boldsymbol{H}$. versicolor liver. Volcano plot showing fold-change thresholds were set to $\pm \log _{2} 1.5$ and a false discovery rate (FDR)-adjusted $p$-value $<0.05$. Red and blue circles indicate microRNA that were significantly downregulated and upregulated, respectively, and grey circles are microRNA that did not pass the fold-change and $p$-value thresholds. 

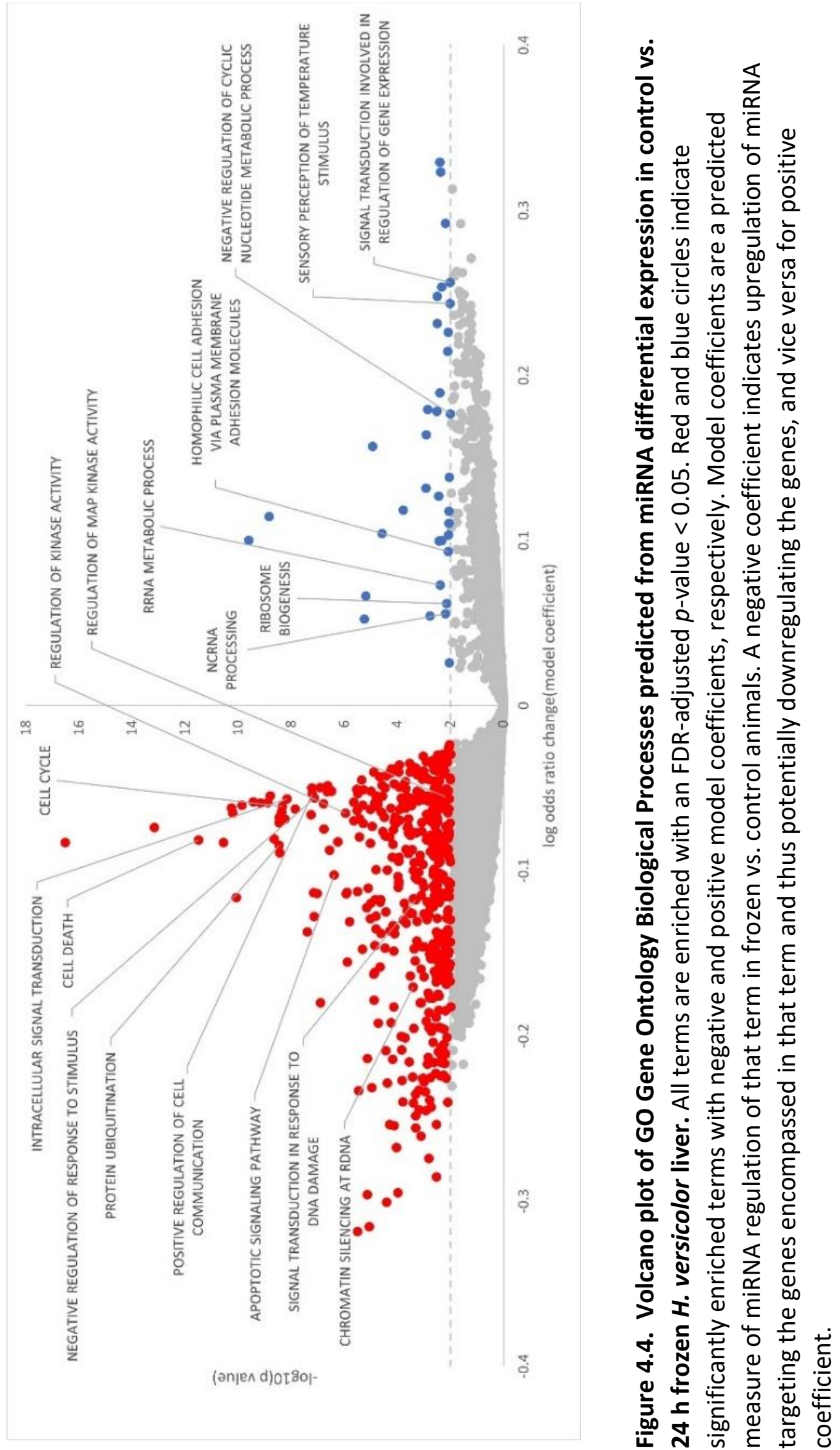


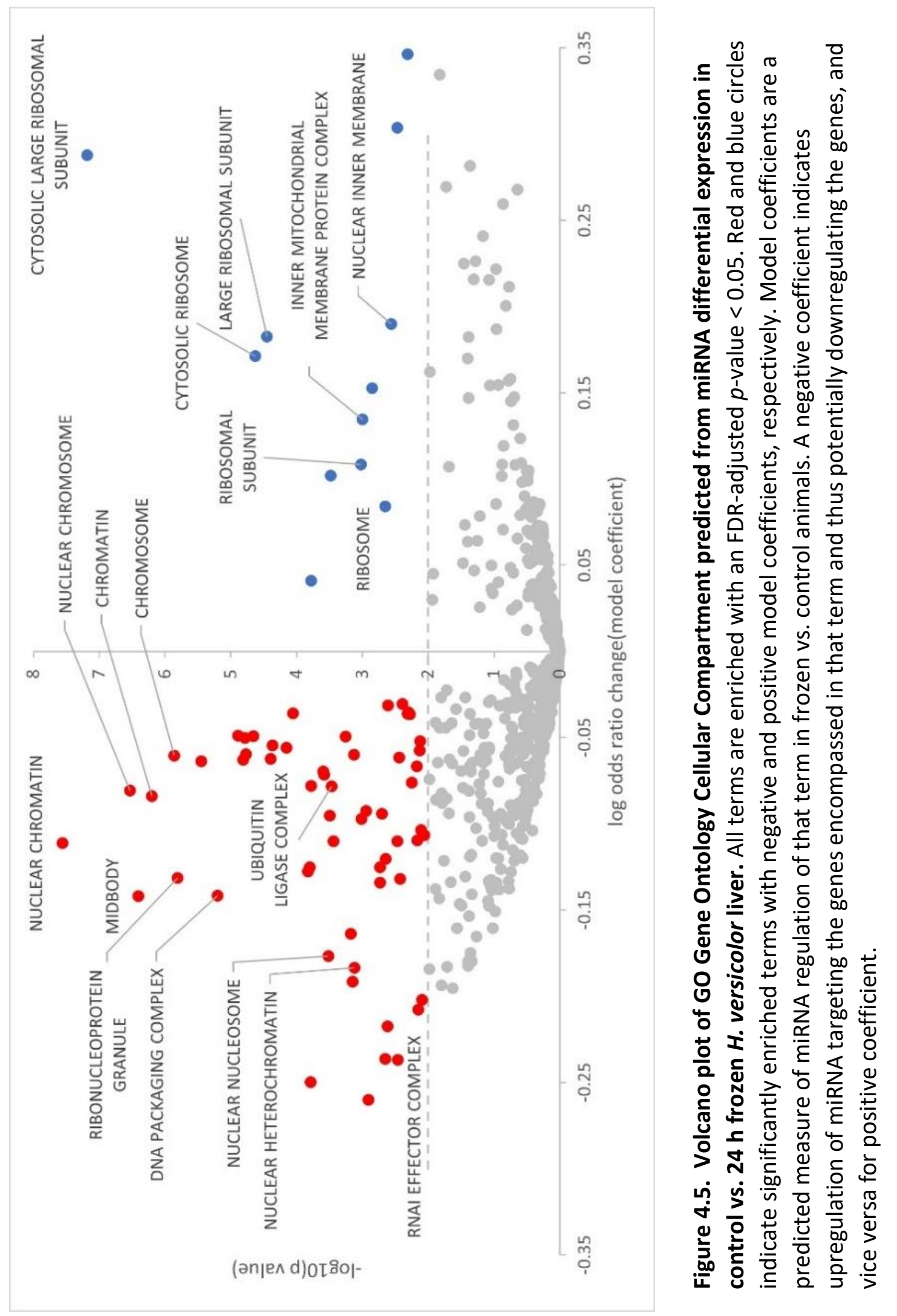




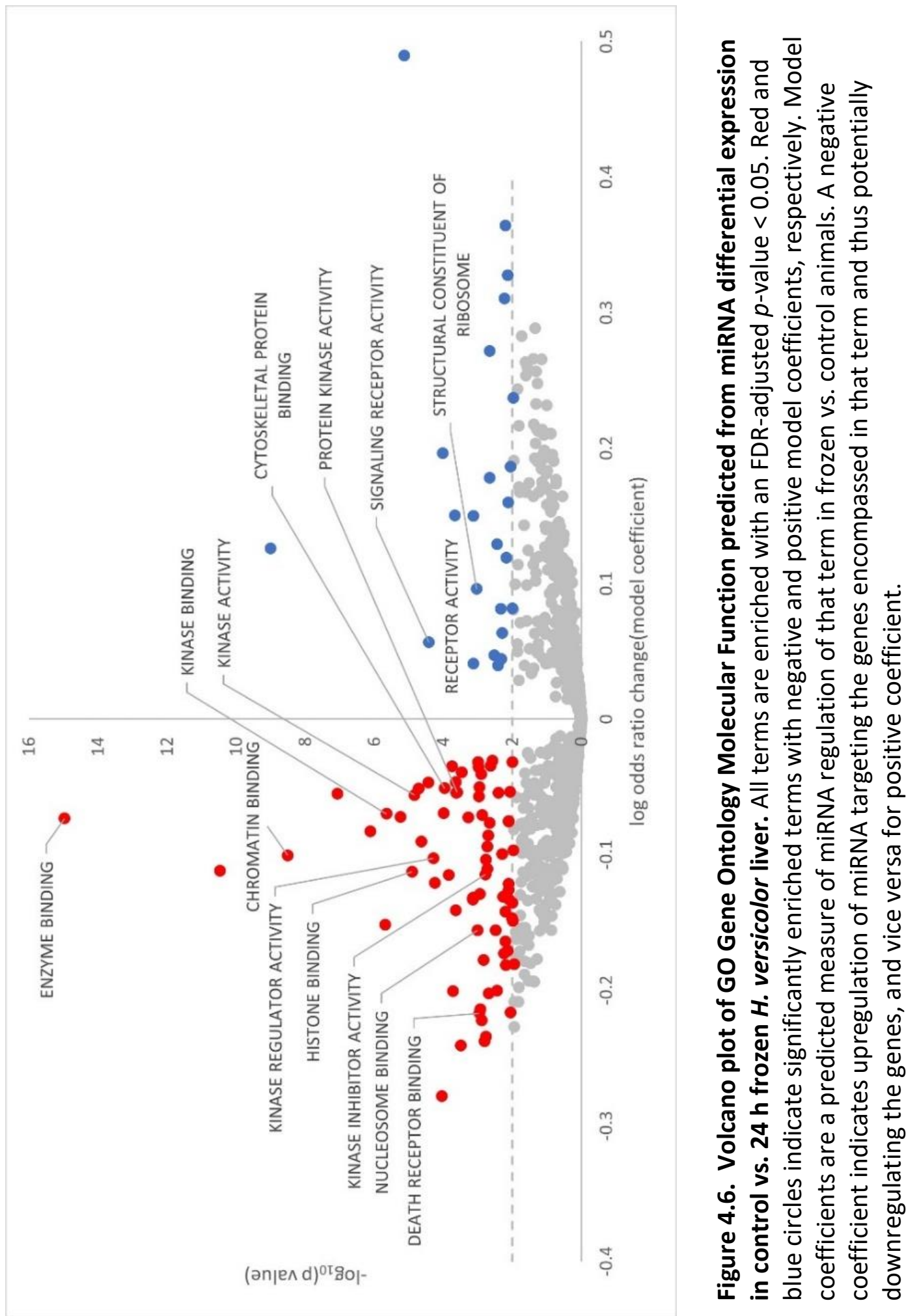




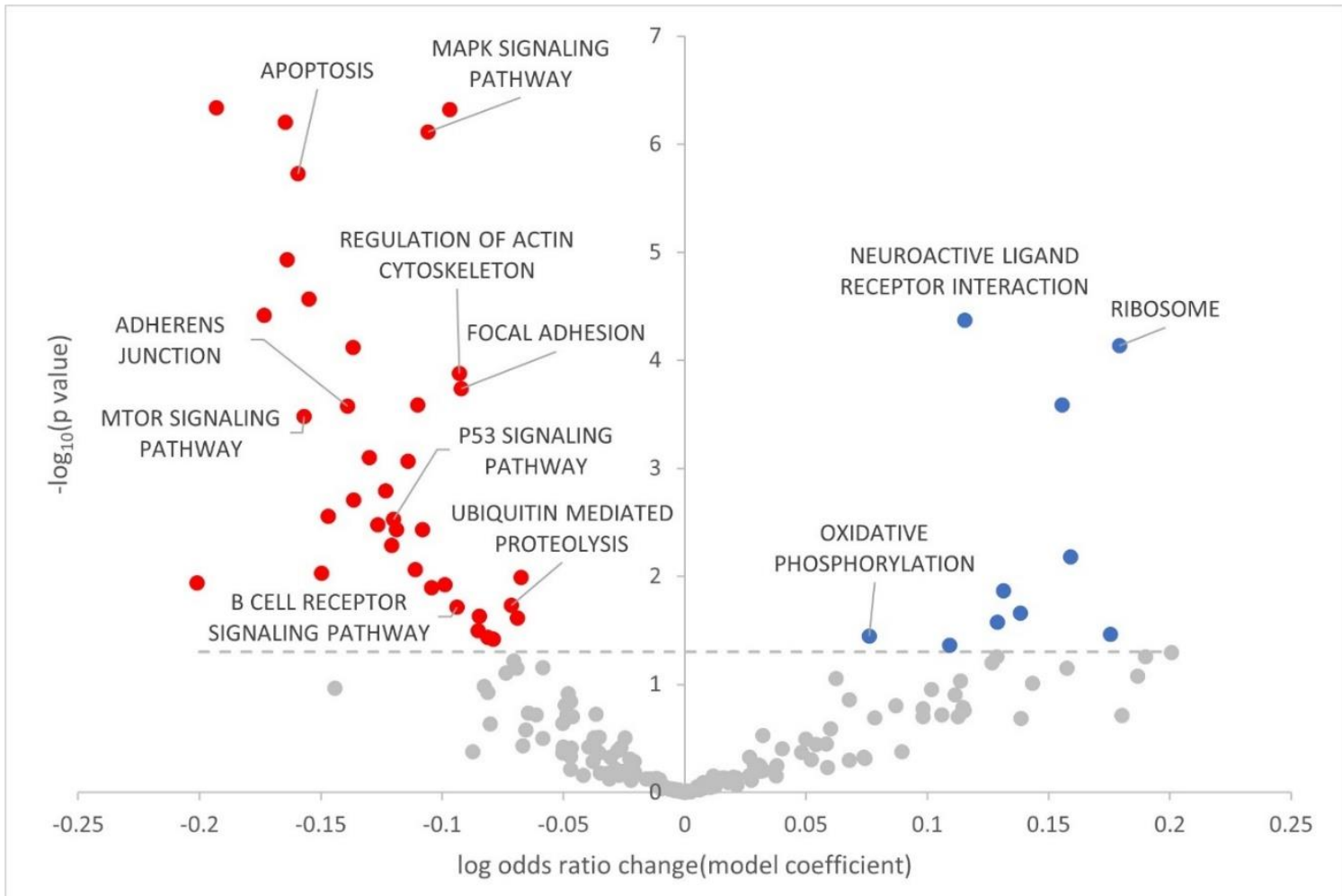

Figure 4.7. Volcano plot of KEGG Pathway Analysis predicted from miRNA differential expression in control vs. $24 \mathbf{h}$ frozen $\boldsymbol{H}$. versicolor liver. All terms are enriched with an FDR-adjusted $p$-value $<0.05$. Red and blue circles indicate significantly enriched terms with negative and positive model coefficients, respectively. Model coefficients are a predicted measure of miRNA regulation of that term in frozen vs. control animals. A negative coefficient indicates upregulation of miRNA targeting the genes encompassed in that term and thus potentially downregulating the genes, and vice versa for positive coefficient. 
CHAPTER 5

General Discussion 


\subsection{Hyla versicolor and freezing:}

Hyla versicolor and some other species of frogs have evolved freeze-tolerance as a mechanism to survive prolonged subzero temperatures and lack of food resources during the winter. The frogs burrow into leaf litter at the base of trees as protective hibernation sites, and undergo whole-body freezing at approximately -2 or $-3^{\circ} \mathrm{C}$ which is maintained until more favourable temperatures return in the spring. However, there are major physiological stresses associated with freezing including anoxia, ischemia, and hyperosmosis. The latter of these threatens lethal cell shrinkage, so $\mathrm{H}$. versicolor synthesizes large quantities of cryoprotectant glycerol to resist intracellular water loss in response. All of these stresses combine with an inability to export waste or import nutrients, so cells must survive on their endogenous fuel reserves for the duration of freezing. To combat this, $H$. versicolor enters a state of metabolic rate depression (MRD) in which cellular energy is diverted towards pro-survival pathways and essential genes, and nonessential processes are suppressed. This requires extensive metabolic reorganization, and to achieve this herculean task, cells enlist transcriptional, posttranscriptional, translational, and post-translational regulatory mechanisms (Storey and Storey, 2017). This thesis focused on post-transcriptional regulation enacted via miRNAs. Chapter 3 studied miRNA biogenesis in three tissues, examining relative protein expression levels of key players in the biogenesis pathway to establish if more miRNAs were being transcribed as a result of freezing stress. This enabled prediction of tissue-specific synthesis of miRNAs, thereby suggesting that miRNA regulation was more or less crucial in the response to freezing stress in different tissues. Following this, 
Chapter 4 centered around a bioinformatics study done with small RNA-seq data to compare liver tissue from control vs $24 \mathrm{~h}$ frozen frogs, in which specific miRNAs that were upregulated or downregulated in response to freezing were predicted. GO Gene Ontology and KEGG Pathway Analysis were also performed to add a cellular-level analysis to specific miRNA function during freeze tolerance. Illuminating the myriad of gene expression patterns and cellular processes under control of miRNA adds a new aspect to our understanding of multifaceted gene regulatory networks and the transcriptome as a whole.

\section{2. miRNAs and freeze tolerance:}

miRNAs are short, single-stranded, noncoding RNA molecules 21-24 nt long that bind to mature mRNA transcripts and suppress their translation. Since the discovery of the first C. elegans miRNA in 1993, hundreds of miRNAs have been identified in both animal and plant species. miRNAs bind through complementarity of a 8 nt seed sequence, with perfect complementarity leading to cleavage of the mRNA transcript and imperfect binding resulting in translational suppression through sequestration of mRNA in p-bodies or stress granules (Bartel, 2004). In mammals, over $70 \%$ of miRNA genes are located within protein-coding gene introns with approximately $30 \%$ of these transcribed independently from the protein-coding gene within which they are located (Finnegan and Pasquinelli, 2013). Since miRNAs exhibit very high conservation between species, this insinuates the crucial regulatory roles that they have in all manner of responses from development to extreme environmental stresses. 
To date, our lab has looked at the miRNA biogenesis pathway in response to extreme environmental stress in only one other instance - wood frog brain during freeze-tolerance (Hadj-Moussa and Storey, 2018). During freezing, AGO2, DGCR8, DROSHA, PACT, and XPO5 were downregulated in wood frog brain whereas all other proteins assessed remained unchanged (Hadj-Moussa and Storey, 2018). This pattern differed substantially from the data for the three tissues studied in $H$. versicolor, although the most similarities were noted for skeletal muscle in which AGO2, DGCR8, and XPO5 were downregulated (Figure 3.2). Further investigation is warranted into miRNA biogenesis during freeze-tolerance as a whole; for example, perhaps $H$. versicolor brain would show a similar response as to $R$. sylvatica brain, which may suggest a conserved response to freezing stress. Correlations with other miRNA studies have been addressed in both discussion sections of Chapter $\mathbf{3}$ and $\mathbf{4}$, and will not be repeated here.

The stark contrast between apparent miRNA roles in liver vs other tissues such as skeletal muscle and kidney highlight the distinct tissue-specific regulation that occurs during vertebrate freeze tolerance. Whereas Chapter $\mathbf{4}$ provided an introductory look into what these miRNAs may be regulating in liver, future research would warrant a detailed investigation into all the signaling pathways and nuclear processes that might be predicted to be altered. Understanding the diverse roles of miRNAs in each tissue during freeze-tolerance would allow us to pinpoint the essential molecular tenets of freeze-tolerance, both within a particular tissue and on a holistic level, and how miRNAs interplay with the numerous other forms of regulation to allow freeze-tolerance to be completed successfully with no harm to the animal. 
This study in $\mathrm{H}$. versicolor is the first survey of miRNA biogenesis and regulation in this species, and will contribute to the modest, yet growing, research into freezetolerant vertebrates. Limitations to further experimental validation arose because the nuclear genome of $H$. versicolor has not been sequenced; nor has its counterpart $R$. sylvatica. However, the Canada 150 Sequencing Initiative (CanSeq150) started in 2018 by Canada's Genomics Enterprise has included both $R$. sylvatica and $H$. versicolor in the 150 endemic Canadian species that will have their genomes sequenced to further biodiversity studies in the country ("Project List - Canada's national platform for genome sequencing \& analysis," n.d.). All miRNA and antibody sequences from this study were obtained through cross-species conservation analysis via miRBase and Clustal Omega, respectively (Kozomara et al., 2019; Madeira et al., 2019). As such, the stage has been set for subsequent full genome de novo assembly and annotation.

\subsection{Limitations and future directions:}

This thesis is far from a comprehensive explanation of the role miRNAs play in inducing and maintaining metabolic rate depression during freeze tolerance in $\mathrm{H}$. versicolor. Moreover, little research has been done into the molecular mechanisms of how $\mathrm{H}$. versicolor enters and maintains a hypometabolic state during freeze-tolerance. Physiological parameters have been well-established through studies done in the 1980s when freeze-tolerance in frogs was originally postulated, all throughout the early 2000 s (Layne, 1999; Layne and Jones, 2001; Layne and Lee, 1989). Molecular research primarily centered around aquaporins and glyceroporins in H. versicolor's diploid, freeze-tolerant counterpart $H$. chrysocelis has also been performed, although this 
remained largely confined to blood studies and the effect of various cryoprotectants on erythrocytes (Geiss et al., 2019; Mutyam et al., 2011; Zimmerman et al., 2007). Beyond this, techniques were limited and other model organisms captured the attention of researchers, so in-depth molecular investigations were not possible until recently. Moreover, the model organism for studying freeze-tolerance has been wood frog $R$. sylvatica, and as a result, many of the molecular processes have been assumed to carry over from the wood frog to $H$. versicolor.

As mentioned earlier, neither $R$. sylvatica nor $H$. versicolor have been genome sequenced, which makes it difficult to ascertain whether the immunogen information for our Western immunoblotting antibodies are conserved with the actual protein sequence in $H$. versicolor. To maximize the certainty that the antibody is binding with the correct protein of interest, please see Appendix C: Verifying antibody specificity for Western immunoblotting.

This thesis presents many avenues of further research which can be pursued to more specifically elucidate the role of miRNAs during freeze tolerance. Chapter 4 involved bioinformatic analysis and predictions for miRNA regulation in liver tissue, all of which warrant further investigations. RT-qPCR can be performed to experimentally validate the small RNA-seq results, and further RT-qPCR in other tissues may highlight new miRNAs for study and begin expanding tissue-specific expression of miRNAs in response to freezing. These can be cross-correlated with the cryomiR family put forth by Lyons (2013a) and improve the robustness of this current family of cold-responsive miRNAs. Intracellular signaling pathways can be investigated, including MAPK, mTOR, 
NFkB, and p53 which can all be linked to concurrent studies already established in $R$. sylvatica. Other areas of investigation include the cell cycle and nuclear processes, which also predicted downregulation in $\mathrm{H}$. versicolor liver. The cell cycle as a metabolically expensive process has been extensively covered in other models of metabolic rate depression including freezing, anoxia, and dehydration stress in $R$. sylvatica (Roufayel et al., 2011; Zhang and Storey, 2012).

On the topic of alternate stresses, it is important to note that freeze-tolerance is not its own stress in of itself. Freeze-tolerance constitutes several other component stresses of dehydration, anoxia, and hyperglycemia which all may be inducing specific cellular responses. Examining the role of miRNA regulation in each of these sub-stresses would allow us to clarify if there is a single miRNA response to varying forms of cellular stress, or if miRNA networks vary in accordance with the stress which the frogs are being challenged by.

The "central dogma" of biology has traditionally been regarded as a linear progression from DNA to RNA to protein; the transitions between which are transcription and translation (respectively). However, miRNAs constitute one of many regulatory mechanisms which alter the central dogma by disrupting one of its transition points, as illustrated in Figure 5.1. Epigenetic processes including DNA methylation and histone modifications affect gene expression without altering the DNA sequence itself, while transcription factors bind to promoter sequences to suppress or enhance transcription. At the post-transcriptional level, miRNAs bind to mRNA transcripts to 
suppress their translation into protein, while other mechanisms may alter the mRNA transcript including RNA editing/methylation, alternative splicing, and other small RNA interference via circular RNAs and long non-coding RNAs. Even if a complete protein is synthesized, it can undergo various post-translational modifications (including phosphorylation, SUMOlyation, glycosylation, etc.) which can affect subcellular localization and enzymatic activity. Proteins can also be degraded via proteolysis or temporarily sequestered for later function.

It is therefore clear that this thesis does not provide an ironclad ultimatum on what cellular processes are affected in $\mathrm{H}$. versicolor during freezing. Chapter 4 applied bioinformatic analyses to predict the pathways suspected to upregulate or downregulate as a direct result of miRNA regulation. These trends can of course be experimentally validated through in-depth transcription factor studies and analysis, but it is possible that other regulatory mechanisms outside the central dogma as illustrated in Figure 5.1 may affect these trends as well. For example, miRNAs may appear to be negatively regulating the MAPK signaling pathway (Figure 4.7), but perhaps posttranslational modifications may be increasing the efficacy of enzymes in this pathway or selectively upregulating/downregulating certain kinases. Likewise, histone modifications and/or DNA methylation may be suppressing the transcription of certain genes in line with global MRD, therefore making downstream regulation via miRNAs or posttranslational modifications irrelevant. The results in Chapter 4 lay out promising opportunities for future research, and additional study would have to be done to truly elucidate the freezing-dependent metabolic reorganization in $\mathrm{H}$. versicolor liver. 
On a broader spectrum, this research has many exciting implications for human health. "Cryosleep" is a term popularized by the science fiction genre which entails freezing a human for a long duration of time to prevent aging or bypass the travel time of a long journey. Obviously, humans are not capable of surviving full-body freezing, so the fact that vertebrates are able to harness this ability is a tantalizing end goal which will require thorough, precise, and intimate knowledge of how frogs such as $H$. versicolor tolerate the stresses of freeze-tolerance at every step of the process. Induced hypothermia is a process adjacent to freeze-tolerance which is already being used for medical applications; namely, the survival of trauma. Doctors at the University of Maryland School of Medicine can cool a patient down with ice-cold saline to $\sim 10{ }^{\circ} \mathrm{C}$, which extends the window of survival to multiple hours instead of minutes which enables life-saving medical intervention (Kutcher et al., 2016). This form of therapeutic hypothermia is also used for ischemic stroke recovery, and with ischemia being a wellknown stress during freeze-tolerance, elucidation of the mechanisms behind ischemia survival during freeze-tolerance could improve clinical outcomes (Kurisu and Yenari, 2018).

The potential for humans to embark on long-duration spaceflight missions has been increasingly highlighted by the widening breadth of space achievements from both private and public sectors. Recent successes and increased public interest have turned the public eye to life on other planets, and what it would take to make this a logistical reality (National Aeronautics and Space Administration, n.d.; SpaceX, n.d.). While the development and testing of new technologies are robust in nature, a glossed-over 
aspect of these developments is the journey itself and in particular the biological toll this would exert on its very human astronauts. A voyage to Mars would take approximately nine months, and as it stands Scott Kelly holds the record for maximum consecutive flight days in 2015-16, with 340 consecutive days in space (National Aeronautics and Space Administration, n.d.). The effect of sustained microgravity on human physiology has been long-studied on the International Space Station, and Scott Kelly's unique scenario allowed his physiology to be rigorously studied and compared with his identical twin Mark Kelly (Garrett-Bakelman et al., 2019). However, it is clear that we must understand these effects far more thoroughly before sending groups of astronauts on long-duration missions where return to Earth in the event of emergency may be difficult if not impossible. Suspended animation has been proposed as a particularly attractive solution, given that it would alleviate technological and psychological concerns as well as physiological ones. If we could put humans in a state of suspended animation by greatly slowing or even fully halting metabolic activity, we could alleviate issues surrounding space travel including social isolation, spacecraft size, fuel and supply requirements, and the effects of long-term physical confinement.

miRNAs have already been definitely linked to microgravity stress responses in all tissues and systems. These range from alterations in immune response, to radiationinduced changes in expression profiles, to roles in muscle atrophy and bone wasting (Allen et al., 2009; Hu et al., 2020; Hughes-Fulford et al., 2015). Even more intriguingly, a circulating miRNA signature coupled with TGF- $\beta 1$ has been proposed to be a master regulator for the spaceflight stress response, showcasing an even more vital role that 
miRNAs may play (Beheshti et al., 2018). This would provide a juxtaposition between miRNAs, their roles in freeze-tolerance, adjacent therapies with and stress of hypothermia, implications in suspended animation, and ultimately spaceflight itself. This research has many far-reaching goals beyond one stress and one species.

\subsection{Summary:}

To survive the myriad of environmental stresses induced by the winter months, $H$. versicolor undergoes freeze tolerance which is characterized by entrance into and maintenance of a hypometabolic state. This thesis illustrated that post-transcriptional control via miRNA appears to constitute an important and dynamic role across many tissues in this frog. miRNA biogenesis appeared to be enhanced in liver and suppressed in both skeletal muscle and kidney, although the expression of specific proteins between the downregulated tissues varied and may point to different strategies of metabolic reorganization in these two tissues. With a focus on liver, bioinformatic analysis identified a subset of 11 miRNAs that appear to be important for freeze-tolerance: 4 downregulated during freezing (miR-140-3p, miR-181a-5p, miR-206-3p, and miR-451a) and 7 upregulated (miR-19a-3p, miR-101-3p, miR-30e-5p, miR-142-3p and -5p, miR-21$5 p$, and miR-34a-5p). Signaling pathways, apoptosis, and protein degradation via ubiquitination may be the processes most affected by miRNA regulation during freezing, but nuclear processes and the cell cycle may exhibit similar inhibition as well. Finally, ribosomal biogenesis may actually increase during freezing due to lack of negative regulation via miRNA, although further study is necessary to elucidate what purposes it would fulfill. Overall, this thesis highlights metabolic reorganization via miRNA 
involvement across three tissues in freeze-tolerant $H$. versicolor, and offers intriguing paths for further study to isolate how this frog uses miRNA to regulate its ability to maintain MRD during winter survival. 


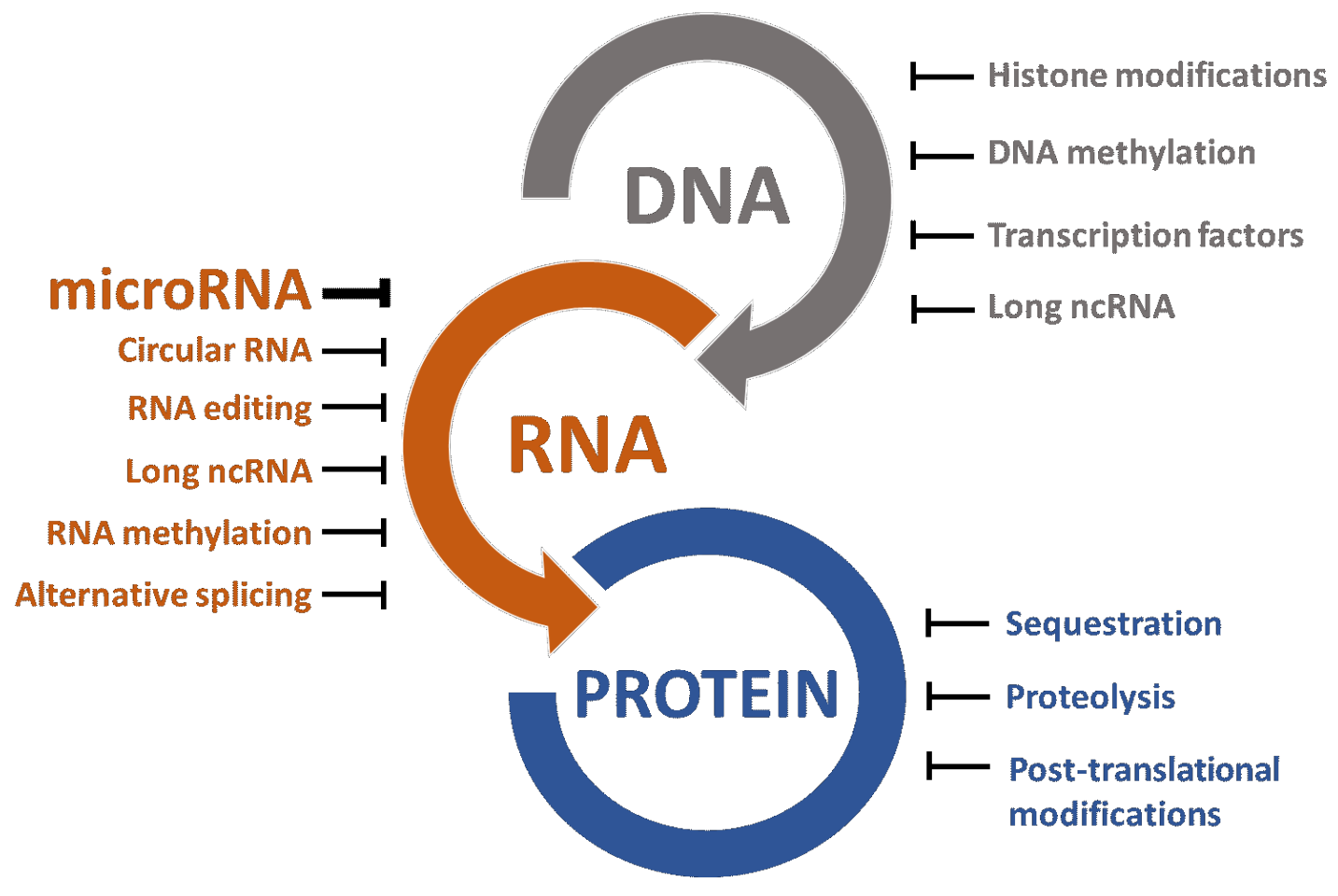

Figure 5.1. The "central" dogma of biology and molecular mechanisms which can alter its traditional progression. Figure created with BioRender.com 
REFERENCES 
Agarwal, V., Bell, G.W., Nam, J.W., Bartel, D.P., 2015. Predicting effective microRNA target sites in mammalian mRNAs. Elife 4. https://doi.org/10.7554/eLife.05005 Aguilar, O.A., Hadj-Moussa, H., Storey, K.B., 2016. Regulation of SMAD transcription factors during freezing in the freeze tolerant wood frog, Rana sylvatica. Comp. Biochem. Physiol. Part - B Biochem. Mol. Biol. 201, 64-71. https://doi.org/10.1016/j.cbpb.2016.07.003

Al-Attar, R., Wu, C.W., Biggar, K.K., Storey, K.B., 2020. Carb-loading: Freeze-induced activation of the glucose-responsive ChREBP transcriptional network in wood frogs. Physiol. Biochem. Zool. 93, 49-61. https://doi.org/10.1086/706463

Allen, D.L., Bandstra, E.R., Harrison, B.C., Thorng, S., Stodieck, L.S., Kostenuik, P.J., Morony, S., Lacey, D.L., Hammond, T.G., Leinwand, L.L., Argraves, W.S., Bateman, T.A., Barth, J.L., 2009. Effects of spaceflight on murine skeletal muscle gene expression. J. Appl. Physiol. 106, 582-592. https://doi.org/10.1152/japplphysiol.90780.2008

An, J., Lai, J., Lehman, M.L., Nelson, C.C., 2013. MiRDeep*: An integrated application tool for miRNA identification from RNA sequencing data. Nucleic Acids Res. 41, 727-737. https://doi.org/10.1093/nar/gks1187

Andrews, S., 2015. FASTQC A Quality Control tool for High Throughput Sequence Data. Babraham Inst.

Arnaoutov, A., Dasso, M., 2005. Ran-GTP regulates kinetochore attachment in somatic cells. Cell Cycle. https://doi.org/10.4161/cc.4.9.1979

Bansal, S., Luu, B.E., Storey, K.B., 2016. MicroRNA regulation in heart and skeletal muscle over the freeze-thaw cycle in the freeze tolerant wood frog. J. Comp. Physiol. B Biochem. Syst. Environ. Physiol. 186, 229-241. https://doi.org/10.1007/s00360-015-0951-3

Bartel, D.P., 2004. MicroRNAs: Genomics, Biogenesis, Mechanism, and Function. Cell 116, 281-297. https://doi.org/10.1016/s0092-8674(04)00045-5

Beheshti, A., Ray, S., Fogle, H., Berrios, D., Costes, S. V., 2018. A microRNA signature and TGF- $\beta 1$ response were identified as the key master regulators for spaceflight 
response. PLoS One 13, 1-19. https://doi.org/10.1371/journal.pone.0199621

Berezikov, E., Chung, W.J., Willis, J., Cuppen, E., Lai, E.C., 2007. Mammalian Mirtron

Genes. Mol. Cell 28, 328-336. https://doi.org/10.1016/j.molcel.2007.09.028

Biggar, K.K., Luu, B.E., Wu, C.W., Pifferi, F., Perret, M., Storey, K.B., 2018. Identification of novel and conserved microRNA and their expression in the gray mouse lemur, Microcebus murinus, a primate capable of daily torpor. Gene 677, 332-339. https://doi.org/10.1016/j.gene.2018.08.014

Bohnsack, M.T., Czaplinski, K., Görlich, D., 2004. Exportin 5 is a RanGTP-dependent dsRNA-binding protein that mediates nuclear export of pre-miRNAs. RNA 10, 185191. https://doi.org/10.1261/rna.5167604

Carbon, S., Douglass, E., Dunn, N., Good, B., Harris, N.L., Lewis, S.E., Mungall, C.J., Basu, S., Chisholm, R.L., Dodson, R.J., Hartline, E., Fey, P., Thomas, P.D., Albou, L.P., Ebert, D., Kesling, M.J., Mi, H., Muruganujan, A., Huang, X., Poudel, S., Mushayahama, T., Hu, J.C., LaBonte, S.A., Siegele, D.A., Antonazzo, G., Attrill, H., Brown, N.H., Fexova, S., Garapati, P., Jones, T.E.M., Marygold, S.J., Millburn, G.H., Rey, A.J., Trovisco, V., Dos Santos, G., Emmert, D.B., Falls, K., Zhou, P., Goodman, J.L., Strelets, V.B., Thurmond, J., Courtot, M., Osumi, D.S., Parkinson, H., Roncaglia, P., Acencio, M.L., Kuiper, M., Lreid, A., Logie, C., Lovering, R.C., Huntley, R.P., Denny, P., Campbell, N.H., Kramarz, B., Acquaah, V., Ahmad, S.H., Chen, H., Rawson, J.H., Chibucos, M.C., Giglio, M., Nadendla, S., Tauber, R., Duesbury, M.J., Del, N.T., Meldal, B.H.M., Perfetto, L., Porras, P., Orchard, S., Shrivastava, A., Xie, Z., Chang, H.Y., Finn, R.D., Mitchell, A.L., Rawlings, N.D., Richardson, L., Sangrador-Vegas, A., Blake, J.A., Christie, K.R., Dolan, M.E., Drabkin, H.J., Hill, D.P., Ni, L., Sitnikov, D., Harris, M.A., Oliver, S.G., Rutherford, K., Wood, V., Hayles, J., Bahler, J., Lock, A., Bolton, E.R., De Pons, J., Dwinell, M., Hayman, G.T., Laulederkind, S.J.F., Shimoyama, M., Tutaj, M., Wang, S.J., D'Eustachio, P., Matthews, L., Balhoff, J.P., Aleksander, S.A., Binkley, G., Dunn, B.L., Cherry, J.M., Engel, S.R., Gondwe, F., Karra, K., MacPherson, K.A., Miyasato, S.R., Nash, R.S., Ng, P.C., Sheppard, T.K., Shrivatsav Vp, A., Simison, M., Skrzypek, M.S., Weng, S., Wong, E.D., Feuermann, M., Gaudet, P., Bakker, E., 
Berardini, T.Z., Reiser, L., Subramaniam, S., Huala, E., Arighi, C., Auchincloss, A., Axelsen, K., Argoud, G.P., Bateman, A., Bely, B., Blatter, M.C., Boutet, E., Breuza, L., Bridge, A., Britto, R., Bye-A-Jee, H., Casals-Casas, C., Coudert, E., Estreicher, A., Famiglietti, L., Garmiri, P., Georghiou, G., Gos, A., Gruaz-Gumowski, N., Hatton-Ellis, E., Hinz, U., Hulo, C., Ignatchenko, A., Jungo, F., Keller, G., Laiho, K., Lemercier, P., Lieberherr, D., Lussi, Y., Mac-Dougall, A., Magrane, M., Martin, M.J., Masson, P., Natale, D.A., Hyka, N.N., Pedruzzi, I., Pichler, K., Poux, S., Rivoire, C., RodriguezLopez, M., Sawford, T., Speretta, E., Shypitsyna, A., Stutz, A., Sundaram, S., Tognolli, M., Tyagi, N., Warner, K., Zaru, R., Wu, C., Chan, J., Cho, J., Gao, S., Grove, C., Harrison, M.C., Howe, K., Lee, R., Mendel, J., Muller, H.M., Raciti, D., Van Auken, K., Berriman, M., Stein, L., Sternberg, P.W., Howe, D., Toro, S., Westerfield, M., 2019. The Gene Ontology Resource: 20 years and still GOing strong. Nucleic Acids Res. https://doi.org/10.1093/nar/gky1055

Castellano, L., Stebbing, J., 2013. Deep sequencing of small RNAs identifies canonical and non-canonical miRNA and endogenous siRNAs in mammalian somatic tissues. Nucleic Acids Res. 41, 3339-3351. https://doi.org/10.1093/nar/gks1474 Chen, L., Heikkinen, L., Wang, C., Yang, Y., Sun, H., Wong, G., 2019. Trends in the development of miRNA bioinformatics tools. Brief. Bioinform. https://doi.org/10.1093/bib/bby054

Chen, Y., Wang, X., 2020. MiRDB: An online database for prediction of functional microRNA targets. Nucleic Acids Res. 48, D127-D131. https://doi.org/10.1093/nar/gkz757

Churchill, T.A., Storey, K.B., 1993. Dehydration tolerance in wood frogs: A new perspective on development of amphibian freeze tolerance. Am. J. Physiol. - Regul. Integr. Comp. Physiol. 265. https://doi.org/10.1152/ajpregu.1993.265.6.r1324

Ciechanover, A., Orian, A., Schwartz, A.L., 2000. Ubiquitin-mediated proteolysis: Biological regulation via destruction. BioEssays. https://doi.org/10.1002/(SICI)15211878(200005)22:5<442::AID-BIES6>3.0.CO;2-Q

Conlon, J.M., Yano, K., Chartrel, N., Vaudry, H., Storey, K.B., 1998. Freeze tolerance in 
the wood frog Rana sylvatica is associated with unusual structural features in insulin but not in glucagon. J. Mol. Endocrinol. 21, 153-159.

https://doi.org/10.1677/jme.0.0210153

Costanzo, J.P., Lee, R.E., 2008. Urea loading enhances freezing survival and postfreeze recovery in a terrestrially hibernating frog. J. Exp. Biol. 211, 2969-2975. https://doi.org/10.1242/jeb.019695

Costanzo, J.P., Lee, R.E., Ultsch, G.R., 2008. Physiological ecology of overwintering in hatchling turtles. J. Exp. Zool. Part A Ecol. Genet. Physiol. 309, 297-379. https://doi.org/10.1002/jez.460

Cowan, K.J., Storey, K.B., 2003. Mitogen-activated protein kinases: New signaling pathways functioning in cellular responses to environmental stress. J. Exp. Biol. https://doi.org/10.1242/jeb.00220

Cowan, K.J., Storey, K.B., 2001. Freeze-thaw effects on metabolic enzymes in wood frog organs. Cryobiology 43, 32-45. https://doi.org/10.1006/cryo.2001.2338

Davis, B.N., Hilyard, A.C., Nguyen, P.H., Lagna, G., Hata, A., 2010. Smad proteins bind a conserved RNA sequence to promote microRNA maturation by Drosha. Mol. Cell. https://doi.org/10.1016/j.molcel.2010.07.011

Dieni, C.A., Storey, K.B., 2014. Protein kinase C in the wood frog, Rana sy/vatica: Reassessing the tissue-specific regulation of PKC isozymes during freezing. PeerJ 2014. https://doi.org/10.7717/peerj.558

Eaton, S.L., Roche, S.L., Llavero Hurtado, M., Oldknow, K.J., Farquharson, C., Gillingwater, T.H., Wishart, T.M., 2013. Total Protein Analysis as a Reliable Loading Control for Quantitative Fluorescent Western Blotting. PLoS One. https://doi.org/10.1371/journal.pone.0072457

Ender, C., Krek, A., Friedländer, M.R., Beitzinger, M., Weinmann, L., Chen, W., Pfeffer, S., Rajewsky, N., Meister, G., 2008. A Human snoRNA with MicroRNA-Like Functions. Mol. Cell 32, 519-528. https://doi.org/10.1016/j.molcel.2008.10.017

English, S.G., Hadj-Moussa, H., Storey, K.B., 2018. MicroRNAs regulate survival in oxygen-deprived environments. J. Exp. Biol. 221, 1-9. 
https://doi.org/10.1242/jeb.190579

Enright, A.J., John, B., Gaul, U., Tuschl, T., Sander, C., Marks, D.S., 2003. MicroRNA targets in Drosophila. Genome Biol. 5, 1. https://doi.org/10.1186/gb-2003-5-1-r1

Fabian, M.R., Sonenberg, N., 2012. The mechanics of miRNA-mediated gene silencing: A look under the hood of miRISC. Nat. Struct. Mol. Biol. https://doi.org/10.1038/nsmb.2296

Feder, M.E., Burggren, W.W., 1992. Environmental Physiology of the Amphibians. The University of Chicago Press, Chicago and London.

Filippov, V., Solovyev, V., Filippova, M., Gill, S.S., 2000. A novel type of RNase III family proteins in eukaryotes. Gene 245, 213-221. https://doi.org/10.1016/S03781119(99)00571-5

Finnegan, E.F., Pasquinelli, A.E., 2013. MicroRNA biogenesis: Regulating the regulators. Crit. Rev. Biochem. Mol. Biol. 48, 51-68. https://doi.org/10.3109/10409238.2012.738643

Fornerod, M., Ohno, M., Yoshida, M., Mattaj, I.W., 1997. CRM1 is an export receptor for leucine-rich nuclear export signals. Cell 90, 1051-1060. https://doi.org/10.1016/S0092-8674(00)80371-2

Fortin, K.R., Nicholson, R.H., Nicholson, A.W., 2002. Mouse ribonuclease III. cDNA structure, expression analysis, and chromosomal location. BMC Genomics 3. https://doi.org/10.1186/1471-2164-3-26

Franks, F., 1985. Biophysics and Biochemistry at Low Temperature, 10th ed. Cambridge University Press, Cambridge.

Fuchs, R.T., Sun, Z., Zhuang, F., Robb, G.B., 2015. Bias in ligation-based small RNA sequencing library construction is determined by adaptor and RNA structure. PLoS One 10. https://doi.org/10.1371/journal.pone.0126049

Garcia-Garcia, F., Panadero, J., Dopazo, J., Montaner, D., 2016. Integrated gene set analysis for microRNA studies. Bioinformatics. https://doi.org/10.1093/bioinformatics/btw334

Garrett-Bakelman, F.E., Darshi, M., Green, S.J., Gur, R.C., Lin, L., Macias, B.R., McKenna, 
M.J., Meydan, C., Mishra, T., Nasrini, J., Piening, B.D., Rizzardi, L.F., Sharma, K., Siamwala, J.H., Taylor, L., Vitaterna, M.H., Afkarian, M., Afshinnekoo, E., Ahadi, S., Ambati, A., Arya, M., Bezdan, D., Callahan, C.M., Chen, S., Choi, A.M.K., Chlipala, G.E., Contrepois, K., Covington, M., Crucian, B.E., De Vivo, I., Dinges, D.F., Ebert, D.J., Feinberg, J.I., Gandara, J.A., George, K.A., Goutsias, J., Grills, G.S., Hargens, A.R., Heer, M., Hillary, R.P., Hoofnagle, A.N., Hook, V.Y.H., Jenkinson, G., Jiang, P., Keshavarzian, A., Laurie, S.S., Lee-McMullen, B., Lumpkins, S.B., MacKay, M., Maienschein-Cline, M.G., Melnick, A.M., Moore, T.M., Nakahira, K., Patel, H.H., Pietrzyk, R., Rao, V., Saito, R., Salins, D.N., Schilling, J.M., Sears, D.D., Sheridan, C.K., Stenger, M.B., Tryggvadottir, R., Urban, A.E., Vaisar, T., Van Espen, B., Zhang, J., Ziegler, M.G., Zwart, S.R., Charles, J.B., Kundrot, C.E., Scott, G.B.I., Bailey, S.M., Basner, M., Feinberg, A.P., Lee, S.M.C., Mason, C.E., Mignot, E., Rana, B.K., Smith, S.M., Snyder, M.P., Turek, F.W., 2019. The NASA twins study: A multidimensional analysis of a year-long human spaceflight. Science (80-. ). 364.

https://doi.org/10.1126/science.aau8650

Geiss, L., do Amaral, M.C.F., Frisbie, J., Goldstein, D.L., Krane, C.M., 2019. Postfreeze viability of erythrocytes from Dryophytes chrysoscelis. J. Exp. Zool. Part A Ecol. Integr. Physiol. 331, 308-313. https://doi.org/10.1002/jez.2262

Gerber, V.E.M., Wijenayake, S., Storey, K.B., 2016. Anti-apoptotic response during anoxia and recovery in a freeze-tolerant wood frog (Rana sylvatica). PeerJ 2016. https://doi.org/10.7717/peerj.1834

Görlich, D., Kraft, R., Kostka, S., Vogel, F., Hartmann, E., Laskey, R.A., Mattaj, I.W., Izaurralde, E., 1996. Importin provides a link between nuclear protein import and U snRNA export. Cell 87, 21-32. https://doi.org/10.1016/S0092-8674(00)81319-7

Greenway, S.C., Storey, K.B., 2000. Activation of mitogen-activated protein kinases during natural freezing and thawing in the wood frog, Molecular and Cellular Biochemistry.

Greenway, S.C., Storey, K.B., 1999. Discordant responses of mitogen-activated protein kinases to anoxia and freezing exposures in hatchling turtles. J. Comp. Physiol. - B 
Biochem. Syst. Environ. Physiol. 169, 521-527.

https://doi.org/10.1007/s003600050251

Guo, W.T., Wang, Y., 2019. Dgcr8 knockout approaches to understand microRNA functions in vitro and in vivo. Cell. Mol. Life Sci. 76, 1697-1711.

https://doi.org/10.1007/s00018-019-03020-9

Gupta, A., Brooks, C., Storey, K.B., 2020. Regulation of NF-kB, FHC and SOD2 in response to oxidative stress in the freeze tolerant wood frog, Rana sylvatica. Cryobiology 97, 28-36. https://doi.org/10.1016/j.cryobiol.2020.10.012

Hadj-Moussa, H., Pamenter, M.E., Storey, K.B., 2021. Hypoxic naked mole-rat brains use microRNA to coordinate hypometabolic fuels and neuroprotective defenses. J. Cell. Physiol. 236, 5080-5097. https://doi.org/10.1002/jcp.30216

Hadj-Moussa, H., Storey, K.B., 2018. Micromanaging freeze tolerance: the biogenesis and regulation of neuroprotective microRNAs in frozen brains. Cell. Mol. Life Sci. 75, 3635-3647. https://doi.org/10.1007/s00018-018-2821-0

Hadj-Moussa, H., Zhang, J., Pifferi, F., Perret, M., Storey, K.B., 2020. Profiling torporresponsive microRNAs in muscles of the hibernating primate Microcebus murinus. Biochim. Biophys. acta. Gene Regul. Mech. 1863, 194473. https://doi.org/10.1016/j.bbagrm.2019.194473

Hansen, T.B., Venø, M.T., Jensen, T.I., Schaefer, A., Damgaard, C.K., Kjems, J., 2016. Argonaute-associated short introns are a novel class of gene regulators. Nat. Commun. 7. https://doi.org/10.1038/ncomms11538

Harris, S.L., Levine, A.J., 2005. The p53 pathway: Positive and negative feedback loops. Oncogene. https://doi.org/10.1038/sj.onc.1208615

Hawkins, L.J., Storey, K.B., 2020. MicroRNA expression in the heart of Xenopus laevis facilitates metabolic adaptation to dehydration. Genomics 112, 3525-3536. https://doi.org/10.1016/j.ygeno.2020.04.003

Hawkins, L.J., Storey, K.B., 2018. Histone methylation in the freeze-tolerant wood frog (Rana sylvatica). J. Comp. Physiol. B Biochem. Syst. Environ. Physiol. https://doi.org/10.1007/s00360-017-1112-7 
Hawkins, L.J., Wang, M., Zhang, B., Xiao, Q., Wang, H., Storey, K.B., 2019. Glucose and urea metabolic enzymes are differentially phosphorylated during freezing, anoxia, and dehydration exposures in a freeze tolerant frog. Comp. Biochem. Physiol. - Part D Genomics Proteomics 30, 1-13. https://doi.org/10.1016/j.cbd.2019.01.009 Hayakawa, Y., Chino, H., 1983. Insect fat body phosphorylase kinase is Ca2+independent and acts even at $0^{\circ} \mathrm{C}$. Biochim. Biophys. Acta (BBA)/Protein Struct. Mol. 746, 14-17. https://doi.org/10.1016/0167-4838(83)90004-3 Herbert, K.M., Sarkar, S.K., Mills, M., De La Herran, H.C.D., Neuman, K.C., Steitz, J.A., 2016. A heterotrimer model of the complete Microprocessor complex revealed by single-molecule subunit counting. RNA 22, 175-183. https://doi.org/10.1261/rna.054684.115

Hillman, S.S., 1978. Some effects of dehydration on internal distributions of water and solutes in Xenopus laevis. Comp. Biochem. Physiol. -- Part A Physiol. 61, 303-307. https://doi.org/10.1016/0300-9629(78)90113-5

Holmstrup, M., 2014. The ins and outs of water dynamics in cold tolerant soil invertebrates. J. Therm. Biol. 45, 117-123. https://doi.org/10.1016/j.jtherbio.2014.09.001

Hu, C.K., Coughlin, M., Mitchison, T.J., 2012. Midbody assembly and its regulation during cytokinesis. Mol. Biol. Cell 23, 1024-1034. https://doi.org/10.1091/mbc.E11-080721

Hu, Z., Zhang, L., Wang, H., Wang, Y., Tan, Y., Dang, L., Wang, K., Sun, Z., Li, G., Cao, X., Zhang, S., Shi, F., Zhang, G., 2020. Targeted silencing of miRNA-132-3p expression rescues disuse osteopenia by promoting mesenchymal stem cell osteogenic differentiation and osteogenesis in mice. Stem Cell Res. Ther. 11. https://doi.org/10.1186/s13287-020-1581-6

Hughes-Fulford, M., Chang, T.T., Martinez, E.M., Li, C.F., 2015. Spaceflight alters expression of microRNA during T-cell activation. FASEB J. 29, 4893-4900. https://doi.org/10.1096/fj.15-277392 Hunter, J.D., 2007. Matplotlib: A 2D graphics environment. Comput. Sci. Eng. 
https://doi.org/10.1109/MCSE.2007.55

Huntzinger, E., Izaurralde, E., 2011. Gene silencing by microRNAs: Contributions of translational repression and mRNA decay. Nat. Rev. Genet. https://doi.org/10.1038/nrg2936

Ipsaro, J.J., Joshua-Tor, L., 2015. From guide to target: Molecular insights into eukaryotic RNA-interference machinery. Nat. Struct. Mol. Biol. https://doi.org/10.1038/nsmb.2931

Irwin, J.T., Lee, R.E., 2003. Geographic variation in energy storage and physiological responses to freezing in the gray treefrogs Hyla versicolor and $\mathrm{H}$. chrysoscelis. J. Exp. Biol. 206, 2859-2867. https://doi.org/10.1242/jeb.00500 Kalvari, I., Argasinska, J., Quinones-Olvera, N., Nawrocki, E.P., Rivas, E., Eddy, S.R., Bateman, A., Finn, R.D., Petrov, A.I., 2018. Rfam 13.0: Shifting to a genome-centric resource for non-coding RNA families. Nucleic Acids Res. https://doi.org/10.1093/nar/gkx1038 Kamel, S., Marsden, J.E., Pough, F.H., 1985. Diploid and tetraploid grey treefrogs (Hyla chrysoscelis and Hyla versicolor) have similar metabolic rates. Comp. Biochem. Physiol. -- Part A Physiol. 82, 217-220. https://doi.org/10.1016/03009629(85)90729-7

Kanehisa, M., Sato, Y., Furumichi, M., Morishima, K., Tanabe, M., 2019. New approach for understanding genome variations in KEGG. Nucleic Acids Res. https://doi.org/10.1093/nar/gky962

Karagkouni, D., Paraskevopoulou, M.D., Chatzopoulos, S., Vlachos, I.S., Tastsoglou, S., Kanellos, I., Papadimitriou, D., Kavakiotis, I., Maniou, S., Skoufos, G., Vergoulis, T., Dalamagas, T., Hatzigeorgiou, A.G., 2018. DIANA-TarBase v8: A decade-long collection of experimentally supported miRNA-gene interactions. Nucleic Acids Res. 46, D239-D245. https://doi.org/10.1093/nar/gkx1141

Kawai, S., Amano, A., 2012. BRCA1 regulates microRNA biogenesis via the DROSHA microprocessor complex. J. Cell Biol. https://doi.org/10.1083/jcb.201110008 Kawamata, T., Tomari, Y., 2010. Making RISC. Trends Biochem. Sci. 35, 368-376. 
https://doi.org/10.1016/j.tibs.2010.03.009

Kim, V.N., 2005. MicroRNA biogenesis: Coordinated cropping and dicing. Nat. Rev. Mol. Cell Biol. 6, 376-385. https://doi.org/10.1038/nrm1644

Kim, Y.K., Kim, B., Kim, V.N., 2016. Re-evaluation of the roles of DROSHA, Exportin 5, and DICER in microRNA biogenesis. Proc. Natl. Acad. Sci. U. S. A. 113, E1881-E1889. https://doi.org/10.1073/pnas.1602532113

Kobayashi, H., Tomari, Y., 2016. RISC assembly: Coordination between small RNAs and Argonaute proteins. Biochim. Biophys. Acta - Gene Regul. Mech. 1859, 71-81. https://doi.org/10.1016/j.bbagrm.2015.08.007

Kozakowska, M., Ciesla, M., Stefanska, A., Skrzypek, K., Was, H., Jazwa, A., GrochotPrzeczek, A., Kotlinowski, J., Szymula, A., Bartelik, A., Mazan, M., Yagensky, O., Florczyk, U., Lemke, K., Zebzda, A., Dyduch, G., Nowak, W., Szade, K., Stepniewski, J., Majka, M., Derlacz, R., Loboda, A., Dulak, J., Jozkowicz, A., 2012. Heme oxygenase- 1 inhibits myoblast differentiation by targeting myoMIRs. Antioxidants Redox Signal. https://doi.org/10.1089/ars.2011.3964

Kozomara, A., Birgaoanu, M., Griffiths-Jones, S., 2019. MiRBase: From microRNA sequences to function. Nucleic Acids Res. https://doi.org/10.1093/nar/gky1141 Kurisu, K., Yenari, M.A., 2018. Therapeutic hypothermia for ischemic stroke; pathophysiology and future promise. Neuropharmacology. https://doi.org/10.1016/j.neuropharm.2017.08.025

Kutay, U., Ralf Bischoff, F., Kostka, S., Kraft, R., Görlich, D., 1997. Export of importin $\alpha$ from the nucleus is mediated by a specific nuclear transport factor. Cell 90, 10611071. https://doi.org/10.1016/S0092-8674(00)80372-4

Kutcher, M.E., Forsythe, R.M., Tisherman, S.A., 2016. Emergency preservation and resuscitation for cardiac arrest from trauma. Int. J. Surg. https://doi.org/10.1016/j.ijsu.2015.10.014

Langmead, B., Trapnell, C., Pop, M., Salzberg, S.L., 2009. Ultrafast and memory-efficient alignment of short DNA sequences to the human genome. Genome Biol. https://doi.org/10.1186/gb-2009-10-3-r25 
Larsen, E.H., 2021. Dual skin functions in amphibian osmoregulation. Comp. Biochem. Physiol. -Part A Mol. Integr. Physiol. https://doi.org/10.1016/j.cbpa.2020.110869 Law, C.W., Chen, Y., Shi, W., Smyth, G.K., 2014. Voom: Precision weights unlock linear model analysis tools for RNA-seq read counts. Genome Biol. https://doi.org/10.1186/gb-2014-15-2-r29

Layne, J.R., 1999. Freeze tolerance and cryoprotectant mobilization in the gray treefrog (Hyla versicolor). J. Exp. Zool. 283, 221-225. https://doi.org/10.1002/(SICI)1097010X(19990215)283:3<221::AID-JEZ1>3.0.CO;2-Q

Layne, J.R., Jones, A.L., 2001. Freeze tolerance in the gray treefrog: Cryoprotectant mobilization and organ dehydration. J. Exp. Zool. 290, 1-5. https://doi.org/10.1002/jez.1030

Layne, J.R., Lee, R.E., 1989. Seasonal variation in freeze tolerance and ice content of the tree frog Hyla versicolor. J. Exp. Zool. 249, 133-137. https://doi.org/10.1002/jez.1402490203

Layne, J.R., Stapleton, M.G., 2009. Annual variation in glycerol mobilization and effect of freeze rigor on post-thaw locomotion in the freeze-tolerant frog Hyla versicolor. J. Comp. Physiol. B Biochem. Syst. Environ. Physiol. 179, 215-221. https://doi.org/10.1007/s00360-008-0304-6

Lee, R.C., Feinbaum, R.L., Ambros, V., 1993. The C. elegans heterochronic gene lin-4 encodes small RNAs with antisense complementarity to lin-14. Cell. https://doi.org/10.1016/0092-8674(93)90529-Y

Li, H., Handsaker, B., Wysoker, A., Fennell, T., Ruan, J., Homer, N., Marth, G., Abecasis, G., Durbin, R., 2009. The Sequence Alignment/Map format and SAMtools. Bioinformatics 25, 2078-2079. https://doi.org/10.1093/bioinformatics/btp352 Lim, L.P., Lau, N.C., Weinstein, E.G., Abdelhakim, A., Yekta, S., Rhoades, M.W., Burge, C.B., Bartel, D.P., 2003. The microRNAs of Caenorhabditis elegans. Genes Dev. 17, 991-1008. https://doi.org/10.1101/gad.1074403

Liu, J., Carmell, M.A., Rivas, F. V., Marsden, C.G., Thomson, J.M., Song, J.J., Hammond, S.M., Joshua-Tor, L., Hannon, G.J., 2004. Argonaute2 is the catalytic engine of 
mammalian RNAi. Science (80-. ). 305, 1437-1441.

https://doi.org/10.1126/science.1102513

Lund, E., Güttinger, S., Calado, A., Dahlberg, J.E., Kutay, U., 2004. Nuclear Export of MicroRNA Precursors. Science (80-. ). 303, 95-98.

https://doi.org/10.1126/science.1090599

Luu, B.E., Storey, K.B., 2015. Dehydration triggers differential microRNA expression in Xenopus laevis brain. Gene 573, 64-69. https://doi.org/10.1016/j.gene.2015.07.027

Lyons, P.J., Crapoulet, N., Storey, K.B., Morin, P.J., 2015a. Identification and profiling of miRNAs in the freeze-avoiding gall moth Epiblema scudderiana via next-generation sequencing. Mol. Cell. Biochem. 410, 155-163. https://doi.org/10.1007/s11010015-2547-3

Lyons, P.J., Govaere, L., Crapoulet, N., Storey, K.B., Morin, P.J., 2016. Characterization of cold-associated microRNAs in the freeze-tolerant gall fly Eurosta solidaginis using high-throughput sequencing. Comp. Biochem. Physiol. - Part D Genomics Proteomics 20, 95-100. https://doi.org/10.1016/j.cbd.2016.08.007

Lyons, P.J., Lang-Ouellette, D., Morin, P.J., 2013a. CryomiRs: Towards the identification of a cold-associated family of microRNAs. Comp. Biochem. Physiol. - Part D Genomics Proteomics 8, 358-364. https://doi.org/10.1016/j.cbd.2013.10.001 Lyons, P.J., Poitras, J.J., Courteau, L.A., Storey, K.B., Morin, P.J., 2013b. Identification of differentially regulated microRNAs in cold-hardy insects. Cryo-Letters 34, 83-89. Lyons, P.J., Storey, K.B., Morin, P.J., 2015b. Expression of miRNAs in response to freezing and anoxia stresses in the freeze tolerant fly Eurosta solidaginis. Cryobiology 71, 97-102. https://doi.org/10.1016/j.cryobiol.2015.05.002

Madeira, F., Park, Y.M., Lee, J., Buso, N., Gur, T., Madhusoodanan, N., Basutkar, P., Tivey, A.R.N., Potter, S.C., Finn, R.D., Lopez, R., 2019. The EMBL-EBI search and sequence analysis tools APIs in 2019. Nucleic Acids Res. 47, W636-W641. https://doi.org/10.1093/nar/gkz268

Martin, M., 2011. Cutadapt removes adapter sequences from high-throughput 
sequencing reads. EMBnet.journal. https://doi.org/10.14806/ej.17.1.200

Meister, G., Landthaler, M., Patkaniowska, A., Dorsett, Y., Teng, G., Tuschl, T., 2004. Human Argonaute2 mediates RNA cleavage targeted by miRNAs and siRNAs. Mol. Cell 15, 185-197. https://doi.org/10.1016/j.molcel.2004.07.007 Mitchell, S., Vargas, J., Hoffmann, A., 2016. Signaling via the NFkB system. Wiley Interdiscip. Rev. Syst. Biol. Med. https://doi.org/10.1002/wsbm.1331 Murphy, D.J., 1983. Freezing Resistance in Intertidal Invertebrates. Annu. Rev. Physiol. 45, 289-299. https://doi.org/10.1146/annurev.ph.45.030183.001445 Mutyam, V., Puccetti, M. V., Frisbie, J., Goldstein, D.L., Krane, C.M., 2011. Dynamic regulation of aquaglyceroporin expression in erythrocyte cultures from cold- and warm-acclimated cope's gray treefrog, Hyla chrysoscelis. J. Exp. Zool. Part A Ecol. Genet. Physiol. 315 A, 424-437. https://doi.org/10.1002/jez.689

National Aeronautics and Space Administration, n.d. Gateway [WWW Document]. URL https://www.nasa.gov/gateway

National Aeronautics and Space Administration, n.d. NASA Station Astronaut Record Holders [WWW Document]. URL https://www.nasa.gov/feature/nasa-stationastronaut-record-holders

Nguyen, T.A., Jo, M.H., Choi, Y.G., Park, J., Kwon, S.C., Hohng, S., Kim, V.N., Woo, J.S., 2015. Functional anatomy of the human microprocessor. Cell 161, 1374-1387. https://doi.org/10.1016/j.cell.2015.05.010

Oeckinghaus, A., Ghosh, S., 2009. The NF-kappaB family of transcription factors and its regulation. Cold Spring Harb. Perspect. Biol. https://doi.org/10.1101/cshperspect.a000034

Olejniczak, M., Kotowska-Zimmer, A., Krzyzosiak, W., 2018. Stress-induced changes in miRNA biogenesis and functioning. Cell. Mol. Life Sci. 75, 177-191. https://doi.org/10.1007/s00018-017-2591-0

Paciello, G., Acquaviva, A., Ficarra, E., Deriu, M.A., Macli, E., 2011. A molecular dynamics study of a miRNA:mRNA interaction. J. Mol. Model. 17, 2895-2906. https://doi.org/10.1007/s00894-011-0991-x 
Pfister, T.D., Storey, K.B., 2006. Insect freeze tolerance: Roles of protein phosphatases and protein kinase A. Insect Biochem. Mol. Biol. 36, 18-24. https://doi.org/10.1016/j.ibmb.2005.10.002

Project List - Canada's national platform for genome sequencing \& analysis [WWW Document], n.d. URL http://www.cgen.ca/canseq150-list (accessed 6.13.21).

Raabe, C.A., Tang, T.H., Brosius, J., Rozhdestvensky, T.S., 2014. Biases in small RNA deep sequencing data. Nucleic Acids Res. https://doi.org/10.1093/nar/gkt1021

Ratti, M., Lampis, A., Ghidini, M., Salati, M., Mirchev, M.B., Valeri, N., Hahne, J.C., 2020. MicroRNAs (miRNAs) and Long Non-Coding RNAs (IncRNAs) as New Tools for Cancer Therapy: First Steps from Bench to Bedside. Target. Oncol. https://doi.org/10.1007/s11523-020-00717-x

Raymond, J.A., 1995. Glycerol synthesis in the rainbow smelt Osmerus mordax. J. Exp. Biol. 198, 2569-25673.

Raymond, J.A., 1992. Glycerol is a colligative antifreeze in some northern fishes. J. Exp. Zool. 262, 347-352. https://doi.org/10.1002/jez.1402620316

Rehmsmeier, M., Steffen, P., Höchsmann, M., Giegerich, R., 2004. Fast and effective prediction of microRNA/target duplexes. RNA 10, 1507-1517. https://doi.org/10.1261/rna.5248604

Reinhart, B.J., Slack, F.J., Basson, M., PasquienellI, A.E., BettInger, J.C., Rougvle, A.E., Horvitz, H.R., Ruvkun, G., 2000. The 21-nucleotide let-7 RNA regulates developmental timing in Caenorhabditis elegans. Nature. https://doi.org/10.1038/35002607

Rider, M.H., Hussain, N., Horman, S., Dilworth, S.M., Storey, K.B., 2006. Stress-induced activation of the AMP-activated protein kinase in the freeze-tolerant frog Rana sylvatica. Cryobiology 53, 297-309. https://doi.org/10.1016/j.cryobiol.2006.08.001

Ring, R.A., 1982. Freezing-tolerant insects with low supercooling points. Comp. Biochem. Physiol. -- Part A Physiol. 73, 605-612. https://doi.org/10.1016/03009629(82)90267-5

Ritchie, M.E., Phipson, B., Wu, D., Hu, Y., Law, C.W., Shi, W., Smyth, G.K., 2015. Limma 
powers differential expression analyses for RNA-sequencing and microarray studies. Nucleic Acids Res. https://doi.org/10.1093/nar/gkv007

Roufayel, R., Biggar, K.K., Storey, K.B., 2011. Regulation of cell cycle components during exposure to anoxia or dehydration stress in the wood frog, Rana sylvatica. J. Exp. Zool. Part A Ecol. Genet. Physiol. 315 A, 487-494. https://doi.org/10.1002/jez.696

Rubinsky, B., Hong, J.S., Storey, K.B., 1994a. Freeze tolerance in turtles: Visual analysis by microscopy and magnetic resonance imaging. Am. J. Physiol. - Regul. Integr. Comp. Physiol. 267. https://doi.org/10.1152/ajpregu.1994.267.4.r1078

Rubinsky, B., Wong, S.T.S., Hong, J.S., Gilbert, J., Roos, M., Storey, K.B., 1994b. 1H magnetic resonance imaging of freezing and thawing in freeze-tolerant frogs. Am. J. Physiol. - Regul. Integr. Comp. Physiol. 266. https://doi.org/10.1152/ajpregu.1994.266.6.r1771

Ruby, J.G., Jan, C.H., Bartel, D.P., 2007. Intronic microRNA precursors that bypass Drosha processing. Nature 448, 83-86. https://doi.org/10.1038/nature05983

Sai lakshmi, S., Agrawal, S., 2008. piRNABank: A web resource on classified and clustered Piwi-interacting RNAs. Nucleic Acids Res. https://doi.org/10.1093/nar/gkm696 Saliminejad, K., Khorram Khorshid, H.R., Soleymani Fard, S., Ghaffari, S.H., 2019. An overview of microRNAs: Biology, functions, therapeutics, and analysis methods. J. Cell. Physiol. 234, 5451-5465. https://doi.org/10.1002/jcp.27486

Schmid, W.D., 1982. Survival of frogs in low temperature. Science (80-. ). 215, 697-698. https://doi.org/10.1126/science.7058335

Shen, J., Xia, W., Khotskaya, Y.B., Huo, L., Nakanishi, K., Lim, S.O., Du, Y., Wang, Y., Chang, W.C., Chen, C.H., Hsu, J.L., Wu, Y., Lam, Y.C., James, B.P., Liu, X., Liu, C.G., Patel, D.J., Hung, M.C., 2013. EGFR modulates microRNA maturation in response to hypoxia through phosphorylation of AGO2. Nature. https://doi.org/10.1038/nature12080

Singh, G., Storey, K.B., 2020. MondoA:MLX complex regulates glucose-dependent gene expression and links to circadian rhythm in liver and brain of the freeze-tolerant wood frog, Rana sylvatica. Mol. Cell. Biochem. 473, 203-216. 
https://doi.org/10.1007/s11010-020-03820-9

SpaceX, n.d. Mars \& Beyond [WWW Document]. URL https://www.spacex.com/humanspaceflight/mars/

Storey, J.M., Storey, K.B., 2019. In defense of proteins: Chaperones respond to freezing, anoxia, or dehydration stress in tissues of freeze tolerant wood frogs. J. Exp. Zool. Part A Ecol. Integr. Physiol. 331, 392-402. https://doi.org/10.1002/jez.2306

Storey, J.M., Storey, K.B., 1996. $\beta$-adrenergic, hormonal, and nervous influences on cryoprotectant synthesis by liver of the freeze-tolerant wood frog Rana sylvatica. Cryobiology 33, 186-195. https://doi.org/10.1006/cryo.1996.0019

Storey, J.M., Storey, K.B., 1985a. Adaptations of metabolism for freeze tolerance in the gray tree frog, Hyla versicolor. Can. J. Zool. 63, 49-54. https://doi.org/10.1139/285009

Storey, J.M., Storey, K.B., 1985b. Triggering of cryoprotectant synthesis by the initiation of ice nucleation in the freeze tolerant frog, Rana sylvatica. J. Comp. Physiol. B 156, 191-195. https://doi.org/10.1007/BF00695773

Storey, K., Storey, J., 2013. Molecular biology of freezing tolerance. Compr. Physiol. 3, 1283-1308.

Storey, K.B., Bischof, J., Rubinsky, B., 1992. Cryomicroscopic analysis of freezing in liver of the freeze-tolerant wood frog. Am. J. Physiol. - Regul. Integr. Comp. Physiol. 263, 185-194. https://doi.org/10.1152/ajpregu.1992.263.1.r185

Storey, K.B., Storey, J.M., 2020. Mitochondria, metabolic control and microRNA: Advances in understanding amphibian freeze tolerance. BioFactors 46, 220-228. https://doi.org/10.1002/biof.1511

Storey, K.B., Storey, J.M., 2017. Molecular physiology of freeze tolerance in vertebrates. Physiol. Rev. 97, 623-665. https://doi.org/10.1152/physrev.00016.2016

Storey, K.B., Storey, J.M., 2012. Insect cold hardiness: Metabolic, gene, and protein adaptation 1. Can. J. Zool. 90, 456-475. https://doi.org/10.1139/Z2012-011

Storey, K.B., Storey, J.M., 2004. Metabolic rate depression in animals: Transcriptional and translational controls. Biol. Rev. Camb. Philos. Soc. 79, 207-233. 
https://doi.org/10.1017/S1464793103006195

Storey, K.B., Storey, J.M., 1986a. Freeze tolerance and intolerance as strategies of winter survival in terrestrially-hibernating amphibians. Comp. Biochem. Physiol. -- Part A Physiol. 83, 613-617. https://doi.org/10.1016/0300-9629(86)90699-7

Storey, K.B., Storey, J.M., 1986b. Freeze tolerant frogs: cryoprotectants and tissue metabolism during freeze-thaw cycles. Can. J. Zool. 64, 49-56. https://doi.org/10.1139/z86-008

Storey, K.B., Storey, J.M., 1984. Biochemical adaption for freezing tolerance in the wood frog, Rana sylvatica. J. Comp. Physiol. B 155, 29-36. https://doi.org/10.1007/BF00688788

Sullivan, K.J., Biggar, K.K., Storey, K.B., 2015. Transcript expression of the freeze responsive gene fr10 in Rana sylvatica during freezing, anoxia, dehydration, and development. Mol. Cell. Biochem. 399, 17-25. https://doi.org/10.1007/s11010014-2226-9

Sun, Y., Liu, W.Z., Liu, T., Feng, X., Yang, N., Zhou, H.F., 2015. Signaling pathway of MAPK/ERK in cell proliferation, differentiation, migration, senescence and apoptosis. J. Recept. Signal Transduct. https://doi.org/10.3109/10799893.2015.1030412

Thomashow, M.F., 1999. PLANT COLD ACCLIMATION: Freezing Tolerance Genes and Regulatory Mechanisms. Annu. Rev. Plant Physiol. Plant Mol. Biol. 50, 571-599. https://doi.org/10.1146/annurev.arplant.50.1.571

Tran, V.D.T., Tempel, S., Zerath, B., Zehraoui, F., Tahi, F., 2015. miRBoost: Boosting support vector machines for microRNA precursor classification. RNA 21, 775-785. https://doi.org/10.1261/rna.043612.113

Van Den Beucken, T., Koch, E., Chu, K., Rupaimoole, R., Prickaerts, P., Adriaens, M., Voncken, J.W., Harris, A.L., Buffa, F.M., Haider, S., Starmans, M.H.W., Yao, C.Q., Ivan, M., Ivan, C., Pecot, C. V., Boutros, P.C., Sood, A.K., Koritzinsky, M., Wouters, B.G., 2014. Hypoxia promotes stem cell phenotypes and poor prognosis through epigenetic regulation of DICER. Nat. Commun. 
https://doi.org/10.1038/ncomms6203

Van Stry, M., Oguin, T.H., Cheloufi, S., Vogel, P., Watanabe, M., Pillai, M.R., Dash, P., Thomas, P.G., Hannon, G.J., Bix, M., 2012. Enhanced Susceptibility of Ago1/3 Double-Null Mice to Influenza A Virus Infection. J. Virol. 86, 4151-4157. https://doi.org/10.1128/jvi.05303-11

Verduci, L., Strano, S., Yarden, Y., Blandino, G., 2019. The circRNA-microRNA code: emerging implications for cancer diagnosis and treatment. Mol. Oncol. https://doi.org/10.1002/1878-0261.12468

Ward, J.H., 1963. Hierarchical Grouping to Optimize an Objective Function. J. Am. Stat. Assoc. https://doi.org/10.1080/01621459.1963.10500845

Warnes, G.R., Bolker, B., Bonebakker, L., Gentleman, R., Liaw, W.H.A., Lumley, T., Maechler, M., Magnusson, A., Moeller, S., Schwartz, M., Venables, B., 2019. gplots: Various R Programming Tools for Plotting Data. R package version 3.0.1.1. http://CRAN.R-project.org/package=gplots.

Waskom, M., Botvinnik, O., Hobson, P., Warmenhoven, J., Cole, J.B., Halchenko, Y., Vanderplas, J., Hoyer, S., Villalba, S., Quintero, E., Miles, A., 2014. Seaborn: statistical data visualization. https://doi.org/https://doi.org/10.5281/zenodo.1313201

Wasserman, A.O., 1970. Polyploidy in the common tree toad Hyla versicolor Le Conte. Science (80-. ). 167, 385-386. https://doi.org/10.1126/science.167.3917.385 Wu, C., So, J., Davis-Dusenbery, B.N., Qi, H.H., Bloch, D.B., Shi, Y., Lagna, G., Hata, A., 2011. Hypoxia Potentiates MicroRNA-Mediated Gene Silencing through Posttranslational Modification of Argonaute2. Mol. Cell. Biol. https://doi.org/10.1128/mcb.05776-11

Wu, C.W., Storey, K.B., 2018. Regulation of Smad mediated microRNA transcriptional response in ground squirrels during hibernation. Mol. Cell. Biochem. 439, 151-161. https://doi.org/10.1007/s11010-017-3144-4

Wu, C.W., Tessier, S.N., Storey, K.B., 2020. Dehydration stress alters the mitogenactivated-protein kinase signaling and chaperone stress response in Xenopus laevis. 
Comp. Biochem. Physiol. Part - B Biochem. Mol. Biol. 246-247.

https://doi.org/10.1016/j.cbpb.2020.110461

Wu, H., Xu, H., Miraglia, L.J., Crooke, S.T., 2000. Human RNase III is a 160-kDa protein involved in preribosomal RNA processing. J. Biol. Chem. 275, 36957-36965. https://doi.org/10.1074/jbc.M005494200

Wu, L., Fan, J., Belasco, J.G., 2008. Importance of Translation and Nonnucleolytic Ago Proteins for On-Target RNA Interference. Curr. Biol. 18, 1327-1332. https://doi.org/10.1016/j.cub.2008.07.072

Wu, Y., Wei, B., Liu, H., Li, T., Rayner, S., 2011. MiRPara: A SVM-based software tool for prediction of most probable microRNA coding regions in genome scale sequences. BMC Bioinformatics 12. https://doi.org/10.1186/1471-2105-12-107

Yoda, M., Kawamata, T., Paroo, Z., Ye, X., Iwasaki, S., Liu, Q., Tomari, Y., 2010. ATPdependent human RISC assembly pathways. Nat. Struct. Mol. Biol. 17, 17-24. https://doi.org/10.1038/nsmb.1733

Zhang, J., Hadj-Moussa, H., Storey, K.B., 2016. Current progress of high-throughput microRNA differential expression analysis and random forest gene selection for model and non-model systems: an R implementation. J. Integr. Bioinform. https://doi.org/10.2390/biecoll-jib-2016-306

Zhang, J., Storey, K.B., 2018. RBiomirGS: An all-in-one miRNA gene set analysis solution featuring target mRNA mapping and expression profile integration. PeerJ 2018, 117. https://doi.org/10.7717/peerj.4262

Zhang, J., Storey, K.B., 2016. RBioplot: An easy-to-use R pipeline for automated statistical analysis and data visualization in molecular biology and biochemistry. PeerJ 2016. https://doi.org/10.7717/peerj.2436

Zhang, J., Storey, K.B., 2013. Akt signaling and freezing survival in the wood frog, Rana sylvatica. Biochim. Biophys. Acta - Gen. Subj. 1830, 4828-4837. https://doi.org/10.1016/j.bbagen.2013.06.020

Zhang, J., Storey, K.B., 2012. Cell cycle regulation in the freeze-tolerant wood frog, Rana sylvatica. Cell Cycle 11, 1727-1742. https://doi.org/10.4161/cc.19880 
Zimmerman, S.L., Frisbie, J., Goldstein, D.L., West, J., Rivera, K., Krane, C.M., 2007. Excretion and conservation of glycerol, and expression of aquaporins and glyceroporins, during cold acclimation in Cope's gray tree frog Hyla chrysoscelis.

Am. J. Physiol. - Regul. Integr. Comp. Physiol. 292.

https://doi.org/10.1152/ajpregu.00434.2006 
APPENDICES 


\section{APPENDIX A - Antibody information and suppliers for Western immunoblotting}

\begin{tabular}{cccc}
\hline Protein target: & Supplier & Catalog number: & Reactivity: \\
\hline AGO1 & GeneTex & GTX47799 & Anti-Rabbit \\
AGO2 & ECM Biosciences & AP5281 & Anti-Rabbit \\
AGO3 & AbCam & AB3593 & Anti-Rabbit \\
AGO4 & AbCam & AB85077 & Anti-Rabbit \\
DGCR8 & GeneTex & GTX130061 & Anti-Rabbit \\
DICER & AbClonal & A6021 & Anti-Rabbit \\
DROSHA & GeneTex & GTX56186 & Anti-Rabbit \\
PACT & GeneTex & GTX114215 & Anti-Rabbit \\
RAN-GTP & GeneTex & GTX114139 & Anti-Rabbit \\
TRBP & GeneTex & GTX48546 & Anti-Rabbit \\
XPO5 & GeneTex & GTX130727 & Anti-Rabbit \\
\hline
\end{tabular}




\section{APPENDIX B - Optimized immunoblotting conditions}

Liver:

\begin{tabular}{ccccccc}
\hline Target: & $\begin{array}{c}\text { Protein } \\
\text { loaded: }\end{array}$ & $\begin{array}{c}\text { Gel } \\
\%:\end{array}$ & $\begin{array}{c}\text { Gel run } \\
\text { time: }\end{array}$ & $\begin{array}{c}\text { Transfer } \\
\text { amperage: }\end{array}$ & $\begin{array}{c}\text { Transfer run } \\
\text { time: }\end{array}$ & Blocking: \\
\hline AG01 & $20 \mu \mathrm{g}$ & $8 \%$ & $100 \mathrm{~min}$ & $160 \mathrm{~mA}$ & $120 \mathrm{~min}$ & $2 \%$ milk \\
AG02 & $20 \mu \mathrm{g}$ & $8 \%$ & $100 \mathrm{~min}$ & $160 \mathrm{~mA}$ & $120 \mathrm{~min}$ & $2 \%$ milk \\
AGO3 & $40 \mu \mathrm{g}$ & $8 \%$ & $77 \mathrm{~min}$ & $160 \mathrm{~mA}$ & $140 \mathrm{~min}$ & $5 \%$ milk \\
AG04 & $40 \mu \mathrm{g}$ & $8 \%$ & $77 \mathrm{~min}$ & $160 \mathrm{~mA}$ & $140 \mathrm{~min}$ & $5 \%$ milk \\
DGCR8 & $25 \mu \mathrm{g}$ & $8 \%$ & $90 \mathrm{~min}$ & $160 \mathrm{~mA}$ & $101 \mathrm{~min}$ & $2 \%$ milk \\
DICER & $20 \mu \mathrm{g}$ & $6 \%$ & $130 \mathrm{~min}$ & $60 \mathrm{~mA}$ & $900 \mathrm{~min}$ & $\mathrm{~N} / \mathrm{A}$ \\
DROSHA & $20 \mu \mathrm{g}$ & $8 \%$ & $90 \mathrm{~min}$ & $160 \mathrm{~mA}$ & $140 \mathrm{~min}$ & $8 \%$ milk \\
PACT & $20 \mu \mathrm{g}$ & $12 \%$ & $50 \mathrm{~min}$ & $160 \mathrm{~mA}$ & $130 \mathrm{~min}$ & $5 \%$ milk \\
RAN- & $20 \mu \mathrm{g}$ & $15 \%$ & $70 \mathrm{~min}$ & $160 \mathrm{~mA}$ & $130 \mathrm{~min}$ & $5 \%$ milk \\
GTP & & & & $160 \mathrm{~mA}$ & $130 \mathrm{~min}$ & $5 \%$ milk \\
TRBP & $20 \mu \mathrm{g}$ & $12 \%$ & $50 \mathrm{~min}$ & $160 \mathrm{~mA}$ & $140 \mathrm{~min}$ & $8 \%$ milk \\
XPO5 & $20 \mu \mathrm{g}$ & $8 \%$ & $90 \mathrm{~min}$ & 160 & &
\end{tabular}

Skeletal muscle:

\begin{tabular}{ccccccc}
\hline Target & $\begin{array}{c}\text { Protein } \\
\text { loaded }\end{array}$ & $\begin{array}{c}\text { Gel } \\
\%\end{array}$ & $\begin{array}{c}\text { Gel run } \\
\text { time }\end{array}$ & $\begin{array}{c}\text { Transfer } \\
\text { amperage }\end{array}$ & $\begin{array}{c}\text { Transfer run } \\
\text { time }\end{array}$ & Blocking \\
\hline AG01 & $21 \mu \mathrm{g}$ & $8 \%$ & $100 \mathrm{~min}$ & $160 \mathrm{~mA}$ & $130 \mathrm{~min}$ & $5 \% \mathrm{milk}$ \\
AG02 & $21 \mu \mathrm{g}$ & $8 \%$ & $100 \mathrm{~min}$ & $160 \mathrm{~mA}$ & $130 \mathrm{~min}$ & $5 \%$ milk \\
DGCR8 & $21 \mu \mathrm{g}$ & $8 \%$ & $90 \mathrm{~min}$ & $160 \mathrm{~mA}$ & $101 \mathrm{~min}$ & $2 \%$ milk \\
DICER & $37.5 \mu \mathrm{g}$ & $6 \%$ & $130 \mathrm{~min}$ & $100 \mathrm{~mA}$ & $900 \mathrm{~min}$ & $2 \%$ milk \\
PACT & $21 \mu \mathrm{g}$ & $12 \%$ & $50 \mathrm{~min}$ & $160 \mathrm{~mA}$ & $130 \mathrm{~min}$ & $5 \%$ milk
\end{tabular}




\begin{tabular}{ccccccc} 
RAN- & $21 \mu \mathrm{g}$ & $15 \%$ & $70 \mathrm{~min}$ & $160 \mathrm{~mA}$ & $130 \mathrm{~min}$ & $5 \%$ milk \\
GTP & & & & & & \\
TRBP & $21 \mu \mathrm{g}$ & $12 \%$ & $50 \mathrm{~min}$ & $160 \mathrm{~mA}$ & $130 \mathrm{~min}$ & $5 \%$ milk \\
XPO5 & $21 \mu \mathrm{g}$ & $8 \%$ & $105 \mathrm{~min}$ & $160 \mathrm{~mA}$ & $140 \mathrm{~min}$ & $5 \% \mathrm{milk}$ \\
\hline
\end{tabular}

Kidney:

\begin{tabular}{ccccccc}
\hline Target & $\begin{array}{c}\text { Protein } \\
\text { loaded }\end{array}$ & $\begin{array}{c}\text { Gel } \\
\%\end{array}$ & $\begin{array}{c}\text { Gel run } \\
\text { time }\end{array}$ & $\begin{array}{c}\text { Transfer } \\
\text { amperage }\end{array}$ & $\begin{array}{c}\text { Transfer } \\
\text { time }\end{array}$ & Blocking \\
\hline AG01 & $20 \mu \mathrm{g}$ & $8 \%$ & $100 \mathrm{~min}$ & $160 \mathrm{~mA}$ & $120 \mathrm{~min}$ & $5 \%$ milk \\
AGO2 & $20 \mu \mathrm{g}$ & $8 \%$ & $100 \mathrm{~min}$ & $160 \mathrm{~mA}$ & $120 \mathrm{~min}$ & $5 \%$ milk \\
AG03 & $20 \mu \mathrm{g}$ & $8 \%$ & $100 \mathrm{~min}$ & $160 \mathrm{~mA}$ & $120 \mathrm{~min}$ & $5 \%$ milk \\
AG04 & $20 \mu \mathrm{g}$ & $8 \%$ & $100 \mathrm{~min}$ & $160 \mathrm{~mA}$ & $120 \mathrm{~min}$ & $5 \%$ milk \\
DGCR8 & $20 \mu \mathrm{g}$ & $8 \%$ & $85 \mathrm{~min}$ & $160 \mathrm{~mA}$ & $120 \mathrm{~min}$ & $5 \%$ milk \\
DICER & $37.5 \mu \mathrm{g}$ & $6 \%$ & $130 \mathrm{~min}$ & $100 \mathrm{~mA}$ & $900 \mathrm{~min}$ & $2 \%$ milk \\
DROSHA & $20 \mu \mathrm{g}$ & $8 \%$ & $150 \mathrm{~min}$ & $160 \mathrm{~mA}$ & $150 \mathrm{~min}$ & $2 \%$ milk \\
PACT & $20 \mu \mathrm{g}$ & $15 \%$ & $85 \mathrm{~min}$ & $160 \mathrm{~mA}$ & $130 \mathrm{~min}$ & $5 \%$ milk \\
RAN- & $20 \mu \mathrm{g}$ & $15 \%$ & $85 \mathrm{~min}$ & $160 \mathrm{~mA}$ & $130 \mathrm{~min}$ & $5 \%$ milk \\
GTP & & & & $16 \% \mathrm{~min}$ & $120 \mathrm{~min}$ & $2 \%$ milk \\
TRBP & $20 \mu \mathrm{g}$ & $15 \%$ & 120 & $160 \mathrm{~mA}$ & $120 \mathrm{~min}$ & $2 \%$ milk \\
XPO5 & $20 \mu \mathrm{g}$ & $10 \%$ & $95 \mathrm{~min}$ & $160 \mathrm{~mA}$ &
\end{tabular}




\section{APPENDIX C - Verifying antibody specificity for Western immunoblotting}

$H$. versicolor has not been genome sequenced; therefore, we could not definitively verify an antibody's conservation against the protein sequence in the animal itself. To ensure that the antibodies used had the highest probability of cross-reacting with the protein target of interest at the appropriate molecular weight, the following steps were taken:

1. When companies provided the immunogen sequence, this was aligned with various species (human, mouse, chicken, Xenopus laevis, Xenopus tropicalis) via the Clustal Omega program to determine if the epitope region is conserved. This increases the possibility that the protein is conserved in H. versicolor. Only antibodies that recognized highly conserved epitopes were used.

2. Wherever possible, polyclonal antibodies that were tested on numerous species were used to heighten the probability of cross-reactivity in $\mathrm{H}$. versicolor.

3. PVDF membranes were washed in milk for $30 \mathrm{~min}$ to minimize non-specific background binding prior to primary antibody incubation. For specific percentages of milk used, please see Appendix B: Optimized immunoblotting conditions. 


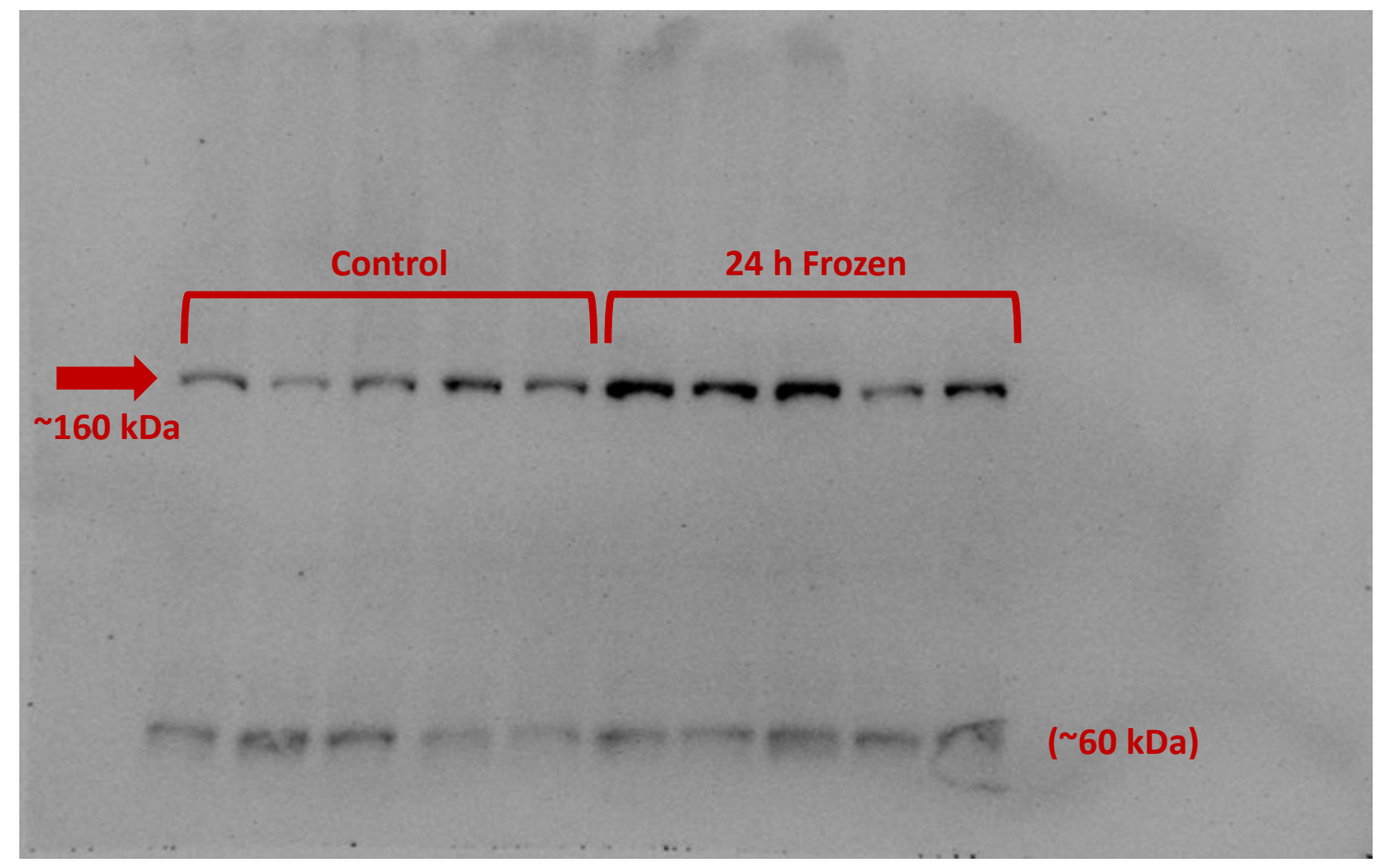

Figure C.1. Representative whole image of Western immunoblot of control vs 24 $\boldsymbol{h}$ frozen liver tissue from $\boldsymbol{H}$. versicolor. Membrane was probed with anti-DROSHA primary antibody and anti-rabbit secondary antibody. 


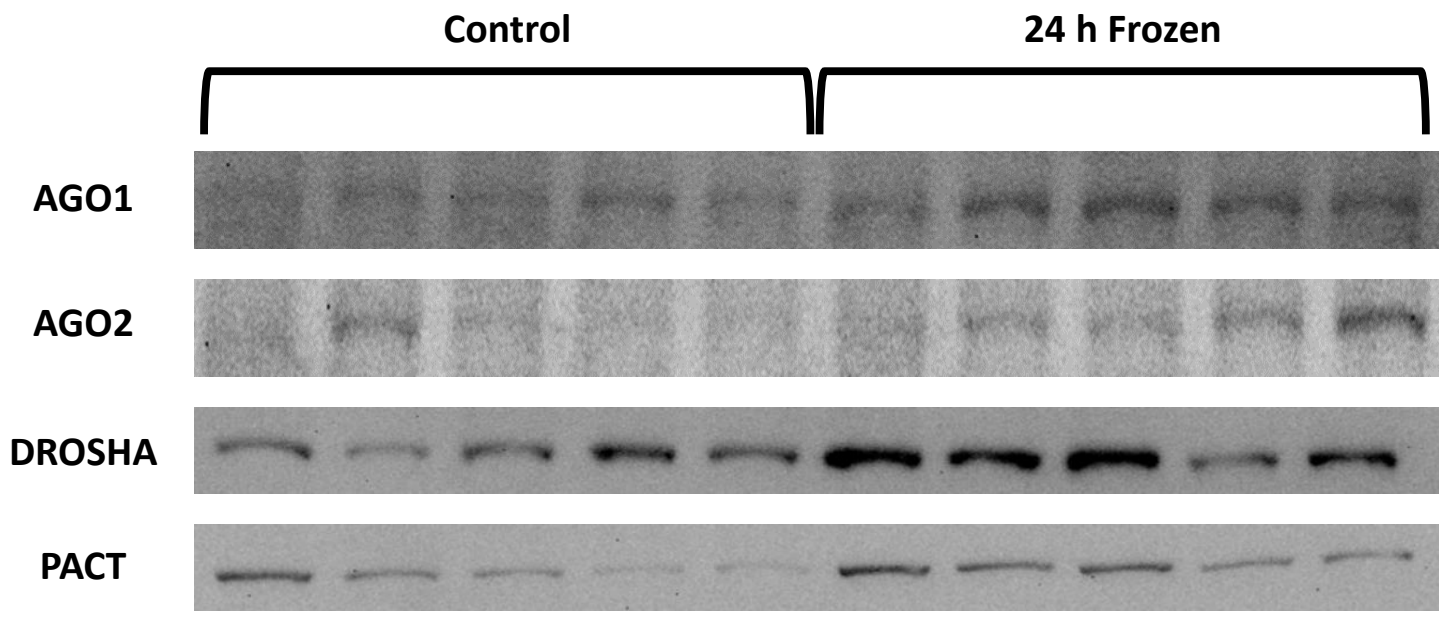

Figure C.2. Representative images of proteins of interest from control vs $\mathbf{2 4} \mathbf{h}$ frozen liver Western immunoblots in $\boldsymbol{H}$. versicolor. Each membrane was probed with primary antibody anti- to the protein of interest, and all membranes were probed with anti-rabbit secondary antibody. 


\section{APPENDIX D - Bioinformatics workflow for small RNA-seq dataset analysis}

\section{OVERALL WORKFLOW:}

(1) UNIX: Get miRNA-sequencing FASTQ files from company.

(2) UNIX: Quality checks - clean up low quality reads, trim reads under $15 \mathrm{bp}$, clip sequencing and PCR adapters off.

(3) UNIX: Filter negative references (non-miRNA small RNA reads; piRNA, rRNA, tRNA, snRNA, snoRNA) from the dataset.

(4) UNIX: Align positive references (mature miRNA and hairpin miRNA from miRBase) to dataset.

(5) UNIX: Generate read count tables of mature and hairpin miRNAs that aligned to datasets.

(6) RSTUDIO: Normalization and differential gene expression analysis.

(7) RSTUDIO: Heatmaps, volcano plots, and PCA plots.

(8) RSTUDIO: RBioFS gene set selection.

(9) RSTUDIO: Downstream KEGG and GO annotsation.

\section{DETAILED WORKFLOW:}

\section{[1] Performing initial FastQC checks:}

To ensure the raw reads sent by the company were good quality, the FastQC executable was used to assess each file. Sequence Length Distribution required one peak at $75 \mathrm{bp}$, and Per Base Sequence Quality was expected to have a score over 28, but no less than 20. Any scores under 20 were removed in the following step (-q 20).

fastqC . /HYLALIV1. fastq

\section{[2] Trimming adapters:}

Adapter sequences were a component of the datafiles as a relic of the Illumina protocols. Known adapter sequences were already composed in a file denoted as adapter_file.fa. Sequences less than $10 \mathrm{bp}(-\mathrm{m} 10)$ were removed.

cutadapt -q 20 -m 10 -j 18 -b file:adapter_file.fa ./HYLALIV1.fastq -0 ./HYLALIV1_trim.fastq

The datafiles for $H$. versicolor were from Genome BC. Specific to this method, each read is prefaced by 6 random nucleotides which were used as indexes to multiplex various samples together. The following command was used to remove these 6 random nucleotides. 
cutadapt -u $6-j 18$./HYLALIV1_trim.fastq -o

. /HYLALIV1_6trim.fastq

\section{[3] Perform another round of FastQC}

Following the read quality check, the trimming of adapters, and the removal of the beginning 6 nucleotides from each read, the FastQC quality check was again preformed to confirm the integrity of the reads. Notably, the peak at Sequence Length Distribution was at $23 \mathrm{nt}$, reflecting the average length of a miRNA. Per Base Sequence Quality was once again expected to have a score over 28, but no less than 20.

fastqC . /HYLALIV1_6trim.fastq

\section{[4] BOWTIE index building}

An index is a specific file structure created by BOWTIE, a short-read aligner software that allows for high-throughput sequence analysis. The trimmed raw datafiles were aligned to a negative reference database composed of non-miRNA small RNAs, including snoRNA, piwiRNA, rRNA, and tRNA to remove these from the dataset.

bowtie-build neg_ref.fasta neg_ref.ebwt

Likewise, the same process needs to be done to generate a positive reference database. This consists of known mature miRNA sequences that can be matched against the trimmed and filtered datafiles. The mature_DNA. fa file was generated from all mature miRNA sequences downloaded from miRBase 22 (www.mirbase.org).

bowtie-build mature_DNA.fa miRNA_ref.ebwt

\section{[5] Filter the negative reads out}

Using the negative reference BOWTIE index created in [4], we aligned the trimmed and filtered datafile to the BOWTIE index to filter any non-miRNA small RNAs out.

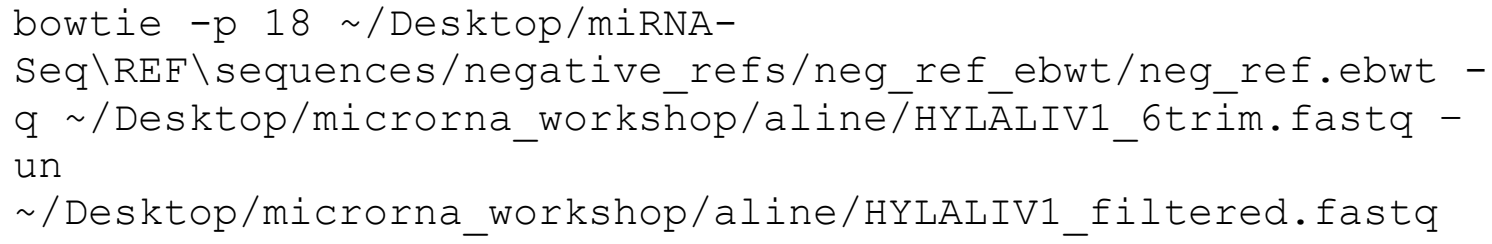

[6] Mature miRNA BOWTIE alignment 
Using the positive reference BOWTIE index created in [4], we aligned the trimmed and filtered datafile to the BOWTIE index to keep all mature miRNA sequences which matched a sequence in the positive reference file.

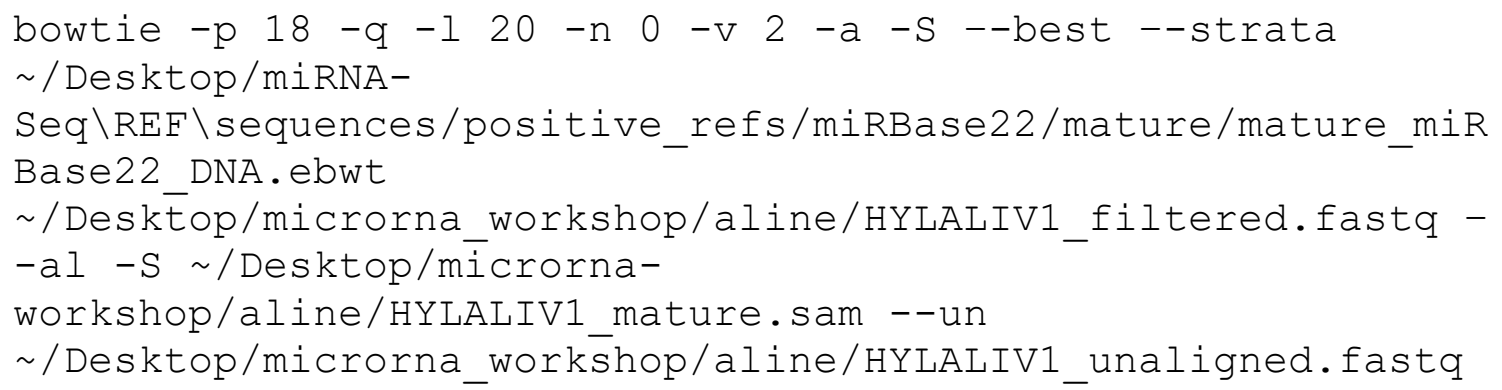

\section{[7] Convert SAM file to BAM file}

To further process the mature miRNA file, we needed to convert it from SAM format to BAM format (a binary version of SAM). This was done using SAMTOOLS.

samtools view $-\mathrm{S}-\mathrm{b}$

/Desktop/microrna_workshop/aline/HYLALIV1_mature.sam >

/ Desktop/microrna_workshop/aline/HYLALIV1_mature.bam

\section{[8] Count final miRNA reads}

The BAM file generated from [7] needed to be sorted before further processing can occur. Once again, SAMTOOLS was used to achieve this.

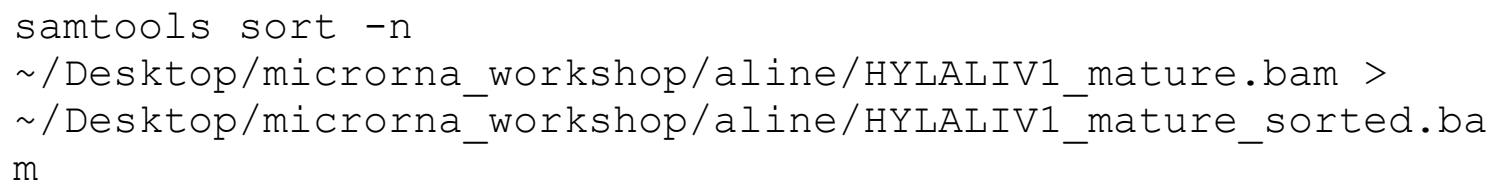

Lastly, the number of reads which aligned to each mature miRNA sequence was counted and exported to a text file.

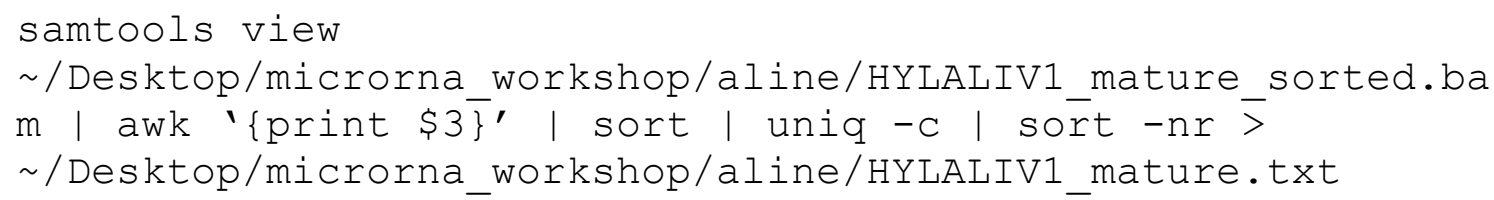

\section{[9] RStudio analysis}

The entire analysis portion in RStudio, including figure generation, was packaged into a script denoted rpipeline. R. As such, the code for each section will be included, but 
it is important to note that this was an entirely automated process with no further user input beyond loading the raw files.

\section{[9.1] Setup commands}

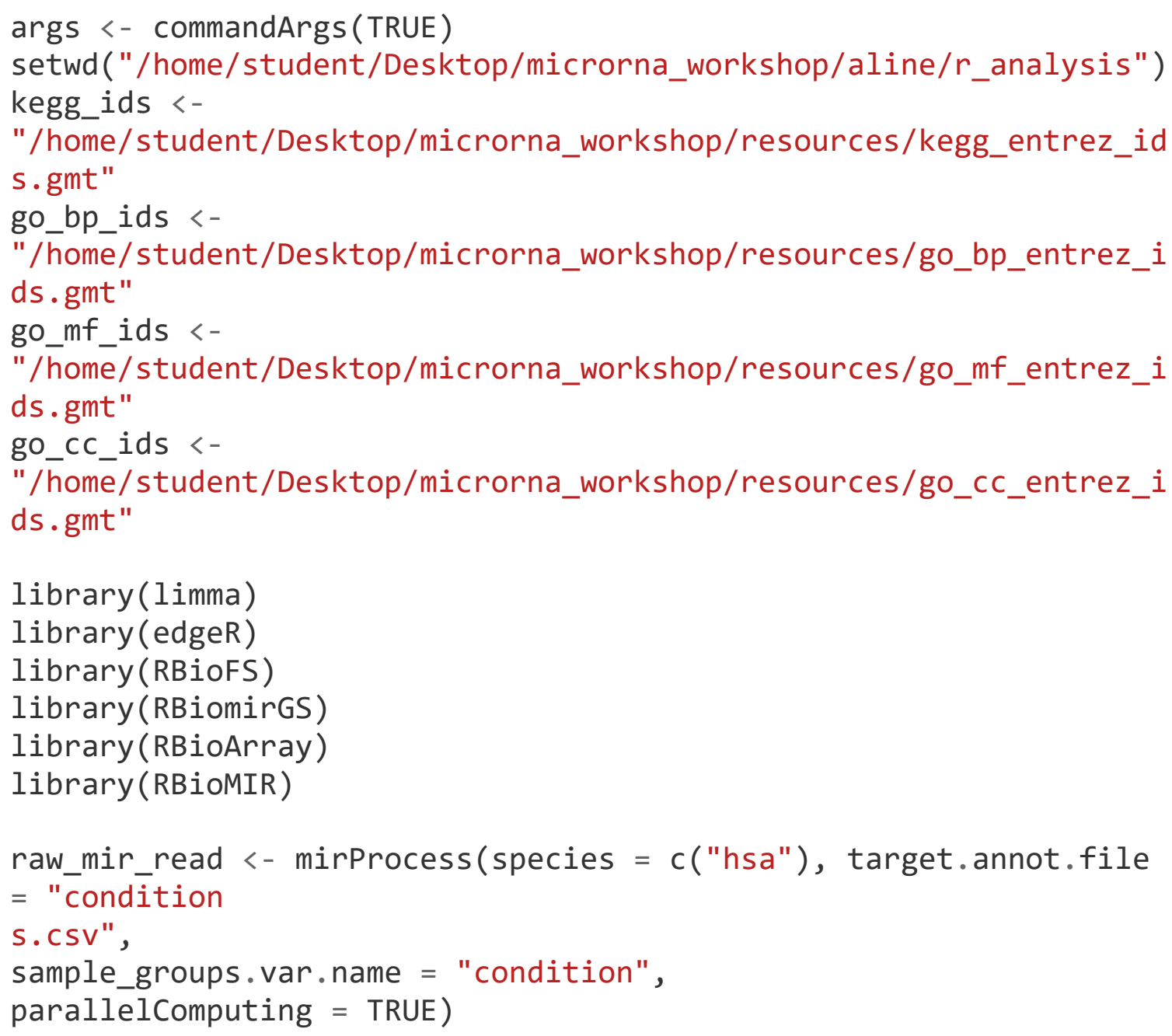

It is important to note that the conditions. cSv file was manually created with the number of samples and the corresponding condition for each one. For this dataset, it looked as follows: 


\begin{tabular}{c|c|c|c}
\hline & \multicolumn{1}{|c|}{ A } & \multicolumn{1}{c|}{ B } & C \\
\hline 1 & sample & condition & \\
\hline 2 & HYLALIV1 & control & \\
\hline 3 & HYLALIV2 & control & \\
\hline 4 & HYLALIV3 & control & \\
\hline 5 & HYLALIV4 & control & \\
\hline 6 & HYLALIV5 & stress & \\
\hline 7 & HYLALIV6 & stress & \\
\hline 8 & HYLALIV7 & stress & \\
\hline 9 & HYLALIV8 & stress & \\
\hline 10 & & & \\
\hline 11 & & & \\
\hline 12 & & & \\
\hline \hline
\end{tabular}

\section{[9.2] Differential expression analysis}

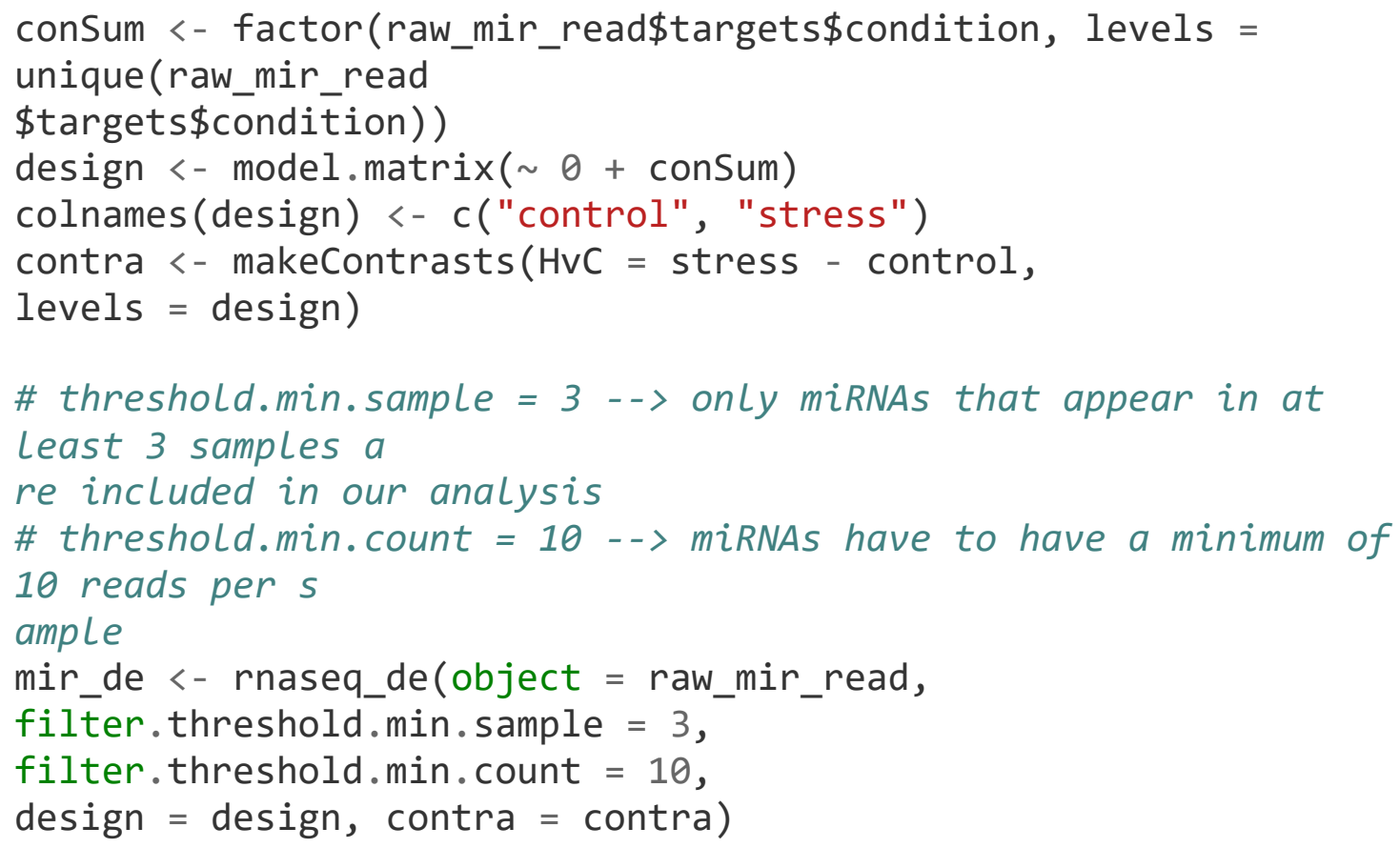

\section{[9.3] Significant miRNA analysis}

\# Labelled volcano plot

\# p-values are fdr corrected with a threshold set to 0.05

mir_sig<- sig(object = mir_de,

plot.top.gene $=$ TRUE,

plot.top.gene. $n=200$,

export.mode = "sig",

$p \cdot v a l \cdot$ correction. method $=" f d r "$, 


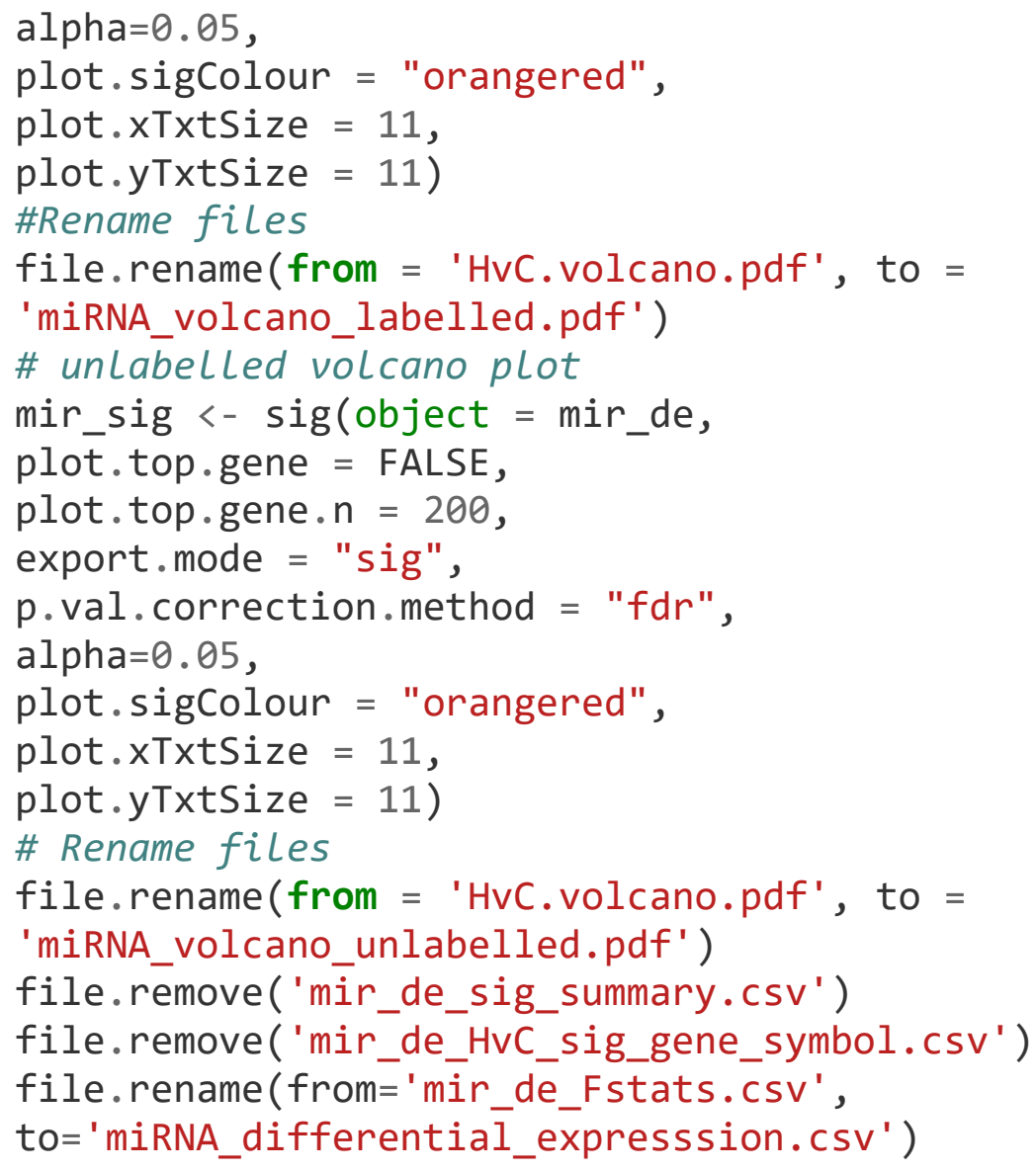

\section{[9.4] Supervised cluster analysis heatmap}

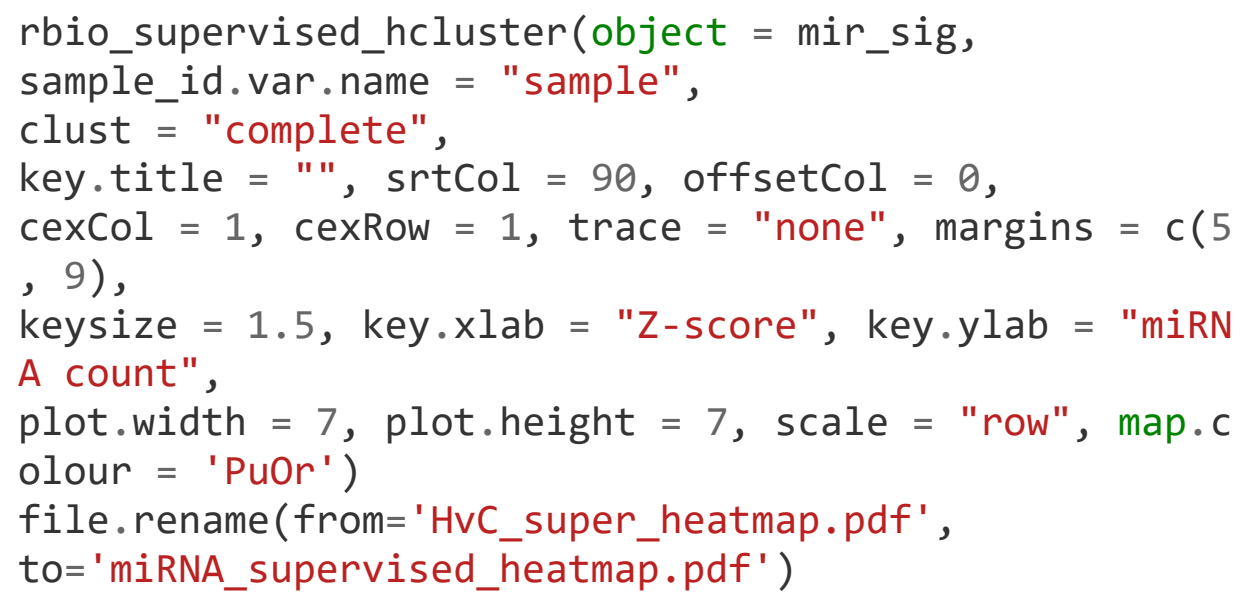

\section{[9.5] Gene set analysis}

rbiomirgs_mrnascan(objTitle = "mir_mrna_hsa_validated", mir = mir_de $\$$ filter_results $\$$ filtered_counts\$genes\$genes, url=' http://multimir.org/cgi-bin/multimir_univ.pl', 


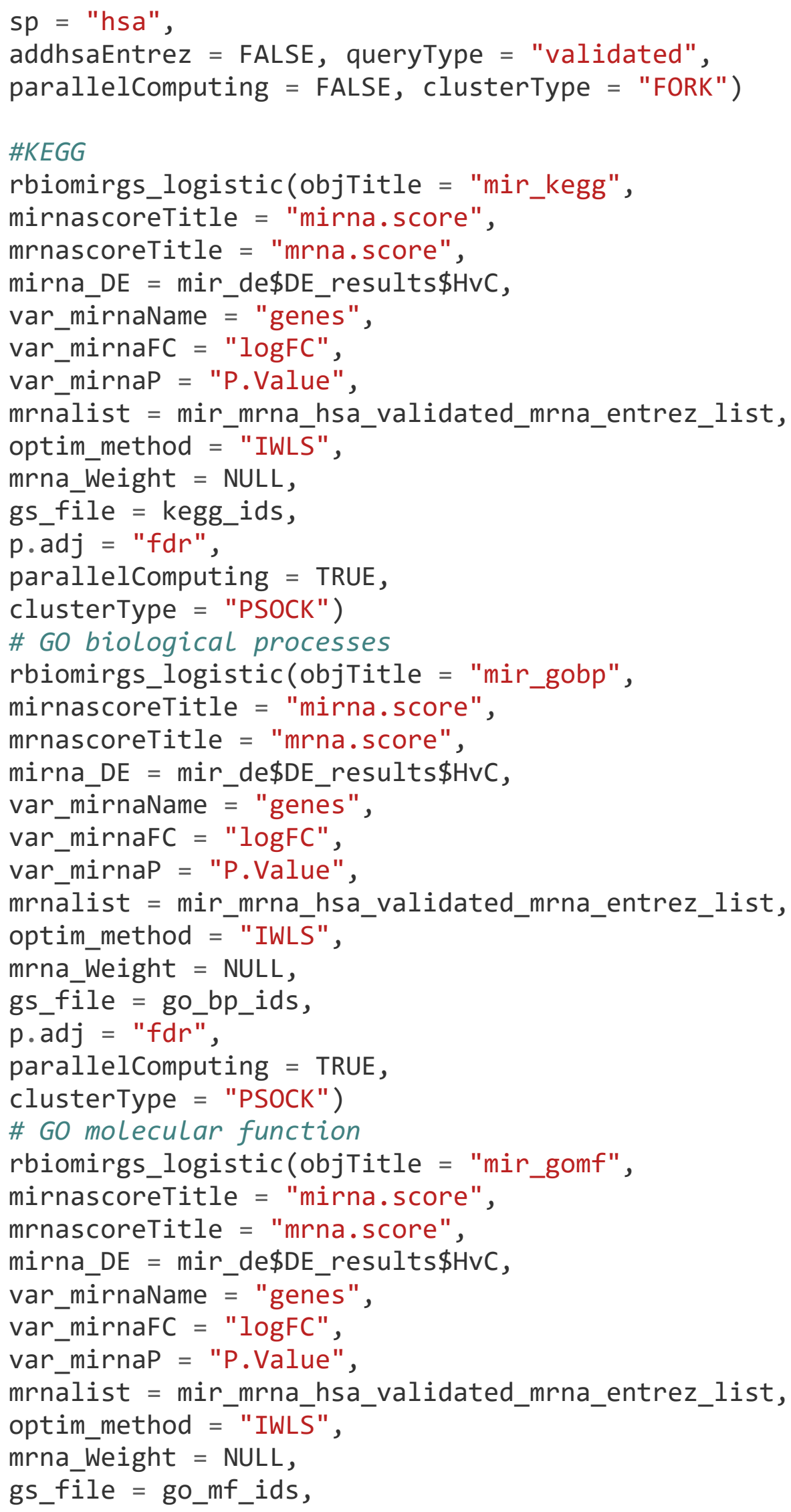


$p \cdot \operatorname{adj}=" f d r "$,

parallelComputing = TRUE,

clusterType = "PSOCK")

\# GO cellular component

rbiomirgs_logistic(objTitle = "mir_gocc",

mirnascoreTitle = "mirna.score",

mrnascoreTitle = "mrna.score",

mirna_DE = mir_de $\$ D E \_r e s u l t s \$ H v C$,

var_mirnaName = "genes",

var_mirnaFC = "logFC",

var_mirnaP = "P.Value",

mrnalist $=$ mir_mrna_hsa_validated_mrna_entrez_list,

optim_method = "IWLS",

mrna_Weight $=$ NULL,

gs_file = go_cc_ids,

p.adj $=$ "fdr",

parallelComputing = TRUE,

clusterType = "PSOCK")

The final output from the completed RStudio analysis are .csv files as follows:

miRNA_differential_expression.csv

miRNA_go_cellular_compartment.csv

miRNA_go_biological_processes.csv

miRNA_go_molecular_function.csv

miRNA_kegg.csv

These were inputted into Microsoft Excel for graphing and formatting, and constituted Figure 4.3-4.7 of this thesis. The supervised heatmap was outputted as a .pdf image which was Figure 4.2 of this thesis:

miRNA_supervised_heatmap.pdf 